\title{
Socioeconomic inequalities in health : exploring new psychosocial pathways in middle-aged and older people.
}

Citation for published version (APA):

Klabbers-Gartsen, A. B. A. (2012). Socioeconomic inequalities in health : exploring new psychosocial pathways in middle-aged and older people. [Doctoral Thesis, Maastricht University]. Datawyse / Universitaire Pers Maastricht. https://doi.org/10.26481/dis.20120614ak

Document status and date:

Published: 01/01/2012

DOI:

10.26481/dis.20120614ak

Document Version:

Publisher's PDF, also known as Version of record

Please check the document version of this publication:

- A submitted manuscript is the version of the article upon submission and before peer-review. There can be important differences between the submitted version and the official published version of record.

People interested in the research are advised to contact the author for the final version of the publication, or visit the DOI to the publisher's website.

- The final author version and the galley proof are versions of the publication after peer review.

- The final published version features the final layout of the paper including the volume, issue and page numbers.

Link to publication

\footnotetext{
General rights rights.

- You may freely distribute the URL identifying the publication in the public portal. please follow below link for the End User Agreement:

www.umlib.nl/taverne-license

Take down policy

If you believe that this document breaches copyright please contact us at:

repository@maastrichtuniversity.nl

providing details and we will investigate your claim.
}

Copyright and moral rights for the publications made accessible in the public portal are retained by the authors and/or other copyright owners and it is a condition of accessing publications that users recognise and abide by the legal requirements associated with these

- Users may download and print one copy of any publication from the public portal for the purpose of private study or research.

- You may not further distribute the material or use it for any profit-making activity or commercial gain

If the publication is distributed under the terms of Article 25fa of the Dutch Copyright Act, indicated by the "Taverne" license above, 
Socioeconomic inequalities in health:

Exploring new psychosocial pathways in middle-aged and older people 
The studies presented in this dissertation were conducted under the auspices of the School for Public Health and Primary Care (CAPHRI) at Maastricht University. CAPHRI is part of the Netherlands School of Primary Care Research (CaRe), acknowledged by the Royal Dutch Academy of Science (KNAW).

CC Copyright G. Klabbers, Maastricht 2012

Cover design: Karin Vissers

Book preparation: I. van Noppen, M. Klabbers, G. Klabbers

Printed by Datawyse | Universitaire Pers Maastricht

ISBN: 9789461591494

All rights reserved. No part of this dissertation may be reproduced, stored in a retrieval system, or transmitted in any form or by any means, electronic or mechanical, including photocopying, recording or otherwise, without permission from the author or from the publisher holding the copyright of the published articles. 


\title{
Socioeconomic inequalities in health:
}

\section{Exploring new psychosocial pathways in middle-aged and older people}

\author{
Proefschrift \\ ter verkrijging van de graad van doctor \\ aan de Universiteit Maastricht, \\ op gezag van de Rector Magnificus, Prof. mr. G.P.M.F. Mols \\ volgens het besluit van het College van Decanen,
}

in het openbaar te verdedigen op donderdag 14 juni 2012 om 16.00 uur

door

Aldegonda Bernardine Annemaria Klabbers-Gartsen

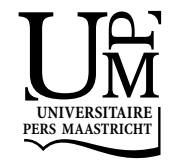




\section{Promotores}

Prof. dr. em. J.Th.M. van Eijk

Prof. dr. G.I.J.M. Kempen

\section{Copromotor}

Dr. H. Bosma

\section{Beoordelingscommissie}

Prof. dr. K. Horstman (voorzitter)

Dr. P.H. Lemmens

Prof. dr. D. van de Mheen (IVO, Addiction Research Institute, Rotterdam)

Prof. dr. J. van Os

Prof. dr. N.K. de Vries 
Questions of science, science and progress do not speak as loud as my heart

(Coldplay, The scientist, 2002)

Voor Leentje 



\section{Contents}

Chapter 1 General Introduction 9

Chapter 2 The relative contributions of hostility and depressive symptoms 21 to the income gradient in hospital-based incidence of ischaemic heart disease: 12-Year follow-up findings from the GLOBE study.

Chapter 3 Measuring rebelliousness and predicting health behaviour and outcomes: an investigation of the construct validity of the Social Reactivity Scale

Chapter 4 Cognitive hostility predicts all-cause mortality irrespective of behavioural risk at late middle and older age

Chapter 5 Predicting health in late middle-aged and older persons: the comparison of a new psychosocial health risk approach with individual psychosocial characteristics

Chapter 6 Early life poverty associated with poor self-rated health in late middle and old age: a pathway through psychosocial profiles

Chapter 7 The educational patterning of health-related adversities in individuals with major depression.

Chapter 8 Discussion

Chapter 9 Summary

Samenvatting

Dankwoord

About the author

Publications 

CHAPTER 1

General Introduction 


\section{GENERAL INTRODUCTION}

\section{Socioeconomic health inequalities}

Socioeconomic inequalities in health provide a major public health problem worldwide. Our socioeconomic status (SES) undisputedly affects our health: health gets poorer and life expectancy shorter with each step down the socioeconomic ladder (Marmot, Ryff, Bumpass, Shipley, \& Marks, 1997; Marmot, Bosma, Hemingway, Brunner, \& Stansfeld, 1997; Schrijvers, Bosma, \& Mackenbach, 2002). Even though mortality and morbidity rates have decreased in all status groups, socioeconomic inequalities in health have been increasing throughout Western Europe and the USA (Huisman et al., 2004; Mackenbach et al., 2003; Mackenbach, Kunst, Cavelaars, Groenhof, \& Geurts, 1997; Marmot \& McDowall, 1986; Singh \& Siahpush, 2002; Vagero \& Erikson, 1997; Virtanen \& Notkola, 2002; Wilkinson, 1997): health in higher SES has improved more than in lower SES. Socioeconomic inequalities exist in a broad range of health outcomes; the most frequently examined being self-reported health, mortality and cardiovascular diseases. Not only are cardiovascular diseases one of the most important causes of death in the western countries, numerous studies have also demonstrated social inequalities in coronary heart disease using a variety of measures of social position (Bosma et al., 2005; Ferrie, Martikainen, Shipley, \& Marmot, 2005; Hemingway et al., 2005).

To date, the gap has not narrowed, despite public health policies and interventions targeted at tackling these inequalities. Mackenbach, in his analysis of the recent large-scale English strategy to reduce health inequalities, argued that there are three barriers to doing so (Mackenbach, 2010). First, there are no clearly defined packages of policies and interventions with proven effectiveness in reducing health inequalities. Second, the scale and intensity of necessary policy change might exceed governmental ability and willingness. Third, health inequalities often are the outcome of long-term, even intergenerational exposure to adversity, which cannot be easily undone in short term interventions. The analysis was concluded with the remark that 'for the foreseeable future we need less ambitious aims, more focused approaches, and much more and better evaluation' (Mackenbach, 2010). In addition to evaluating intervention effectiveness, efforts aimed at reducing health inequalities might still benefit from further insight into the mechanisms that define health by SES.

\section{Explaining socioeconomic health inequalities}

Most interventions aimed at reducing health inequalities have been based on eliminating or diminishing risk, with risk factors determined by prior research. Evidence so far indicates that psychosocial factors could be of major importance in the 
explanation of socioeconomic health inequalities. Psychosocial attributes such as hostility or depressive symptoms might affect health directly, through sustained physiological reactivity which may have direct long-term adverse effects on the immune and cardiovascular systems (Adler \& Ostrove, 1999; Kristenson, Eriksen, Sluiter, Starke, \& Ursin, 2004; Rozanski, Blumenthal, Davidson, Saab, \& Kubzansky, 2005; Rozanski, Blumenthal, \& Kaplan, 1999), affecting health. Psychosocial adversity might also affect health indirectly through lifestyle; less healthy behaviours are not only more highly prevalent in lower SES (Hemmingsson \& Lundberg, 2005; Power et al., 2007; Van de Mheen, Stronks, Looman, \& Mackenbach, 1998), but also associated with psychosocial attributes (Laitinen, Ek, \& Sovio, 2002; Mackenbach, Simon, Looman, \& Joung, 2002).

Adverse (levels of) psychosocial characteristics are more highly prevalent at lower SES, such as depressive mood or depressive symptomatology (Kempen, van Jaarsveld, van Sonderen, Sanderman, \& Ormel, 2001; Lorant et al., 2003; Stansfeld, Head, Fuhrer, Wardle, \& Cattell, 2003), hostility (Carroll, Davey Smith, Sheffield, Shipley, \& Marmot, 1997), neuroticism (Bosma, van de Mheen, \& Mackenbach, 1999), low control beliefs (Bailis, Segall, Mahon, Chipperfield, \& Dunn, 2001; Bosma, Schrijvers, \& Mackenbach, 1999; Lachman \& Weaver, 1998), ineffective coping mechanisms (Bosma, van de Mheen, et al., 1999) lack of social support (Mickelson \& Kubzansky, 2003), and social isolation (Danese et al., 2009), perhaps due to long-term exposure to adverse circumstances, which might even stem from growing up and being socialised within such unfavourable surroundings. The origin of these attributes might thus go back as far as childhood. Socioeconomic adversity in early life has been found to cause unhealthy personality change (Hart, Atkins, \& Matsuba, 2008), depressive and anxiety symptoms (Power, et al., 2007), external locus of control (versus a more internal locus), neuroticism, and an avoidant coping style during adulthood (Bosma, van de Mheen, et al., 1999). There is also a substantial body of evidence which demonstrates that individual psychosocial factors affect (somatic) health and longevity (Bosma, Schrijvers, et al., 1999; Chapman, Fiscella, Kawachi, \& Duberstein, 2009; Chida \& Steptoe, 2009; Egan, Tannahill, Petticrew, \& Thomas, 2008; Kubzansky, Cole, Kawachi, Vokonas, \& Sparrow, 2006; Kuper, Marmot, \& Hemingway, 2002; Nabi et al., 2008; Penninx et al., 2001; Rugulies, 2002; Stansfeld, 2006; Stansfeld, Bosma, Hemingway, \& Marmot, 1998; Van den Akker, Buntinx, Metsemakers, van der Aa, \& Knottnerus, 2001). Given these findings, it is highly likely that growing up in unfavourable socioeconomic conditions affect health through psychosocial make-up. As yet, the contributions of those psychosocial factors to social health inequalities are relatively little studied (Bosma, Schrijvers, et al., 1999; Bosma, van de Mheen, et al., 1999; Bosma, et al., 2005; Hemingway \& Marmot, 1999; Horsten et al., 1999; Penninx et al., 1999), and the results of those studies are often inconclusive and not easily comparable, due to differences in study populations, methodology, health outcomes, and psychoso- 
cial characteristics studied. Especially the health risks in older populations are understudied, yet these are important considering the ageing population in most western societies. The longer duration of exposure to adversity combined with the ageing body becoming less able to repair damage (Kuh, Ben-Shlomo, Lynch, Hallqvist, \& Power, 2003) might very well enhance the negative consequences for health.

Further, psychosocial risk factors are often included separately and individually in the various analyses. However, they might have synergistic effects on health and longevity; many psychological attributes are interrelated (Koster et al., 2006; Martin, Watson, \& Wan, 2000; Miller, Smith, Turner, Guijarro, \& Hallet, 1996; Smith, 1992; Smith, Glazer, Ruiz, \& Gallo, 2004). Taking into account this covariation and the potentially synergistic effects on health outcomes might add to their predictive power.

Considering the above, it is of major importance to determine whether or not psychosocial make-up contributes to the excess health risk by socioeconomic status and how exactly psychosocial make-up can be measured. Gathering evidence on this topic not only increases understanding in the exact mechanisms leading from SES to health, but ultimately might help in the timing and tailoring of interventions to reduce socioeconomic health inequalities.

\section{Research model and research questions}

This thesis describes the relationships between socioeconomic status, several psychosocial variables, and health. The overall research model is depicted in figure 1. This model suggests that there are associations between early life SES, adulthood SES, psychosocial attributes, and health.

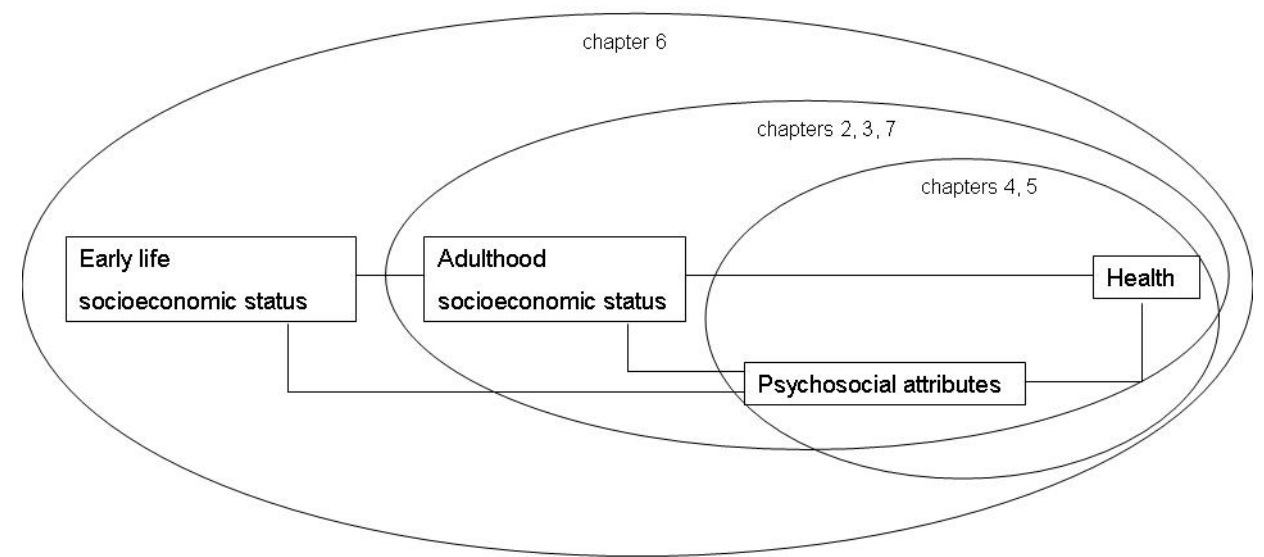

Figure 1 Research model on associations between early life SES, adulthood SES, psychosocial attributes and health 
The following research questions were derived from this overall model:

1. What psychosocial attributes are important in their relationship with SES and how can they be measured? We examined a new concept in this field of research: rebelliousness, and its psychometric properties (chapter 3)

2. What psychosocial attributes are important in their relationship with health and how can they be measured? Besides examining the mortality risk posed by rebelliousness and associated psychosocial risk factors such as hostility and anger (chapter 4), we used an innovative approach in determining psychosocial health risk by clustering a number of psychosocial attributes, hypothesising that the different attributes operate in concordance or synergistically with each other (chapter 5)

3. Do psychosocial factors contribute to explaining health from SES?

Besides the contribution of accepted psychosocial health risk factors such as cognitive hostility and depressive symptoms (chapter 2 ) we also studied the contribution of the innovative psychosocial clusters to health inequalities (chapter 6)

4. What is the influence of early life poverty on a person's psychosocial profile and health in later life? Early life as critical period in the development of health risk was examined from a lifecourse perspective (chapter 6)

Apart from these four questions we also studied the likelihood of health-related adversities across different educational levels in persons with a psychiatric disorder (chapter 7).

\section{Description of studies used}

The different parts of this research model were studied using longitudinal and cross-sectional data of four different datasets: GLOBE, MAAS, NESDA, and SMILE

\section{The GLOBE study}

GLOBE, a Dutch acronym for 'Health and Living conditions of the Population of (the city of) Eindhoven and Surroundings', is a prospective cohort study aimed at explaining socioeconomic inequalities in health (Mackenbach, van de Mheen, \& Stronks, 1994). In 1991, a postal survey was conducted among 27,070 Dutch individuals aged $15-74$ years, of which 18,973 persons $(70.1 \%)$ completed the questionnaire. More detailed risk factor information by means of questionnaires and interviews between 1991 and 1997 was collected in two subsamples, one of which was randomly drawn $(\mathrm{N}=2,802)$, and in the other one individuals with chronic diseases were oversampled $(n=2,867)$. Representativeness of the sample for the source population was re-established by calculating weight factors for all respondents (Mackenbach, et al., 2002). The interview and questionnaire data were linked to data from the municipal register on mortality and with hospital admission data 
from five hospitals in the catchment area of the GLOBE study between 1991 and 2003. For purpose of our study, we used longitudinal data from the two subsamples.

\section{The MAAS study}

MAAS (the Maastricht Aging Study) is a prospective study of the biological, medical and psychosocial determinants of cognitive aging (Jolles, Houx, Boxtel, \& Ponds, 1995). The study started in 1993, and included 1869 individuals aged 24 to 81 years. Individuals were randomly drawn from a patient database of general practices connected to the University of Maastricht, the Netherlands. Individuals were not included in the MAAS study if they had brain-related morbidity. The sample was stratified for age, sex, and occupational achievement. Participants were tested in four independent panel studies that were comparable with respect to inclusion and stratification criteria. Data collection involved a postal survey and a medical and neuropsychological test programme. Follow-up time differed by age at first measurement: 3 yeas follow-up for those 54 years and older, and 6 years for those younger than 54 years. The cross-sectional MAAS data we used were derived from the fourth panel, 2005, and comprised 513 male and female respondents.

\section{The NESDA study}

The Netherlands Study of Depression and Anxiety (NESDA) was designed to study the long-term course of depression and anxiety disorders in a naturalistic longitudinal cohort, and includes 2,981 Dutch respondents aged 18 to 65 years (Penninx et al., 2008). These respondents were recruited from different health care settings, and include individuals in different stages of the developmental history of depressive and anxiety disorders. Exclusion criteria were a primary clinical diagnosis of a psychiatric disorder not the subject of NESDA (e.g. psychotic or bipolar disorders), and not being fluent in Dutch. Recruitment lasted from 2004 until 2007, with a follow-up time of 8 years. For our research, we used psychiatric data (diagnosed major depressive disorder), medical data (on metabolic functioning and medication use), interview data (on demographics, mental health care use and medication), and questionnaire data (on lifestyles, presence of somatic diseases and psychological function) that were collected at the first measurement wave. Our final sample comprised 992 male and female participants.

\section{The SMILE study}

SMILE (Study of Medical Information and Lifestyles in the city of Eindhoven) is a prospective cohort study, focusing on a broad range of aspects of disease, health and lifestyles of people living in Eindhoven, the Netherlands (Van den Akker et al., 2008). Self-report data on sociodemographics, lifestyle, psychosocial characteristics, health-related functioning and various health outcomes were linked with 
medical data on morbidity, mortality, medication and health care use. SMILE started in 2002, and had a 9-year follow-up period. Thirty-two general practitioners of nine participating primary health care centres were involved in the recruitment of the participants (from teenage until old age). Participants received annual selfreport questionnaires, adolescents and people aged 55 years or older received one additional questionnaire annually. Among the participants aged 55 years and older, which was considered a specific subsample of the SMILE population, the sociodemographic and psychosocial data collection was more extensive than among the other participants. Our analyses (cross-sectional and longitudinal) were based on this subsample. Of the 5000 participants aged 55 years and older consenting to the questionnaires, 3022 male and female participants (60.4\%) consented to the linkage with medical data.

\section{Aim and outline of thesis}

This thesis aims at increasing the understanding of 1) how SES is associated with psychosocial attributes, 2) how psychosocial attributes relate to health, 3) how to operationalise and measure psychosocial health risk, 4) whether these attributes can explain the health inequalities, and 5) whether these associations originate in early life SES or adulthood SES. Insight into these psychosocial mechanisms not only adds to the existing evidence but might ultimately contribute to the tailoring as well as the timing of interventions to reduce socioeconomic health inequalities. In the second chapter the contribution of depressive symptoms and hostile personality to educational difference in hospital admissions for cardiac events was examined using GLOBE data (see above for description of datasets). Chapter three describes the psychometric evaluation of the Social Reactivity Scale, which measures the degree of proactive and reactive rebelliousness as potential health risk factors, including determining the factor solution and construct validity of the scale. These analyses were based on MAAS and SMILE data. The fourth chapter investigates the predictive value of rebelliousness and its associated attributes cognitive hostility, anger and verbal aggression for all-cause mortality in the late middle aged and older subsample of the SMILE population. Chapter five describes a new approach of determining psychosocial health risk, by clustering individuals into groups based on their scores on thirteen different psychosocial variables, including psychological characteristics, control beliefs, coping style and social support. Mortality, diagnosed morbidity and self-rated health risk by cluster is compared to the risk predicted by the individual psychosocial characteristics. These analyses were conducted using data of the late middle aged and older subsample of SMILE. In chapter six the contribution of the psychosocial profile to the association between early life poverty and self-rated health in later life was calculated and compared with the contribution of adulthood education and health behaviours, again using 
data of the SMILE subsample of late middle aged and older individuals. In chapter seven the educational patterning of health-related adversities such as lifestyle, mood, and cardiac risk was examined among NESDA participants with a major depressive disorder. To conclude, the findings are discussed in chapter eight, thereby taking into account the current discourse and state of research of socioeconomic health inequalities. 


\section{References}

Adler, N. E., \& Ostrove, J. M. (1999). Socioeconomic status and health: what we know and what we don't. Ann N Y Acad Sci, 896, 3-15.

Bailis, D. S., Segall, A., Mahon, M. J., Chipperfield, J. G., \& Dunn, E. M. (2001). Perceived control in relation to socioeconomic and behavioral resources for health. Soc Sci Med, 52(11), 1661-1676.

Bosma, H., Schrijvers, C., \& Mackenbach, J. P. (1999). Socioeconomic inequalities in mortality and importance of perceived control: cohort study. BMJ, 319(7223), 1469-1470.

Bosma, H., van de Mheen, H. D., \& Mackenbach, J. P. (1999). Social class in childhood and general health in adulthood: questionnaire study of contribution of psychological attributes. BMJ, 318(7175), 1822.

Bosma, H., Van Jaarsveld, C. H., Tuinstra, J., Sanderman, R., Ranchor, A. V., Van Eijk, J. T., et al. (2005). Low control beliefs, classical coronary risk factors, and socio-economic differences in heart disease in older persons. Soc Sci Med, 60(4), 737-745.

Carroll, D., Davey Smith, G., Sheffield, D., Shipley, M. J., \& Marmot, M. G. (1997). The relationship between socioeconomic status, hostility, and blood pressure reactions to mental stress in men: data from the Whitehall II study. Health Psychol, 16(2), 131-136.

Chapman, B. P., Fiscella, K., Kawachi, I., \& Duberstein, P. R. (2009). Personality, socioeconomic status, and all-cause mortality in the United States. Am J Epidemiol, 171(1), 83-92.

Chida, Y., \& Steptoe, A. (2009). The association of anger and hostility with future coronary heart disease: a meta-analytic review of prospective evidence. J Am Coll Cardiol, 53(11), 936-946.

Danese, A., Moffitt, T. E., Harrington, H., Milne, B. J., Polanczyk, G., Pariante, C. M., et al. (2009). Adverse childhood experiences and adult risk factors for age-related disease: depression, inflammation, and clustering of metabolic risk markers. Arch Pediatr Adolesc Med, 163(12), 1135-1143.

Egan, M., Tannahill, C., Petticrew, M., \& Thomas, S. (2008). Psychosocial risk factors in home and community settings and their associations with population health and health inequalities: a systematic meta-review. BMC Public Health, 8, 239.

Ferrie, J. E., Martikainen, P., Shipley, M. J., \& Marmot, M. G. (2005). Self-reported economic difficulties and coronary events in men: evidence from the Whitehall II study. Int J Epidemiol, 34(3), 640-648.

Hart, D., Atkins, R., \& Matsuba, M. K. (2008). The association of neighborhood poverty with personality change in childhood. J Pers Soc Psychol, 94(6), 1048-1061.

Hemingway, H., \& Marmot, M. (1999). Evidence based cardiology: psychosocial factors in the aetiology and prognosis of coronary heart disease. Systematic review of prospective cohort studies. BMJ, 318(7196), 1460-1467.

Hemingway, H., Shipley, M., Brunner, E., Britton, A., Malik, M., \& Marmot, M. (2005). Does autonomic function link social position to coronary risk? The Whitehall II study.[see comment]. Circulation, 111(23), 3071-3077.

Hemmingsson, T., \& Lundberg, I. (2005). How far are socioeconomic differences in coronary heart disease hospitalization, all-cause mortality and cardiovascular mortality among adult Swedish males attributable to negative childhood circumstances and behaviour in adolescence? Int J Epidemiol, 34(2), 260-267.

Horsten, M., Ericson, M., Perski, A., Wamala, S. P., Schenck-Gustafsson, K., \& Orth-Gomer, K. (1999). Psychosocial factors and heart rate variability in healthy women. Psychosom Med, 61(1), 49-57.

Huisman, M., Kunst, A. E., Andersen, O., Bopp, M., Borgan, J. K., Borrell, C., et al. (2004). Socioeconomic inequalities in mortality among elderly people in 11 European populations.[see comment]. $J$ Epidemiol Community Health, 58(6), 468-475.

Jolles, J., Houx, P. J., Boxtel, M. P. J. v., \& Ponds, R. W. H. M. (Eds.). (1995). The Maastricht Aging Study. Determinants of cognitive aging. Maastricht: Neuropsych Publishers.

Kempen, G. I., van Jaarsveld, C. H., van Sonderen, E., Sanderman, R., \& Ormel, J. (2001). Risk factors for developing cardiac disease in late middle-aged and older men and women: a prospective study. $J$ Am Geriatr Soc, 49(11), 1575-1577. 
Koster, A., Bosma, H., Kempen, G. I., Penninx, B. W., Beekman, A. T., Deeg, D. J., et al. (2006). Socioeconomic differences in incident depression in older adults: the role of psychosocial factors, physical health status, and behavioral factors. J Psychosom Res, 61(5), 619-627.

Kristenson, M., Eriksen, H. R., Sluiter, J. K., Starke, D., \& Ursin, H. (2004). Psychobiological mechanisms of socioeconomic differences in health. Soc Sci Med, 58(8), 1511-1522.

Kubzansky, L. D., Cole, S. R., Kawachi, I., Vokonas, P., \& Sparrow, D. (2006). Shared and unique contributions of anger, anxiety, and depression to coronary heart disease: a prospective study in the normative aging study. Ann Behav Med, 31(1), 21-29.

Kuh, D., Ben-Shlomo, Y., Lynch, J., Hallqvist, J., \& Power, C. (2003). Life course epidemiology. J Epidemiol Community Health, 57(10), 778-783.

Kuper, H., Marmot, M., \& Hemingway, H. (2002). Systematic review of prospective cohort studies of psychosocial factors in the etiology and prognosis of coronary heart disease. Semin Vasc Med, 2(3), 267-314.

Lachman, M. E., \& Weaver, S. L. (1998). The sense of control as a moderator of social class differences in health and well-being. J Pers Soc Psychol, 74(3), 763-773.

Laitinen, J., Ek, E., \& Sovio, U. (2002). Stress-related eating and drinking behavior and body mass index and predictors of this behavior. Prev Med, 34(1), 29-39.

Lorant, V., Deliege, D., Eaton, W., Robert, A., Philippot, P., \& Ansseau, M. (2003). Socioeconomic inequalities in depression: a meta-analysis. Am J Epidemiol, 157(2), 98-112.

Mackenbach, J. P. (2010). Has the English strategy to reduce health inequalities failed? Soc Sci Med, 71(7), 1249-1253; discussion 1254-1248.

Mackenbach, J. P., Bos, V., Andersen, O., Cardano, M., Costa, G., Harding, S., et al. (2003). Widening socioeconomic inequalities in mortality in six Western European countries. Int J Epidemiol, 32(5), 830-837.

Mackenbach, J. P., Kunst, A. E., Cavelaars, A. E., Groenhof, F., \& Geurts, J. J. (1997). Socioeconomic inequalities in morbidity and mortality in western Europe. The EU Working Group on Socioeconomic Inequalities in Health. Lancet, 349(9066), 1655-1659.

Mackenbach, J. P., Simon, J. G., Looman, C. W., \& Joung, I. M. (2002). Self-assessed health and mortality: could psychosocial factors explain the association? Int J Epidemiol, 31(6), 1162-1168.

Mackenbach, J. P., van de Mheen, H., \& Stronks, K. (1994). A prospective cohort study investigating the explanation of socio-economic inequalities in health in The Netherlands. Soc Sci Med, 38(2), 299308.

Marmot, M., Ryff, C. D., Bumpass, L. L., Shipley, M., \& Marks, N. F. (1997). Social inequalities in health: next questions and converging evidence. Soc Sci Med, 44(6), 901-910.

Marmot, M. G., Bosma, H., Hemingway, H., Brunner, E., \& Stansfeld, S. (1997). Contribution of job control and other risk factors to social variations in coronary heart disease incidence. Lancet, 350(9073), 235-239.

Marmot, M. G., \& McDowall, M. E. (1986). Mortality decline and widening social inequalities. Lancet, 2(8501), 274-276.

Martin, R., Watson, D., \& Wan, C. K. (2000). A three-factor model of trait anger: dimensions of affect, behavior, and cognition. J Pers, 68(5), 869-897.

Mickelson, K. D., \& Kubzansky, L. D. (2003). Social distribution of social support: the mediating role of life events. Am J Community Psychol, 32(3-4), 265-281.

Miller, T. Q., Smith, T. W., Turner, C. W., Guijarro, M. L., \& Hallet, A. J. (1996). A meta-analytic review of research on hostility and physical health. Psychol Bull, 119(2), 322-348.

Nabi, H., Kivimaki, M., Zins, M., Elovainio, M., Consoli, S. M., Cordier, S., et al. (2008). Does personality predict mortality? Results from the GAZEL French prospective cohort study. Int J Epidemiol, 37(2), 386-396.

Penninx, B. W., Beekman, A. T., Honig, A., Deeg, D. J., Schoevers, R. A., van Eijk, J. T., et al. (2001). Depression and cardiac mortality: results from a community-based longitudinal study. Arch Gen Psychiatry, 58(3), 221-227. 
Penninx, B. W., Beekman, A. T., Smit, J. H., Zitman, F. G., Nolen, W. A., Spinhoven, P., et al. (2008). The Netherlands Study of Depression and Anxiety (NESDA): rationale, objectives and methods. Int J Methods Psychiatr Res, 17(3), 121-140.

Penninx, B. W., Geerlings, S. W., Deeg, D. J., van Eijk, J. T., van Tilburg, W., \& Beekman, A. T. (1999). Minor and major depression and the risk of death in older persons. Arch Gen Psychiatry, 56(10), 889-895.

Power, C., Atherton, K., Strachan, D. P., Shepherd, P., Fuller, E., Davis, A., et al. (2007). Life-course influences on health in British adults: effects of socio-economic position in childhood and adulthood. Int J Epidemiol, 36(3), 532-539.

Rozanski, A., Blumenthal, J. A., Davidson, K. W., Saab, P. G., \& Kubzansky, L. (2005). The epidemiology, pathophysiology, and management of psychosocial risk factors in cardiac practice: the emerging field of behavioral cardiology. J Am Coll Cardiol, 45(5), 637-651.

Rozanski, A., Blumenthal, J. A., \& Kaplan, J. (1999). Impact of Psychological Factors on the Pathogenesis of Cardiovascular Disease and Implications for Therapy. Circulation, 99, 2192-2217.

Rugulies, R. (2002). Depression as a predictor for coronary heart disease. a review and meta-analysis. Am J Prev Med, 23(1), 51-61.

Schrijvers, C. T., Bosma, H., \& Mackenbach, J. P. (2002). Hostility and the educational gradient in health. The mediating role of health-related behaviours. Eur J Public Health, 12(2), 110-116.

Singh, G. K., \& Siahpush, M. (2002). Increasing inequalities in all-cause and cardiovascular mortality among US adults aged 25-64 years by area socioeconomic status, 1969-1998. Int J Epidemiol, 31(3), 600-613.

Smith, T. W. (1992). Hostility and health: current status of a psychosomatic hypothesis. Health Psychol, 11(3), 139-150.

Smith, T. W., Glazer, K., Ruiz, J. M., \& Gallo, L. C. (2004). Hostility, anger, aggressiveness, and coronary heart disease: an interpersonal perspective on personality, emotion, and health. J Pers, 72(6), 1217-1270.

Stansfeld, S. A. (2006). Social support and social cohesion. In M. Marmot \& R. G. Wilkinson (Eds.), Social determinants of health. (Second ed., pp. 148-171). Oxford: Oxford University Press.

Stansfeld, S. A., Bosma, H., Hemingway, H., \& Marmot, M. G. (1998). Psychosocial work characteristics and social support as predictors of SF-36 health functioning: the Whitehall II study. Psychosom Med, 60(3), 247-255.

Stansfeld, S. A., Head, J., Fuhrer, R., Wardle, J., \& Cattell, V. (2003). Social inequalities in depressive symptoms and physical functioning in the Whitehall II study: exploring a common cause explanation. J Epidemiol Community Health, 57(5), 361-367.

Vagero, D., \& Erikson, R. (1997). Socioeconomic inequalities in morbidity and mortality in western Europe. Lancet, 350(9076), 516; author reply 517-518.

Van de Mheen, H., Stronks, K., Looman, C., \& Mackenbach, J. (1998). Does childhood socioeconomic status influence adult health through behavioural factors? Int J Epidemiol, 27(3), 431-437.

Van den Akker, M., Buntinx, F., Metsemakers, J. F. M., van der Aa, M., \& Knottnerus, J. A. (2001). Psychosocial patient characteristics and GP-registered chronic morbidity: A prospective study. J Psychosom Res, 50(2), 95-102.

Van den Akker, M., Spigt, M. G., De Raeve, L., van Steenkiste, B., Metsemakers, J. F., van Voorst, E. J., et al. (2008). The SMILE study: A Study of Medical Information and Lifestyles in Eindhoven, the rationale and contents of a large prospective dynamic cohort study. BMC Public Health, 8(1), 19.

Virtanen, S. V., \& Notkola, V. (2002). Socioeconomic inequalities in cardiovascular mortality and the role of work: a register study of Finnish men. Int J Epidemiol, 31(3), 614-621.

Wilkinson, R. G. (1997). Socioeconomic inequalities in morbidity and mortality in western Europe. Lancet, 350(9076), 516-517; author reply 517-518. 



\section{CHAPTER 2}

The relative contributions of hostility and depressive symptoms to the income gradient in hospital-based incidence of ischaemic heart disease:

12-Year follow-up findings from the GLOBE study

G. Klabbers, H. Bosma, F.J. van Lenthe, G.I. Kempen, J.T. van Eijk, J.P. Mackenbach. 


\section{Abstract}

There is evidence to support the view that both hostility and depressive symptoms are psychological risk factors for ischaemic heart disease (IHD), additional to the effects of lifestyle and biomedical risk factors. Both are also more common in lower socioeconomic groups. Studies to find out how socioeconomic status (SES) gets under the skin have not yet determined the relative contributions of hostility and depression to the income gradient in IHD. This has been examined in a Dutch prospective population-based cohort study (GLOBE study), with participants aged 15 to 74 years ( $n=2,374$ ). Self-reported data at baseline (1991) and in 1997 provided detailed information on income and on psychological, lifestyle and biomedical factors, which were linked to hospital admissions due to incident IHD over a period of 12 years since baseline. Cox proportional hazard models were used to study the contributions of hostility and depressive symptoms to the association between income and time to incident IHD. The relative risk of incident IHD was highest in the lowest income group, with a hazard ratio of $2.71(\mathrm{Cl} 1.60$ 4.61). Men on the lowest incomes reported more adverse lifestyles and biomedical factors, which contributed to their higher risk of incident IHD. An unhealthy psychological profile, particularly hostility, contributed to the income differences in incident IHD among women. The low number of IHD incidents in the women however, warrants additional research in larger samples. 


\section{Introduction}

Ischaemic heart disease (IHD) is the number one cause of death worldwide (Murray \& Lopez, 1997; WHO, 2003). There is a strong socioeconomic gradient in IHD morbidity and mortality in the Western European countries disfavouring the lower socioeconomic groups (Dalstra et al., 2005; Huisman et al., 2005; Kunst et al., 1999; Kunst, Groenhof, Mackenbach, \& Health, 1998; Mackenbach et al., 2003; Mackenbach, Kunst, Cavelaars, Groenhof, \& Geurts, 1997; Marmot \& McDowall, 1986). There may be gender differences in this gradient, although these differences seem to depend on the outcome as the gradient for cardiac morbidity seems to be steeper in women (Loucks, Rehkopf, Thurston, \& Kawachi, 2007; Thurston \& Kubzansky, 2007), and that for cardiac mortality has been found to be steeper in men (Dalstra, et al., 2005; Huisman, et al., 2005; Kunst, et al., 1999; Kunst, et al., 1998; Mackenbach, et al., 2003; Mackenbach, et al., 1997; Marmot \& McDowall, 1986).

In order to allow interventions aimed at reducing heart disease inequalities to be tailored, research has focused on explaining this gradient for several decades. Evidence points in the direction of classical risk factors for heart disease, such as lifestyle factors (smoking, alcohol consumption and physical inactivity) and biomedical factors (obesity, hypertension and diabetes), mediating the socioeconomic gradient in heart disease. However substantial the contribution of these classical risk factors may be (reported contributions vary from $16 \%$ to as much as $60 \%$ ) (Ferrie, Martikainen, Shipley, \& Marmot, 2005; Lynch, Kaplan, Cohen, Tuomilehto, \& Salonen, 1996; Van Lenthe, Gevers, Joung, Bosma, \& Mackenbach, 2002), a moderate part of the gradient remains unexplained. Psychological risk factors, which have been the subject of numerous studies in the last decade, might shed further light upon the pathways by which socioeconomic status gets under the skin.

Specifically, hostility and depressive symptoms have emerged as potential contributing factors to the socioeconomic gradient in IHD. Both are considered important psychological risk factors for incident heart disease, although the evidence is stronger for depressive symptoms and depression than for hostility (Frasure-Smith \& Lespérance, 2005; Hemingway \& Marmot, 1999; Kuper, Marmot, \& Hemingway, 2002; Penninx et al., 2001; Penninx et al., 1998; Wulsin \& Singal, 2003). Also, both depressive symptoms and hostility are more prevalent in lower than in higher socioeconomic groups (Appels, Meesters, \& Collijn, 1995; Carroll, Davey Smith, Sheffield, Shipley, \& Marmot, 1997; Chaput et al., 2002; Everson et al., 1997; Everson, Maty, Lynch, \& Kaplan, 2002; Gallo \& Matthews, 2003; Lorant et al., 2003; Marmot et al., 1991; Scherwitz, Perkins, Chesney, \& Hughes, 1991; Stansfeld, Head, Fuhrer, Wardle, \& Cattell, 2003), perhaps due to a long-term exposure to adverse circumstances.

Few studies have investigated the influence of depressive symptoms on the socioeconomic gradient in heart disease and results have so far been inconclusive. 
Whereas Lynch and colleagues (Lynch, et al., 1996) found that psychological and social risk factors, including depression, attenuated the association between income and cardiovascular mortality in a population of middle-aged Finnish men, Thurston and colleagues (Thurston, Kubzansky, Kawachi, \& Berkman, 2006) concluded that depression did not appear to mediate the relation between educational attainment and incident CHD. The contribution of hostility in a general population has, to our knowledge, only been examined longitudinally by Schrijvers and colleagues (Schrijvers, Bosma, \& Mackenbach, 2002), who found that a substantial part of the educational gradient in general perceived health could be ascribed to the intermediary effects of hostility in both men and women.

Although hostility and depressive symptoms differ conceptually, in the sense that hostility is an outward-focused negative emotion, directed at others and therefore reactive by nature, whereas depressive symptoms are more inwardfocused, directed at oneself (De Vogli, Brunner, \& Marmot, 2007; Suarez, Kuhn, Schanberg, Williams, \& Zimmermann, 1998), pathways by which they affect IHD might be similar. Both are responses to stressful circumstances, which are more common in lower SES groups, and both evoke a sustained physiological reactivity characterised by activation of the sympathetic nervous system and hypersecretion of the stress hormone cortisol (Rozanski, Blumenthal, \& Kaplan, 1999; Strike \& Steptoe, 2004). This, in turn, may have direct long-term adverse effects on the immune and cardiovascular systems (Adler \& Ostrove, 1999; Kristenson, Eriksen, Sluiter, Starke, \& Ursin, 2004). Depressive symptoms and hostility might also affect cardiovascular health indirectly through lifestyle as depressed and hostile individuals tend to engage in less healthy behaviours, such as smoking and heavy drinking (Laitinen, Ek, \& Sovio, 2002).

Using 12-year longitudinal data from the Dutch GLOBE study, we examined the relative contributions of hostility and depressive symptoms to the income gradient in IHD (in addition to the contribution of the classical risk factors) and the possible gender differences therein. Given the above-mentioned associations, we hypothesised that individuals with lower incomes would be at higher risk of IHD, because they are more likely to suffer from depressive symptoms or to have hostile cognitions than their higher income counterparts. The aim of the study was to explore the complex pathways underlying socioeconomic inequalities in incident IHD and thereby to identify opportunities for prevention and intervention aimed at reducing these inequalities. 


\section{Methods}

\section{Design}

Longitudinal data were gathered between 1991 and 2003 as part of the prospective cohort study called GLOBE, a Dutch acronym for 'Health and Living conditions of the Population of Eindhoven and Surroundings'. The GLOBE study aims to explain socioeconomic inequalities in health. The design and rationale of the study have been published elsewhere (Mackenbach, van de Mheen, \& Stronks, 1994). Briefly, a postal survey was conducted in 1991 among 27,070 non-institutionalised individuals aged 15-74 years, with a Dutch nationality. With a response rate of $70.1 \%$, 18,973 respondents completed this baseline questionnaire. There were no significant differences in non-response by socioeconomic position, age, sex, marital status or degree of urbanisation (Mackenbach, et al., 1994). Two sub-samples were drawn to gather more detailed risk factor information by means of questionnaires and interviews between 1991 and 1997. One sub-sample was randomly drawn and consisted of 2,802 respondents (response rate $79.4 \%$ ) whereas in the other subsample, individuals with chronic diseases were oversampled $(n=2,867$, response rate $72.3 \%$ ). Because the non-random sampling in the latter sample compromises its representativeness of the source population and possibly the estimation of effect sizes, weight factors were calculated for all respondents to re-establish the representativeness of the sample (Mackenbach, 2002).

The interview and questionnaire data were linked to data from the municipal register on mortality and addresses (or changes of address), and with hospital admission data from five hospitals in the catchment area of the GLOBE study between 1991 and 2003. The catchment area of the hospitals was defined as the area around the city of Eindhoven, encompassing the villages where at least $90 \%$ of the population would be admitted to one of the five hospitals, when requiring hospital admission. Linkage was based on date of birth, gender and postal code. If identical combinations of these key variables were found, patient numbers, hospital codes and information on health insurance were checked to determine whether the admission was a re-admission or whether different individuals had been admitted. When re-admissions where found, only the first admissions were selected (Van Lenthe, et al., 2002). Data on hospital admission were complete for all but 19 respondents.

\section{Participants}

The present study is based on the questionnaire and interview data from the two sub-samples. A total of 4,109 (72.5\%) respondents completed the 1991 baseline and 1997 follow-up measurements, which included detailed risk factor information. 
We excluded (a) individuals who were included in the sample because of known heart disease (chronic diseases were oversampled in one of the sub-samples) and those who reported heart disease at baseline or in the 5 years prior to baseline ( $n=962$ ), (b) respondents whose hospital admission data or municipal register data were missing $(n=19),(c)$ respondents with missing data for the risk factors under study $(n=345)$ and (d) respondents with missing income data $(n=409)$. The final sample comprised 2,374 individuals.

\section{Measures}

Hospital-based incident ischaemic heart disease (referred to below as incident IHD) was determined according to ICD-9 classification codes 410-414. An incident IHD event was defined as a first hospital admission diagnosis of IHD after baseline. Fatal events were considered cases if death occurred after admission. Pre-hospital IHD deaths were not considered cases, since data on cause-specific mortality were not available. Incident IHD was measured continuously from baseline until 22 December 2003.

All other measures were assessed at baseline in 1991, except for hostility, which was measured in 1997 only.

Income and education were used to determine SES. Net household income was adjusted for the number of adults and children who were part of the household (Hagenaars, Vos, \& Zaidi, 1994) and classified into thirds (based on tertiles). Three levels of education were distinguished: higher secondary education, higher professional education or university education (level 1 ), senior secondary vocational education or general secondary education (level 2), and lower secondary vocational education or primary education only (level 3).

Hostility was measured by the 6-item version of the hostility sub-scale of the Aggression Questionnaire (Buss \& Perry, 1992; Meesters, Muris, Bosma, Schouten, \& Beuving, 1996) in 1997. This questionnaire has been proven reliable and valid (Buss \& Perry, 1992; Felsten \& Hill, 1999; Harris, 1997; Meesters, et al., 1996). A seven-month test-retest stability of 0.67 has been reported by Harris and colleagues (Harris, 1997). An example item is 'I wonder why sometimes I feel so bitter about things'. Items were rated on a 5-point Likert scale, ranging from 1 ('totally disagree') to 5 ('totally agree'). Items were summed to obtain an overall score (630) with higher scores indicating more hostility. Internal consistency, as measured by Cronbach's $\alpha$, was 0.71 . The scores were categorised into tertiles, the highest tertile reflecting the greatest hostility.

The 9-item emotional reactions sub-scale of the Nottingham Health Profile (NHP) (Erdman, Passchier, Kooijman, \& Stronks, 1993; Hunt, McEwen, \& McKenna, 1986) was used as a proxy for depressive symptoms. The NHP has been found to be valid and reliable (Coons, Rao, Keininger, \& Hays, 2000). Comparison with the Gen- 
eral Health Questionnaire (GHQ) has shown that a high NHP-ER score is indicative of depressed mood as measured with the GHQ, at least in stroke patients (Ebrahim, Barer, \& Nouri, 1986). An example item is 'I wake up feeling depressed'. Using predefined item weights, the dichotomous items were converted into a continuous scale score ranging from 0 to 100 (Hunt, et al., 1986). Cronbach's $\alpha$ of the continuous scale was 0.78 . Based on the skewed distribution ( $81 \%$ scored 0 ), we dichotomised this score ( $0=$ no depressive symptoms, $>0=$ depressive symptoms).

Classical risk factors were self-reported smoking, alcohol consumption, physical activity, hypertension, diabetes and obesity. Smoking status was indicated as never smoker, former smoker, pipe/cigar smoker, current smoker $\leq 20$ cigarettes a day or current smoker $>20$ cigarettes a day. Individuals were categorised into five groups for alcohol consumption: total abstainers, light, moderate, excessive and very excessive drinkers (Droomers, Schrijvers, \& Mackenbach, 2001). Physical activity was based on the number of hours spent per week on sports activities and on gardening, cycling and walking. It was classified into inactivity, low, moderate or high physical activity (Droomers, et al., 2001). Hypertension and diabetes were selfreported and dichotomised into 'never had the condition' versus '(ever) had the condition'. Body Mass Index (BMI) was calculated by dividing self-reported weight $(\mathrm{kg})$ by the square of self-reported height $(\mathrm{m})$, and two groups were distinguished with obesity defined as $\mathrm{BMI} \geq 30$.

Age, sex and marital status (married, single, divorced, widowed) were the basic confounders included in the analyses.

\section{Data analyses}

First, the association between all variables and sex was examined by means of $t$ testing and chi-square testing, depending on the variable measurement levels. Cox proportional hazard models were used to study the association of income with incident IHD between 1991 and 2003. Survival time was defined as the time from baseline to the date of (a) first hospital admission due to diagnosed IHD, (b) death, (c) emigration outside the catchment area or (d) complete follow-up (22 December 2003). All total group analyses were adjusted for age, sex and marital status. The interaction between income and gender for the income differences in IHD was not significant. However, because of significant interactions between gender and income for the income differences in hostility $(p=0.01)$ and between gender and hostility for the association between hostility and IHD $(p=0.00)$, all results were reported for men and women separately. There were no significant interactions with age. The reference model included income and the basic confounders. Survival curves, indicating the cumulative proportion of participants without an admission during the follow-up interval, were estimated for men and women. 
Second, we examined the associations of income with hostility and depressive symptoms by means of logistic regression and of hostility and depressive symptoms with incident IHD by means of Cox regression.

Third, we compared the basic model including income and the basic confounders with models including classical risk factors (model 2) depressive symptoms (model 3), depressive symptoms and classical risk factors (model 3a), hostility (model 4), hostility and classical risk factors (model 4a), depressive symptoms and hostility (model 5) and classical risk factors, depressive symptoms and hostility (model 6). The contribution of each of the added factors was expressed as the reduction in hazard ratio (HR) for income after inclusion of the additional factors (Baron \& Kenny, 1986). This reduction was calculated as follows: (HR restricted model ${ }^{-}$ $\left.\mathrm{HR}_{\text {extended model }}\right)$ / ( $\mathrm{HR}_{\text {restricted model }}$ - 1) (Schrijvers, et al., 2002). In order to verify the robustness of the results, the analyses were repeated with education as an SES measure, and with 1997 as the baseline year, as hostility was measured in 1997 only.

\section{Results}

A total of 106 respondents suffered incident IHD between 1991 and 2003. Men were more likely to suffer an IHD event $(n=75)$ than women $(n=31)$ (Table 1). Further, men were older, had higher incomes, smoked more and consumed more alcohol, and were more likely to have diabetes, compared to women. Women were more likely to report depressive symptoms ( $20.1 \%$ vs. $17.0 \%$ in men), although the difference was not significant. 
Table 1 Sample characteristics and difference testing for men and women

\begin{tabular}{|c|c|c|c|}
\hline & Men $(n=1,168)$ & Women $(n=1,206)$ & $p^{b}$ \\
\hline Incident IHD events & $6.4(\mathrm{~N}=75)$ & $2.6(\mathrm{~N}=31)$ & 0.00 \\
\hline $\mathrm{Age}^{\mathrm{a}}$ & 42.6 (SD 13,5) & 41.2 (SD 13.5) & 0.01 \\
\hline \multicolumn{4}{|l|}{ Marital status } \\
\hline Married & 74.3 & 73.1 & 0.00 \\
\hline Single & 20.4 & 18.1 & \\
\hline Divorced & 4.5 & 5.7 & \\
\hline Widowed & 0.8 & 3.1 & \\
\hline Income & & & 0.00 \\
\hline High & 35.2 & 28.6 & \\
\hline Intermediate & 32.5 & 33.6 & \\
\hline Low & 32.3 & 37.8 & \\
\hline Depressive symptoms & 17.0 & 20.1 & 0.06 \\
\hline Hostility & & & 0.49 \\
\hline Low & 41.1 & 42.8 & \\
\hline Intermediate & 27.8 & 28.3 & \\
\hline High & 31.1 & 28.8 & \\
\hline Smoking & & & 0.00 \\
\hline Never & 24.1 & 38.9 & \\
\hline Former & 36.7 & 27.9 & \\
\hline Pipe/cigar & 5.6 & 0 & \\
\hline$<20 \mathrm{cig} /$ day & 26.2 & 27.7 & \\
\hline$>20$ cig/day & 7.4 & 5.5 & \\
\hline Alcohol consumption & & & 0.00 \\
\hline Abstainers & 9.5 & 25.2 & \\
\hline Light & 49.1 & 57.6 & \\
\hline Moderate & 28.0 & 14.6 & \\
\hline Excessive & 8.7 & 2.2 & \\
\hline Very excessive & 4.7 & 0.5 & \\
\hline Physical inactivity & & & 0.28 \\
\hline High & 41.0 & 38.1 & \\
\hline Moderate & 46.9 & 49.4 & \\
\hline low & 8.7 & 9.9 & \\
\hline Inactive & 3.3 & 2.6 & \\
\hline Hypertension & 9.8 & 9.0 & 0.53 \\
\hline Diabetes & 3.9 & 2.4 & 0.04 \\
\hline $\mathrm{BMI} \geq 30$ & 4.6 & 4.9 & 0.77 \\
\hline
\end{tabular}

${ }^{a}$ the mean age is provided, of all other variables the percentages within the groups of men and women are given ${ }^{b}$ gender differences in age were tested by means of a t-test statistic, gender differences in all other variables were tested by means of a chi-square test statistic 
Lower income levels were associated with a higher risk of incident IHD in both men and women (Figure 1, and Table 4, model 1).

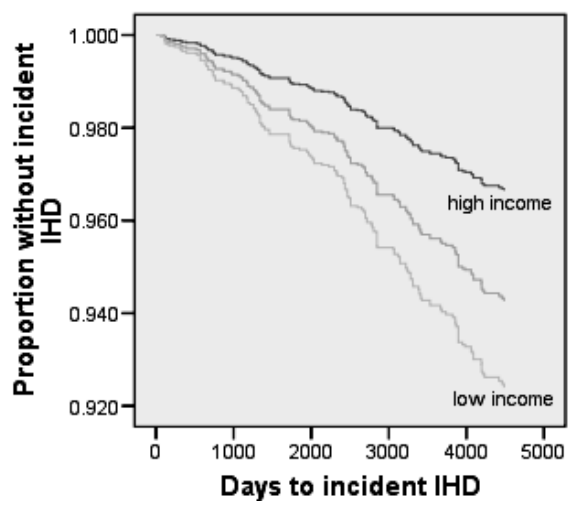

Figure 1a Hazard rate for incident IHD in men by three categories of income, adjusted for age and marital status

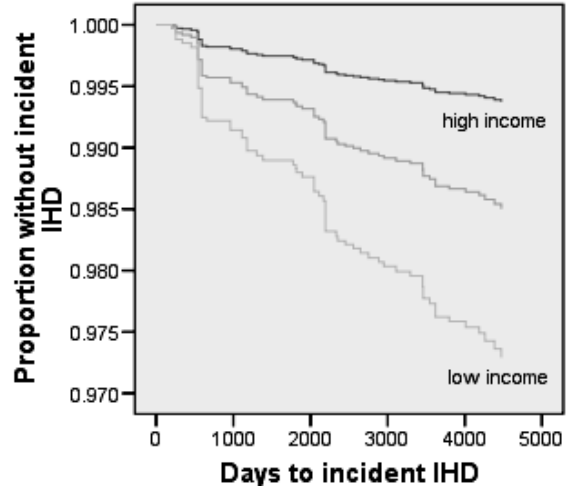

Figure 1b Hazard rate for incident IHD in women by three categories of income, adjusted for age and marital status

Income was significantly related to depressive symptoms in the total group and in women, but not in men (Table 2). Income was significantly related to hostility in the total group and in men and women separately, although the association was stronger for men. These results were summarised in the odds ratios for trend, which show significant increases in depressive symptoms and hostility with decreasing incomes, except for depressive symptoms in men. 
Table 2 Odds ratios of depressive symptoms and hostility (95\% confidence interval) according to income, for the total group (adjusted for age, sex and marital status) and for men and women separately (adjusted for age and marital status)

\begin{tabular}{lllll}
\hline & & & Depressive symptoms & Hostility $^{\mathrm{a}}$ \\
& Income & $\mathrm{N}$ & OR $(95 \% \mathrm{Cl})$ & OR $(95 \% \mathrm{Cl})$ \\
\hline Total group & high & 755 & 1.00 & 1.00 \\
& intermediate & 768 & $1.01(0.77-1.33)$ & $1.38(1.09-1.75)$ \\
& low & 833 & $1.65(1.28-2.12)$ & $2.66(2.12-3.34)$ \\
\multirow{3}{*}{ Men } & trend & 2,374 & $1.30(1.14-1.48)$ & $1.65(1.48-1.85)$ \\
& high & 411 & 1.00 & 1.00 \\
& intermediate & 380 & $0.85(0.57-1.26)$ & $1.71(1.22-2.38)$ \\
& low & 377 & $1.37(0.95-1.98)$ & $3.66(2.65-5.07)$ \\
& trend & 1168 & $1.18(0.98-1.43)$ & $1.93(1.64-2.27)$ \\
& High & 344 & 1.00 & 1.00 \\
& Intermediate & 406 & $1.13(0.77-1.67)$ & $1.09(0.78-1.53)$ \\
& Low & 456 & $1.83(1.28-2.62)$ & $1.92(1.40-2.64)$ \\
& trend & 1206 & $1.38(1.15-1.65)$ & $1.42(1.21-1.66)$ \\
\hline
\end{tabular}

${ }^{a}$ for the purpose of this analysis, hostility was entered in the regression model as a dichotomous variable (1=highest tertile, $0=$ lowest two tertiles) ${ }^{b}$ tests for trend were performed by modelling the three categories (high, intermediate, low) of income as a continuous variable.

The respondents with depressive symptoms had a $66 \%$ higher risk of incident IHD, compared to the respondents without these symptoms (Table 3). This relationship was significant for men ( $\mathrm{HR}=1.74, \mathrm{Cl} 1.03-2.95)$, but not for women. The association between hostility and incident IHD in the total group was marginally statistically significant $(p<0.10)$. However, there were gender differences: whereas in men with the highest hostility scores the hazard ratio of incident IHD was not statistically significant, and intermediate scores even had a protective effect, the most hostile women had an almost three times higher risk of incident IHD compared to the least hostile women ( $\mathrm{HR}=2.80,95 \% \mathrm{Cl} 1.09-7.18)$. 
Table 3 Hazard ratios of incident IHD (95\% confidence interval) according to depressive symptoms and hostility for the total group (adjusted for age, sex and marital status) and for men and women separately (adjusted for age and marital status)

\begin{tabular}{|c|c|c|c|c|c|c|c|c|c|}
\hline & \multicolumn{3}{|c|}{ Total group } & \multicolumn{3}{|l|}{ Men } & \multicolumn{3}{|c|}{ Women } \\
\hline & $\mathrm{N}$ & $\% \mathrm{IHD}$ & $\mathrm{HR}(95 \% \mathrm{Cl})$ & $\mathrm{N}$ & $\% \mathrm{IHD}$ & $\mathrm{HR}(95 \% \mathrm{Cl})$ & $\mathrm{N}$ & $\% \mathrm{IHD}$ & $\mathrm{HR}(95 \% \mathrm{Cl})$ \\
\hline $\begin{array}{l}\text { Depressive } \\
\text { symptoms }^{\text {a }}\end{array}$ & & & $1.02(1.00-1.04)$ & & & $1.02(1.00-1.04)$ & & & $1.02(1.00-1.04)$ \\
\hline no & 1932 & $4.0(n=78)$ & 1.00 & 968 & $5.9(n=57)$ & 1.00 & 963 & $2.2(n=21)$ & 1.00 \\
\hline high & 442 & $6.3(n=28)$ & $1.66(1.08-2.56)$ & 200 & $9.0(n=18)$ & $1.74(1.03-2.95)$ & 243 & $4.1(n=10)$ & $1.47(0.68-3.16)$ \\
\hline Hostility $^{a}$ & & & $1.05(1.00-1.08)$ & & & $1.01(0.96-1.07)$ & & & $1.09(1.03-1.16)$ \\
\hline low & 997 & $4.0(n=40)$ & 1.00 & 481 & $7.1(n=34)$ & 1.00 & 516 & $1.2(n=6)$ & 1.00 \\
\hline middle & 666 & $3.3(n=22)$ & $0.70(0.41-1.18)$ & 324 & $3.7(n=12)$ & $0.49(0.25-0.89)$ & 342 & $2.9(n=10)$ & $1.89(0.68-5.22)$ \\
\hline high & 711 & $6.2(n=44)$ & $1.26(0.82-1.94)$ & 363 & $8.0(n=29)$ & $0.98(0.59-1.63)$ & 348 & $34.3(n=15)$ & $2.80(1.09-7.18)$ \\
\hline
\end{tabular}

${ }^{a}$ analyses were performed by including the continuous as well as the categorical measures of depressive symptoms and hostility

The highest risks of incident IHD were found in the lowest income groups (Table 4, model 1). Due to the low number of IHD events in women, the confidence intervals around the hazard ratios were wide compared to those in men. The classical risk factors made a modest contribution to the income differences in IHD in the total group and in men, but not in women (model 2). Depressive symptoms made a modest contribution to the income differences in the total group and in men and women (model 3). Hostility had an effect in women, but not in men (model 4). Models 3a and 4a show that although there were shared effects of the classical and psychological risk factors (the contributions in models $3 a$ and $4 a$ were smaller than the sum of the contributions in models 2 and 3 , and 2 and 4 respectively), they exerted independent effects on the income differences in IHD. Adding the combined psychological risk factors to the model containing the basic confounders (model 5) shows that these combined psychological risk factors could only 'explain' part of the income differences in IHD for women, not for men. 


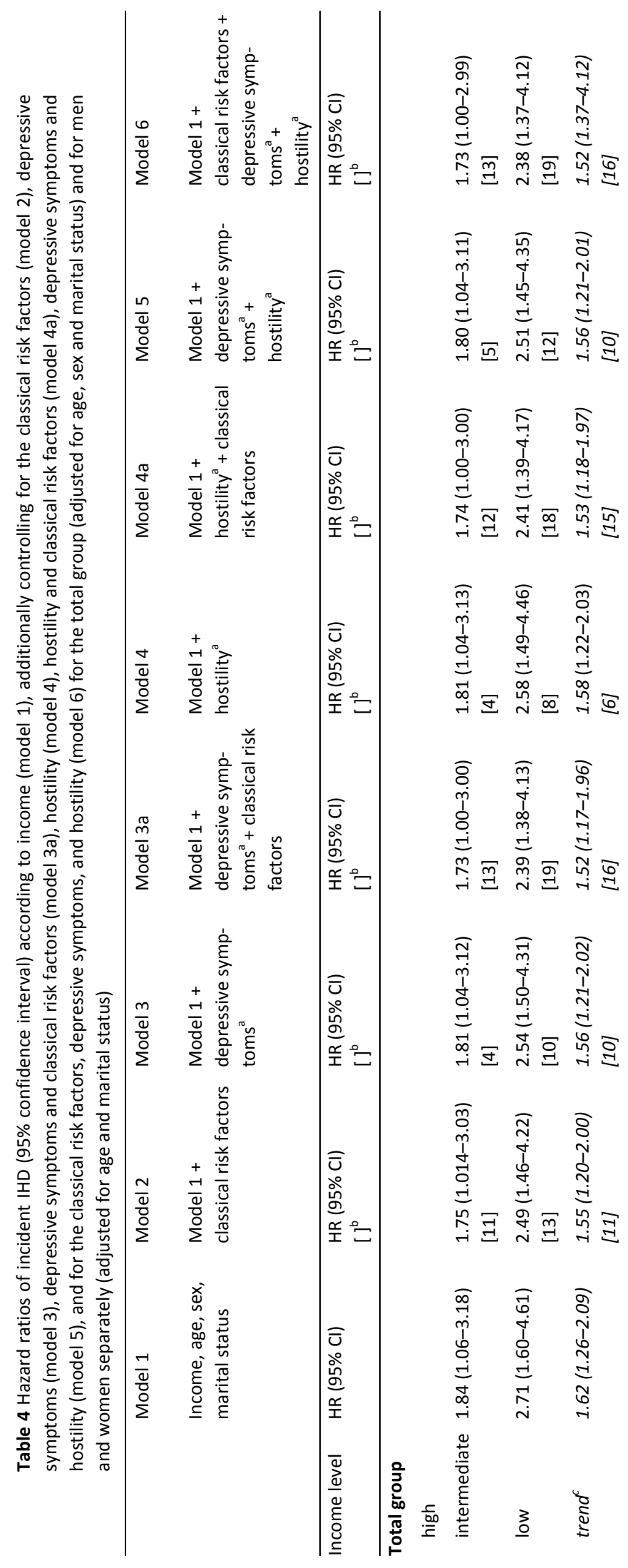




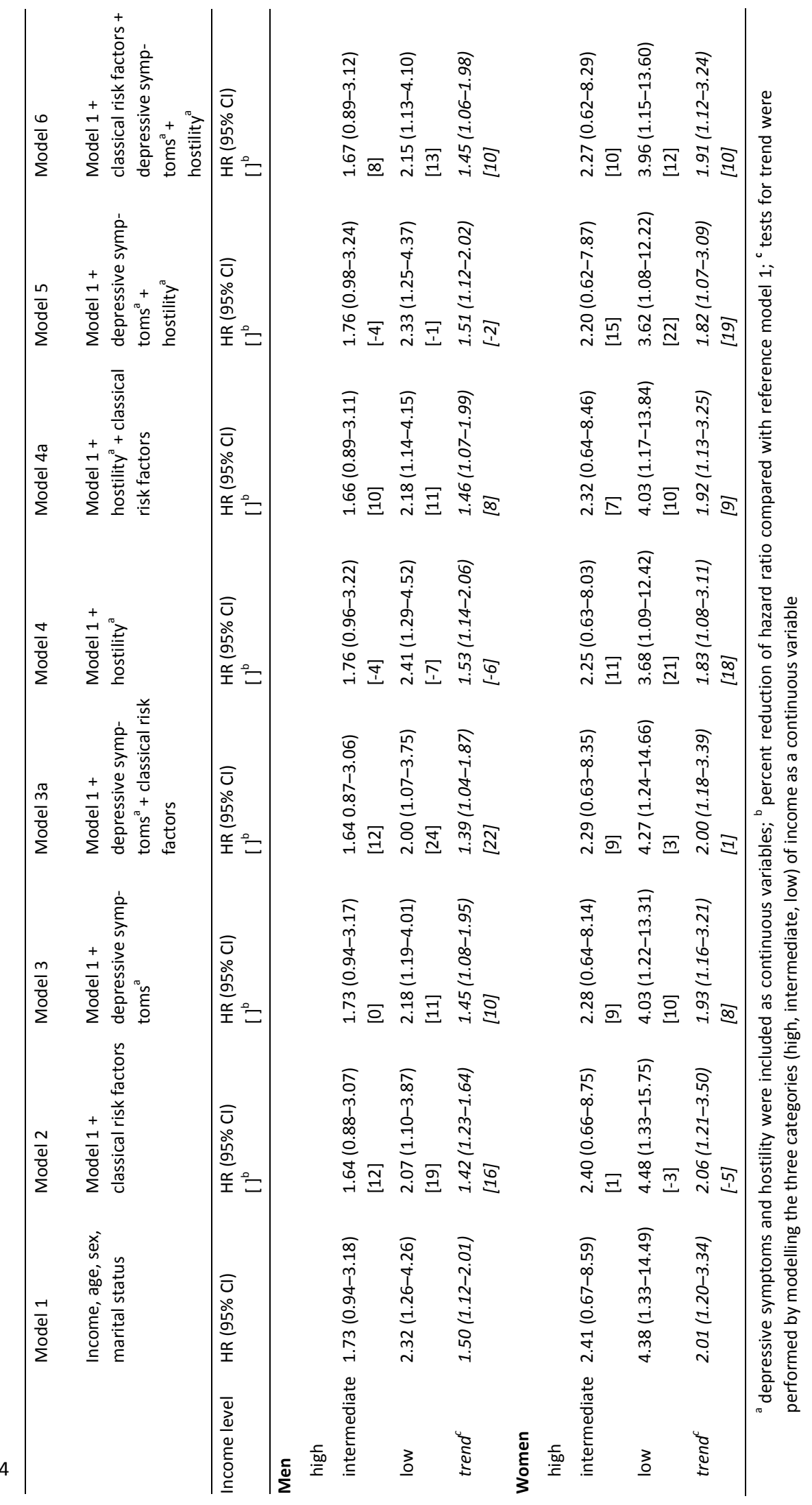


We also compared the models with education as an SES measure (not tabulated). The results supported our findings for income. The reference model, including the basic confounders age, sex and marital status showed that the highest risks of IHD events were for the lowest educated ( $H R=2.01$ for the total sample, $H R=1.85$ for men and $H R=3.16$ for women). The pattern of contributions of the psychological and classical risk factors and the gender differences therein was similar to that for income. However, the educational gradient in incident IHD was no longer statistically significant for men after stratification by gender. Analyses taking 1997, when hostility was first measured, as the baseline showed similar trends and contributional patterns, although the hazard ratios were somewhat smaller (HR for the lowest income and educational groups being 1.73 and 1.75 respectively) and not significant, due to the smaller number of IHD cases $(n=52)$ (not tabulated). Finally, hostility and depressive symptoms correlated modestly (Spearmans $r h o=0.20$ ), but did not interact in their effect on incident IHD or in their contribution to the socioeconomic differences in incident IHD.

\section{Discussion}

To our knowledge, this study is the first to stratify for gender in examining the contributions of both hostility and depressive symptoms to income differences in IHD. The results of the GLOBE study show that the lowest income group had a significantly higher risk of incident IHD than the highest income group. Persons in the lowest income group were more hostile and reported more depressive symptoms. The results indicate that there were gender differences in the contributions of the classical and psychological risk factors. In men, it was especially the classical risk factors which contributed to the income differences in IHD, whereas in women, the psychological factors, and particularly hostility, made higher contributions than the classical risk factors. However, due the low number of IHD events in women and the resulting wide confidence intervals around the hazard ratios our results have to be interpreted with some caution.

Income and education basically yielded the same results. After stratification for gender, however, the reference model including education was no longer significant for men. Associations between socioeconomic position and health vary with the measure used to express SES (Schrijvers, et al., 2002), or with the population being examined: where sometimes education was found to better predict cardiac disease (Schrijvers, et al., 2002), others found income to predict cardiac disease best (Schrijvers, et al., 2002). In our population, income was the stronger predictor of cardiac health than education. The GLOBE data had already shown that income (measured by a proxy variable) rendered the educational differences in acute myocardial infarction non-significant (Schrijvers, et al., 2002). 
An unexpected finding was that hostility contributed to income differences in IHD events only in women but not in men. Schrijvers and colleagues (Schrijvers, et al., 2002) reported intermediary effects of hostility to the educational gradient in general perceived health that were of similar size in men and women. Studies examining the association between hostility and cardiac disease have focused predominantly on men, and most reported a positive association ((Frasure-Smith \& Lespérance, 2005; Hemingway \& Marmot, 1999; Kuper, et al., 2002; Penninx, et al., 2001; Penninx, et al., 1998; Wulsin \& Singal, 2003), though not all (Ranchor, Sanderman, Bouma, Buunk, \& van den Heuvel, 1997). We cannot explain why we neither found an elevated risk of IHD events in hostile men, nor a contribution of hostility to the income gradient in IHD events.

While the higher risk of reporting depressive symptoms was significant in low income women only (Table 2), depressive symptoms were a risk factor for IHD events in men only (Table 3). Although this gender difference has been found before (Penninx, et al., 1998), most studies find a cardiac risk in both depressed men and women (Penninx, et al., 1998). The low number of IHD events in women in the present study may explain the found gender differences in IHD risk. However, no notable gender differences were found in the contribution of depressive symptoms to the income differences in IHD events in men and women.

Hence, despite hostility and, to a lesser extent, depressive symptoms being more prevalent in lower-class men and women, only women appear to experience negative effects of this profile. For the time being, we cannot explain this genderspecific effect of the psychological risk factors and of hostility in particular. Similarly, the absence of an effect of the classical risk factors in women was hard to explain. The results for women should, however, be interpreted with caution. The number of IHD events in women was small, $\mathrm{N}=31$ (versus 75 in men), which may have been caused by the relatively low age of the women in our sample. In women, a lesser number of cardiac events occurred at a higher mean age in a Dutch general practice population (Penninx, et al., 1998), which supports our results. Thus, the gender differences in the response profiles that we found (psychological in women and behavioural in men) need to be confirmed in larger samples, also including older women.

Hostility and depressive symptoms have been found to cluster within individuals (Felsten, 1996; Raynor, Pogue-Geile, Kamarck, McCaffery, \& Manuck, 2002) and they might even interact within each other, although the existing evidence on this interaction is inconclusive (Miller, Freedland, Carney, Stetler, \& Banks, 2003; Ravaja, Kauppinen, \& Keltikangas-Jarvinen, 2000; Suarez, 2003). We only found a modest correlation, and no synergistic effect of hostility and depression on incident IHD, indicating that depression and hostility are not necessarily simultaneous responses in the same lower-class individual. 
Despite the gender-specific effect of potentially unhealthy psychological profiles, the general tendency we found was that both men and women in lower socioeconomic groups were more likely to report such potentially unhealthy profiles than their better-off counterparts. Being exposed to prolonged adverse circumstances might leave people insecure and less in control (Bosma, 2006). Especially the latter, the lower control beliefs, might be an underlying factor of hostility and depressive symptoms. Bosma and colleagues (Bosma, Schrijvers, \& Mackenbach, 1999) found that 'low control beliefs or socialised fatalism have important roots in adverse environmental factors, circumstances, and events in early and adult life'. Not only are individuals in lower socioeconomic groups more likely to end up in jobs with low autonomy and control (Bosma, Stansfeld, \& Marmot, 1998), but being poor and deprived also leaves them with fewer resources (e.g. financial resources) and options, which may further decrease their sense of control. This sense of low control may evoke inward-focused negative responses (negative self-evaluation) such as occur in depressive states. Several studies have demonstrated a direct association between low control beliefs and elevated risks of depression in lower socioeconomic status groups (Haidt \& Rodin, 1999; Ross \& Mirowsky, 1989). Low control, on the other hand, might also evoke a more outward-focused negative response (externalizing blame), such as hostility (Syme, 1989). The extent to which low control beliefs are contributing to the pathway between low socioeconomic status, hostility/depression, biomedical/behavioural factors and incident IHD needs to be examined in more depth in future studies, focusing on any gender-specific patterns.

\section{Methodological limitations}

First, hospital-based incident IHD as the outcome excludes silent myocardial ischaemia (minor asymptomatic infarctions) and pre-hospital deaths due to IHD. Data on cause-specific mortality were not available for this study. However, we assume that a substantial proportion of pre-hospital deaths is caused by cardiac events (IHD being the number one cause of death). Pre-hospital deaths due to IHD are generally more common in lower SES groups (Morrison, Woodward, Leslie, \& Tunstall-Pedoe, 1997). Consequently, the socioeconomic risk differences in IHD might possibly have been underestimated in our study. Further, although the record linkage was complete for all but 19 respondents, we cannot be completely sure that there were no hospital admissions outside the catchment area. It is not clear, however, if this occurred more often in higher or lower socioeconomic groups and therefore whether this has resulted in overestimation or underestimation of the income differences (Morrison, et al., 1997).

Second, self-report of the risk factors may have resulted in misclassification. Diabetes, hypertension, weight (or overweight) and depressive symptoms are possibly underreported among the less educated (Mackenbach, Looman, \& van der 
Meer, 1996; Nieto-Garcia, Bush, \& Keyl, 1990; Okura, Urban, Mahoney, Jacobsen, \& Rodeheffer, 2004). How this may have affected the relative contributions of classical and psychological risk factors is unclear, but such differential underreports may underlie the finding that the effect of the classical risk factors in our study was in the lower range of the values found in other studies (16-60\%) (Ferrie, et al., 2005; Lynch, et al., 1996; Van Lenthe, et al., 2002).

Third, the relationship between depressive symptoms and IHD is usually studied using validated and widely accepted self-reported measures of depression, such as the Beck Depression Inventory (Beck, Steer, \& Garbin, 1999), Center for Epidemiologic Studies Depression Scale (Radloff, 1977) or Patient Health Questionnaire (Spitzer, Kroenke, \& Williams, 1999). Although the 9 items of the NHP-ER are very similar to the 9 depression items of the PHQ and also cover the anhedonism and depressive moods that are indicative of depression, the NHP-ER has only been validated as a measurement instrument for depressive symptoms in a group of stroke patients (Ebrahim, et al., 1986). Hence, the validity of this instrument might be compromised.

Fourth, although hostility was measured in 1997, it was included in the analyses with 1991 as the baseline year. The underlying idea is that hostility is fairly stable (Costa, McCrae, \& Dye, 1992), which was confirmed by a seven-month testretest stability of 0.67 (Harris, 1997), although that study population differed from ours. Repeating our analyses by taking the 1997 measurements as the baseline year showed that the pattern of findings was similar. Notwithstanding the fact that hostility is generally considered to be a trait, it is more prevalent in lower SES, either indicating that it might be influenced and evoked by adverse (social) circumstances, or that hostility (and its potentially partially genetic roots) is involved in downward social mobility, in terms of indirect selection processes. This needs to be examined further.

Fifth, the mediational method we used assumes causality and is based on an experimental design (Baron \& Kenny, 1986), while our study was an observational cohort study. Income, our main independent variable, was measured at the same time as depressive complaints, one of the assumed 'mediators'. This implies that we cannot make any causal inferences, which is a limitation. Further, this mediational method has low power and does not address the question of whether the indirect effect (effect through psychological factors) is significantly different from zero (MacKinnon, Lockwood, Hoffman, West, \& Sheets, 2002). This is another reason why our results should be interpreted with caution.

Finally, we had to exclude a substantial number of respondents with missing data on hostility, as they had not responded to the 1997 (hostility) questionnaire. However, we do have follow-up data on hospital admission for all respondents. We found that there were no significant income differences in IHD events between the respondents and those who were lost to follow-up. 


\section{Conclusion}

Although potentially unhealthy psychological profiles, as characterised by hostility and depressive symptoms, were more prevalent in the lower income groups, our findings suggest gender differences in pathways through which socioeconomic adversity gets under the skin. An unhealthy psychological profile, particularly hostility, contributed to the income differences in incident IHD in women only whereas the classical risk factors explained more of the income differences in incident IHD in men. Although our results need further empirical verification from larger samples (at least for women), with a study design more suitable for examining causal pathways, we recommend that interventions aimed at reducing socioeconomic inequalities in incident IHD should take account of both classical and psychological risk factors as well as possible gender differences therein. 


\section{References}

Adler, N. E., \& Ostrove, J. M. (1999). Socioeconomic status and health: what we know and what we don't. Ann N Y Acad Sci, 896, 3-15.

Appels, A., Meesters, C., \& Collijn, D. (1995). Socio-economical status and risk of myocardial infarction: the influence of hostility and vital exhaustion (in Dutch). Gedrag en Gezondheid, 23, 261-271.

Baron, R. M., \& Kenny, D. A. (1986). The moderator-mediator variable distinction in social psychological research: conceptual, strategic, and statistical considerations. J Pers Soc Psychol, 51(6), 1173-1182.

Beck, A. T., Steer, R. A., \& Garbin, M. G. (1999). Psychometric properties of the Beck Depression Inventory: Twenty-five years of evaluation. Clin Psychol Rev, 8(1), 77-100.

Bosma, H. (2006). Socio-economic differences in health: are control beliefs fundamental mediators? In J. Siegrist \& M. Marmot (Eds.), Social Inequalities in Health. New evidence and policy implications (pp. 153-166). Oxford: Oxford University Press.

Bosma, H., Schrijvers, C., \& Mackenbach, J. P. (1999). Socioeconomic inequalities in mortality and importance of perceived control: cohort study. BMJ, 319(7223), 1469-1470.

Bosma, H., Stansfeld, S. A., \& Marmot, M. G. (1998). Job control, personal characteristics, and heart disease. J Occup Health Psychol, 3(4), 402-409.

Buss, A. H., \& Perry, M. (1992). The aggression questionnaire. J Pers Soc Psychol, 63(3), 452-459.

Carroll, D., Davey Smith, G., Sheffield, D., Shipley, M. J., \& Marmot, M. G. (1997). The relationship between socioeconomic status, hostility, and blood pressure reactions to mental stress in men: data from the Whitehall II study. Health Psychol, 16(2), 131-136.

Chaput, L. A., Adams, S. H., Simon, J. A., Blumenthal, R. S., Vittinghoff, E., Lin, F., et al. (2002). Hostility predicts recurrent events among postmenopausal women with coronary heart disease. Am J Epidemiol, 156(12), 1092-1099.

Coons, S. J., Rao, S., Keininger, D. L., \& Hays, R. D. (2000). A comparative review of generic quality-of-life instruments. Pharmacoeconomics, 17(1), 13-35.

Costa, P. T. J., McCrae, R. R., \& Dye, D. A. (1992). Professional manual for the NEO PI-R and NEO-FFI. Odessa, Fl.: Psychological Assessment Resources.

Dalstra, J. A., Kunst, A. E., Borrell, C., Breeze, E., Cambois, E., Costa, G., et al. (2005). Socioeconomic differences in the prevalence of common chronic diseases: an overview of eight European countries. Int J Epidemiol, 34(2), 316-326.

De Vogli, R., Brunner, E., \& Marmot, M. G. (2007). Unfairness and the social gradient of metabolic syndrome in the Whitehall II Study. J Psychosom Res, 63(4), 413-419.

Droomers, M., Schrijvers, C. T., \& Mackenbach, J. P. (2001). Educational level and decreases in leisure time physical activity: predictors from the longitudinal GLOBE study. J Epidemiol Community Health, 55(8), 562-568.

Ebrahim, S., Barer, D., \& Nouri, F. (1986). Use of the Nottingham Health Profile with patients after a stroke. J Epidemiol Community Health, 40, 166-169.

Erdman, R. A., Passchier, J., Kooijman, M., \& Stronks, D. L. (1993). The Dutch version of the Nottingham Health Profile: investigations of psychometric aspects. Psychol Rep, 72(3 Pt 1), 1027-1035.

Everson, S. A., Kauhanen, J., Kaplan, G. A., Goldberg, D. E., Julkunen, J., Tuomilehto, J., et al. (1997). Hostility and increased risk of mortality and acute myocardial infarction: the mediating role of behavioral risk factors. Am J Epidemiol, 146(2), 142-152.

Everson, S. A., Maty, S. C., Lynch, J. W., \& Kaplan, G. A. (2002). Epidemiologic evidence for the relation between socioeconomic status and depression, obesity, and diabetes. J Psychosom Res, 53(4), 891895.

Felsten, G. (1996). Hostility, Stress and symptoms of depression. Pers Indiv Differ, 21(4), 461-467.

Felsten, G., \& Hill, V. (1999). Aggression Questionnaire hostility scale predicts anger in response to mistreatment. Behav Res Ther, 37(1), 87-97.

Ferrie, J. E., Martikainen, P., Shipley, M. J., \& Marmot, M. G. (2005). Self-reported economic difficulties and coronary events in men: evidence from the Whitehall II study. Int J Epidemiol, 34(3), 640-648. 
Frasure-Smith, N., \& Lespérance, F. (2005). Reflections on Depression as a Cardiac Risk Factor. Psychosom Med, 67(Supplement 1), S19-S25.

Gallo, L. C., \& Matthews, K. A. (2003). Understanding the association between socioeconomic status and physical health: do negative emotions play a role? Psychol Bull, 129(1), 10-51.

Hagenaars, A., Vos, K. d., \& Zaidi, M. A. (1994). Poverty Statistics in the late 1980s: Research based on Micro-data. Luxembourg: Office for Official Publications for the European Communities.

Haidt, J., \& Rodin, J. (1999). Control and efficacy as interdisciplinary bridges. Rev Gen Psychol, 3, 317337.

Harris, J. A. (1997). A further evaluation of the Aggression Questionnaire: issues of validity and reliability. Behav Res Ther, 35(11), 1047-1053.

Hemingway, H., \& Marmot, M. (1999). Evidence based cardiology: psychosocial factors in the aetiology and prognosis of coronary heart disease. Systematic review of prospective cohort studies. BMJ, 318(7196), 1460-1467.

Huisman, M., Kunst, A. E., Bopp, M., Borgan, J. K., Borrell, C., Costa, G., et al. (2005). Educational inequalities in cause-specific mortality in middle-aged and older men and women in eight western European populations. Lancet, 365(9458), 493-500.

Hunt, S. M., McEwen, J., \& McKenna, S. P. (1986). Measuring health status. London: Chroom Helm.

Kristenson, M., Eriksen, H. R., Sluiter, J. K., Starke, D., \& Ursin, H. (2004). Psychobiological mechanisms of socioeconomic differences in health. Soc Sci Med, 58(8), 1511-1522.

Kunst, A. E., Groenhof, F., Andersen, O., Borgan, J. K., Costa, G., Desplanques, G., et al. (1999). Occupational class and ischemic heart disease mortality in the United States and 11 European countries. Am J Public Health, 89(1), 47-53.

Kunst, A. E., Groenhof, F., Mackenbach, J. P., \& Health, E. W. (1998). Occupational class and cause specific mortality in middle aged men in 11 European countries: comparison of population based studies. EU Working Group on Socioeconomic Inequalities in Health. BMJ, 316(7145), 1636-1642.

Kuper, H., Marmot, M., \& Hemingway, H. (2002). Systematic review of prospective cohort studies of psychosocial factors in the etiology and prognosis of coronary heart disease. Semin Vasc Med, 2(3), 267-314.

Laitinen, J., Ek, E., \& Sovio, U. (2002). Stress-related eating and drinking behavior and body mass index and predictors of this behavior. Prev Med, 34(1), 29-39.

Lorant, V., Deliege, D., Eaton, W., Robert, A., Philippot, P., \& Ansseau, M. (2003). Socioeconomic inequalities in depression: a meta-analysis. Am J Epidemiol, 157(2), 98-112.

Loucks, E. B., Rehkopf, D. H., Thurston, R. C., \& Kawachi, I. (2007). Socioeconomic disparities in metabolic syndrome differ by gender: evidence from NHANES III. Ann Epidemiol, 17(1), 19-26.

Lynch, J. W., Kaplan, G. A., Cohen, R. D., Tuomilehto, J., \& Salonen, J. T. (1996). Do cardiovascular risk factors explain the relation between socioeconomic status, risk of all-cause mortality, cardiovascular mortality, and acute myocardial infarction? Am J Epidemiol, 144(10), 934-942.

Mackenbach, J. P., Bos, V., Andersen, O., Cardano, M., Costa, G., Harding, S., et al. (2003). Widening socioeconomic inequalities in mortality in six Western European countries. Int J Epidemiol, 32(5), 830-837.

Mackenbach, J. P., Kunst, A. E., Cavelaars, A. E., Groenhof, F., \& Geurts, J. J. (1997). Socioeconomic inequalities in morbidity and mortality in western Europe. The EU Working Group on Socioeconomic Inequalities in Health. Lancet, 349(9066), 1655-1659.

Mackenbach, J. P., Looman, C. W., \& van der Meer, J. B. (1996). Differences in the misreporting of chronic conditions, by level of education: the effect on inequalities in prevalence rates. Am J Public Health, 86(5), 706-711.

Mackenbach, J. P., van de Mheen, H., \& Stronks, K. (1994). A prospective cohort study investigating the explanation of socio-economic inequalities in health in The Netherlands. Soc Sci Med, 38(2), 299308.

MacKinnon, D. P., Lockwood, C. M., Hoffman, J. M., West, S. G., \& Sheets, V. (2002). A comparison of methods to test mediation and other intervening variable effects. Psychol Methods, 7(1), 83-104. 
Marmot, M. G., Davey Smith, G., Stansfeld, S., Patel, C., North, F., Head, J., et al. (1991). Health inequalities among British civil servants: the Whitehall II study. The Lancet, 337, 1387-1393.

Marmot, M. G., \& McDowall, M. E. (1986). Mortality decline and widening social inequalities. Lancet, 2(8501), 274-276.

Meesters, C., Muris, P., Bosma, H., Schouten, E., \& Beuving, S. (1996). Psychometric evaluation of the Dutch version of the Aggression Questionnaire. Behav Res Ther, 34(10), 839-843.

Miller, G. E., Freedland, K. E., Carney, R. M., Stetler, C. A., \& Banks, W. A. (2003). Cynical hostility, depressive symptoms, and the expression of inflammatory risk markers for coronary heart disease. $J$ Behav Med, 26(6), 501-515.

Morrison, C., Woodward, M., Leslie, W., \& Tunstall-Pedoe, H. (1997). Effect of socioeconomic group on incidence of, management of, and survival after myocardial infarction and coronary death: analysis of community coronary event register. BMJ, 314(7080), 541-546.

Murray, C. J., \& Lopez, A. D. (1997). Mortality by cause for eight regions of the world: Global Burden of Disease Study. Lancet, 349(9061), 1269-1276.

Nieto-Garcia, F. J., Bush, T. L., \& Keyl, P. M. (1990). Body mass definitions of obesity: sensitivity and specificity using self-reported weight and height. Epidemiology, 1(2), 146-152.

Okura, Y., Urban, L. H., Mahoney, D. W., Jacobsen, S. J., \& Rodeheffer, R. J. (2004). Agreement between self-report questionnaires and medical record data was substantial for diabetes, hypertension, myocardial infarction and stroke but not for heart failure. J Clin Epidemiol, 57(10), 1096-1103.

Penninx, B. W., Beekman, A. T., Honig, A., Deeg, D. J., Schoevers, R. A., van Eijk, J. T., et al. (2001). Depression and cardiac mortality: results from a community-based longitudinal study. Arch Gen Psychiatry, 58(3), 221-227.

Penninx, B. W., Guralnik, J. M., Mendes de Leon, C. F., Pahor, M., Visser, M., Corti, M. C., et al. (1998). Cardiovascular events and mortality in newly and chronically depressed persons $>70$ years of age. Am J Cardiol, 81(8), 988-994.

Radloff, L. S. (1977). The CES-D scale: a self-report depresion scale for research in the general population. Appl Psychol Meas, 1, 385-401.

Ranchor, A. V., Sanderman, R., Bouma, J., Buunk, B. P., \& van den Heuvel, W. J. (1997). An exploration of the relation between hostility and disease. J Behav Med, 20(3), 223-240.

Ravaja, N., Kauppinen, T., \& Keltikangas-Jarvinen, L. (2000). Relationships between hostility and physiological coronary heart disease risk factors in young adults: the moderating influence of depressive tendencies. Psychol Med, 30(2), 381-393.

Raynor, D. A., Pogue-Geile, M. F., Kamarck, T. W., McCaffery, J. M., \& Manuck, S. B. (2002). Covariation of psychosocial characteristics associated with cardiovascular disease: genetic and environmental influences. Psychosom Med, 64(2), 191-203; discussion 204-195.

Ross, C. E., \& Mirowsky, J. (1989). Explaining the social patterns of depression: control and problem solving--or support and talking? J Health Soc Behav, 30(2), 206-219.

Rozanski, A., Blumenthal, J. A., \& Kaplan, J. (1999). Impact of Psychological Factors on the Pathogenesis of Cardiovascular Disease and Implications for Therapy. Circulation, 99, 2192-2217.

Scherwitz, L., Perkins, L., Chesney, M., \& Hughes, G. (1991). Cook-Medley Hostility scale and subsets: relationship to demographic and psychosocial characteristics in young adults in the CARDIA study. Psychosom Med, 53(1), 36-49.

Schrijvers, C. T., Bosma, H., \& Mackenbach, J. P. (2002). Hostility and the educational gradient in health. The mediating role of health-related behaviours. Eur J Public Health, 12(2), 110-116.

Spitzer, R. L., Kroenke, K., \& Williams, J. B. (1999). Validation and utility of a self-report version of PRIMEMD: the PHQ primary care study. Primary Care Evaluation of Mental Disorders. Patient Health Questionnaire. Jama, 282(18), 1737-1744.

Stansfeld, S. A., Head, J., Fuhrer, R., Wardle, J., \& Cattell, V. (2003). Social inequalities in depressive symptoms and physical functioning in the Whitehall II study: exploring a common cause explanation. J Epidemiol Community Health, 57(5), 361-367. 
Strike, P. C., \& Steptoe, A. (2004). Psychosocial factors in the development of coronary artery disease. Prog Cardiovasc Dis, 46(4), 337-347.

Suarez, E. C. (2003). Joint effect of hostility and severity of depressive symptoms on plasma interleukin-6 concentration. Psychosom Med, 65(4), 523-527.

Suarez, E. C., Kuhn, C. M., Schanberg, S. M., Williams, R. B., Jr., \& Zimmermann, E. A. (1998). Neuroendocrine, cardiovascular, and emotional responses of hostile men: the role of interpersonal challenge. Psychosom Med, 60(1), 78-88.

Syme, S. L. (1989). Control and health: A personal perspective. In A. Steptoe \& A. Appels (Eds.), Stress, personal control and health (pp. 3-18). London: Wiley.

Thurston, R. C., \& Kubzansky, L. D. (2007). Multiple sources of psychosocial disadvantage and risk of coronary heart disease. Psychosom Med, 69(8), 748-755.

Thurston, R. C., Kubzansky, L. D., Kawachi, I., \& Berkman, L. F. (2006). Do depression and anxiety mediate the link between educational attainment and CHD? Psychosom Med, 68(1), 25-32.

Van Lenthe, F. J., Gevers, E., Joung, I. M., Bosma, H., \& Mackenbach, J. P. (2002). Material and behavioral factors in the explanation of educational differences in incidence of acute myocardial infarction: the Globe study. Ann Epidemiol, 12(8), 535-542.

WHO. (2003). Noncommunicable Diseases, Mental Health and Injuries. Noncommunicable conditions and their risk factors, deaths, burden, country levels and trends. Noncommunicable Diseases and Mental Health. Retrieved August 22, 2007

Wulsin, L. R., \& Singal, B. M. (2003). Do depressive symptoms increase the risk for the onset of coronary disease? A systematic quantitative review. Psychosom Med, 65(2), 201-210. 



\section{CHAPTER 3}

Measuring rebelliousness and predicting health behaviour and outcomes:

An investigation of the construct validity of the Social Reactivity Scale

G. Klabbers, H. Bosma, M. van den Akker, M.P.J. van Boxtel, G.I.J.M. Kempen, M.R. McDermott, J.Th.M. van Eijk

Journal of Health Psychology, 2009, 14(6), 771-779. 


\section{Abstract}

The Social Reactivity Scale is a questionnaire measure of individual differences in rebelliousness. The associations between rebelliousness, health behaviours and health outcomes were examined in two Dutch samples by means of cross-sectional survey data. We found moderate support for the reliability and construct validity of the scale. Findings were suggestive of rebelliousness, firstly, being associated with low control beliefs, secondly, being related to hostility, and, thirdly, also heightening the risk of engaging in unhealthy behaviours and that of poor health (perhaps through deliberately rejecting health education messages). Findings thus contribute to the ongoing emergence of an empirically viable theoretical construct. 


\section{Introduction}

The Social Reactivity Scale (SRS) has been developed to measure rebelliousness (McDermott \& Apter, 1987b). Being rebellious has been defined by Apter (Apter, 1982) as 'wanting or feeling compelled to do something contrary to that required by some external agency' (p. 198). Two forms of rebelliousness have been distinguished by McDermott \& Apter (McDermott \& Apter, 1987b): proactive rebelliousness (PR), in which the feeling is one of wanting to oppose a perceived requirement in order to obtain fun and excitement, and reactive rebelliousness (RR), in which the feeling is one of wanting to oppose a perceived requirement that is judged to be unfair, unreasonable or unjust. External requirements, such as rules and authorities, may be perceived as threats to personal freedom and perceived control, and rebelliousness can be a way of regaining that control (Bosma, 2006; Brehm \& Brehm, 1981; Lee \& Chen, 2004).

Rebelliousness has been found to be related to health behaviours and mental health. Rebelliousness plays a role in maintaining maladaptive health behaviours and refraining from adopting new health-promoting ones (McDermott, 2001). For example, a variety of adverse health behaviours has been found to be more common among rebellious compared with non-rebellious individuals, including: use of alcohol (Poikolainen, 1997; Turner \& Heskin, 1998); cocaine use (Hamil-Luker, Land, \& Blau, 2004); smoking marijuana (Sartori, 2003); and smoking tobacco (Choi, Harris, Okuyemi, \& Ahluwalia, 2003; Spijkerman, van den Eijnden, Vitale, \& Engels, 2004; Tyc et al., 2004). Furthermore, being in a rebellious state of mind lowers the threshold for tobacco smoking relapse (O'Connell, Schwartz, Gerkovich, Bott, \& Shiffman, 2004; O'Connell, Cook, Gerkovich, Potocky, \& Swan, 1990). Mental health difficulties are also more common in rebellious individuals. Albers \& Biener (Albers \& Biener, 2002) showed that rebellious adolescents were twice as likely to develop depressive symptoms compared to less rebellious adolescents, while reactive rebelliousness was specifically related to psychoticism (North, Desborough, \& Skarstein, 2005), and proactive rebelliousness to defiance (Carpentier, Knobloch, \& Zillman, 2003). Plausibly, rebelliousness exerts an effect on physical health as well (directly or through adverse health behaviours). This latter relationship, however, has barely been studied as yet.

The concept of rebelliousness has almost exclusively been studied in adolescents or students. The question whether rebelliousness (supposedly a pervasive individual attribute) in the long term might facilitate health damage and deterioration, increases the necessity of studying rebelliousness in an older population as well. The aim of the present validation study is to establish the relationship between rebelliousness and a range of health behaviours and outcomes in two Dutch population-based samples comprising the elderly. We hypothesise that men tend to be more rebellious than women, that rebelliousness is more prevalent in indi- 
viduals in the lowest socioeconomic groups, that rebelliousness is associated positively with hostility, and that higher rebelliousness is related to adverse health behaviours and poor health. In order to determine construct validity, first we need to validate the two-factor structure supporting the presence of the sub-domains of proactive and reactive rebelliousness, and the internal consistency of the scale (McDermott \& Apter, 1987a; Robinson, Weaver, \& Zillmann, 1996).

\section{Method}

\section{Study design}

Cross-sectional data on rebelliousness, hostility, control beliefs, socioeconomic status, health outcomes, and health behaviours were gathered by means of selfreported questionnaires in 2004-2006 in two independent samples, varying in age, recruitment and recruitment area.

\section{Participants}

The SMILE (Study of Medical Information and Lifestyles in Eindhoven) sample consisted of 5,001 older Dutch respondents, 46\% men and 54\% women of mean age 69 years (SD 8.70, range 55-95 years), recruited from a registration network of seven primary health care centres in the East of The Netherlands (Van den Akker et al., 2008). The data were derived from the 2004 and 2005 measurements. The MAAS sample comprised 513 respondents, $49 \%$ men and $51 \%$ women of mean age 60 years, (SD 14.0, range 36-92 years) of the Maastricht Aging Study (MAAS) (Jolles, Houx, Boxtel, \& Ponds, 1995), a study of determinants of cognitive aging. Respondents were recruited through a registration network of family practices in the South of the Netherlands. Between September 2005 and March 2006, the respondents completed the questionnaires. We excluded the respondents with missing data on the Social Reactivity Scale. The final samples comprised 4,485 respondents in SMILE and 492 respondents in MAAS.

\section{The Social Reactivity Scale}

The Social Reactivity Scale (SRS) is an 18-item self-report questionnaire, with a total score reflecting the degree of rebelliousness and two subscale scores reflecting the degree of proactive $(P R)$ and reactive $(R R)$ rebelliousness (McDermott \& Apter, 1987b). Both subscales consist of seven items; four items are 'filler' items included to mitigate against socially desirable responses; these are not included in the subscale scores. Each item was rated on a 3-point Likert scale with responses scored as: 0 (not rebellious), 1 (not sure), and, 2 (rebellious). An example item of proactive 
rebelliousness is: 'Do you find it exciting to do something 'shocking'?', with response options (2) yes, often, (0) no, hardly ever, (1) not sure. An example of a reactive rebelliousness item is: 'If people are unkind to you, do you feel you should be (2) unkind back, (0) understanding, (1) not sure?'. Total scale score ranges from 0 to 28 , and subscale scores from 0 to 14 , with higher scores reflecting more rebelliousness. The questionnaire was translated into Dutch by author HB and translated back into English by an independent translator. This demonstrated that the translated items closely resembled the meaning of the original English items. The current Dutch version was approved of by the original designer of the scale, author MM.

\section{Construct validity measures}

Socioeconomic status, control beliefs, hostility, health behaviours, and health were measured in order to examine construct validity. Socioeconomic status was indicated by the highest education completed, with seven categories ranging from elementary school (1) to academic degree (7). Control beliefs were measured with the 7-item Pearlin \& Schooler's Mastery Scale (Kempen et al., 1999; Pearlin \& Schooler, 1978) in SMILE and with Rotter's 11-item locus of control scale (Andriessen, 1972; Rotter, 1966) in MAAS. Hostility was only measured in SMILE, by means of the hostility subscale of the Aggression Questionnaire (Buss \& Perry, 1992; Meesters, Muris, Bosma, Schouten, \& Beuving, 1996). Self-reported smoking, alcohol consumption, and exercise reflected health behaviours. Smoking was classified into five categories (never smoked, quit smoking, and currently smoking <10 cigarettes, 10-20 cigarettes, or $>20$ cigarettes a day). Alcohol consumption was measured by the mean number of alcoholic beverages consumed per week. Exercise was measured by hours per week engaged in sports. Health was measured by two summary scales of the SF-36: mental and physical functioning (Aaronson et al., 1992; Ware, Kosinski, \& Keller, 1994).

\section{Analyses}

Firstly, confirmatory factor analyses (CFA) were performed, comparing two models: a one-factor model with rebelliousness as the underlying domain, and a two-factor model with proactive and reactive rebelliousness as underlying sub-domains. Given the categorical/ordinal nature of the rebelliousness items, weighted least squares (WLS) method, based on polychoric correlations for large samples, was used (Jöreskog, 1990; Jöreskog \& Sörbom, 1985) in SMILE. In the smaller MAAS sample, the robust maximum likelihood method was used, which is specifically developed for small-sized samples in non-asymptotic and non-normal applications (Satorra \& Bentler, 2001). With CFA, a detailed model is specified in advance. Here, we speci- 
fied both a one-factor model with all 14 items loading on one factor and a twofactor model. In the latter, the items indicating proactive and reactive rebelliousness were fixed to load on two different factors and all other relationships were fixed to zero, which renders loading simultaneously on two factors impossible. The chi-square difference test statistic (for MAAS: the scaled difference test statistic) was computed to indicate whether or not the two-factor model had a significantly better fit. The model fit was assessed by the non-normed fit index (NNFI) and the root mean square error of approximation (RMSEA). The NNFI measures how much better the model fits than the so-called 'null' model, a baseline model which assumes all variables are uncorrelated. The RMSEA can be used as a measure of discrepancy per degree of freedom for the model. Good model fit is indicated by NNFI $>0.90$ and RMSEA < 0.05 (Bentler \& Bonett, 1980; Browne \& Cudeck, 1993; Curran, Bollen, Chen, Paxton, \& Kirby, 2003). Factor loadings $>0.3$ are generally considered acceptable (Stewart, Barnes, Cudeck, Cote, \& Malthouse, 2001).

Subsequently, internal consistency was analysed by calculating Cronbach's $\alpha$ 's for both subscales. The differences in factor-specific sample means and between men and women were tested by means of t-tests. Construct validity was assessed by calculating Pearson's correlations of proactive rebelliousness and reactive rebelliousness with age, education, control beliefs, hostility, health behaviours, and health. Construct validity was considered acceptable when the correlations were in the expected direction and consistent across the samples. Factor analyses were done with LISREL 8.71, all other analyses with SPSS 15.0.

\section{Results}

\section{Factor analysis}

The confirmatory factor analyses indicated that the difference chi-square test statistics comparing the one and two-factor model were highly significant $\left(\chi^{2}\right.$ SMILE $=$ 396.04, df 1 , and $\chi^{2}$ MAAS $=34.49$, df 1 ), confirming the underlying two subdomains of the scale: proactive and reactive rebelliousness. Model fit for the twofactor model was appropriate. RMSEA was 0.03 in both SMILE and MAAS; the NNFI was 0.99 in the MAAS sample and 0.84 in the SMILE sample, which was slightly lower than the acceptable cut-off. The explained variance of the two-factor model was higher (31.8\% in SMILE and 31.3\% in MAAS) than the explained variance of the one-factor model ( $22.3 \%$ and $21.9 \%$ respectively).

The standardised factor loadings showed a substantive correlation between the variables and the factor (Table 1 ). The factor loadings were fairly consistent across the samples, with highest loadings for items 2, 6, 7 and 14, and lowest loadings for items 1 and 18. Item 1 also proved the most difficult to answer: most miss- 
ing values were found for this item (236 in SMILE and 32 in MAAS). Correlations between the two factors were 0.42 in SMILE and 0.41 in MAAS.

Table 1 Confirmative factor analysis: factor loadings of the two-factor solution

\begin{tabular}{lcc}
\hline Factor item & Factor loading \\
\hline & SMILE & MAAS \\
& $\mathrm{N}=4,485$ & $\mathrm{~N}=492$ \\
\hline
\end{tabular}

Reactive rebelliousness

2 You have been treated badly by someone. Do you $\quad \ldots \quad 0.69 \quad 0.70$

$\begin{array}{llll}5 & \text { If people are unkind to you, do you feel you should be . . } & 0.64 & 0.48\end{array}$

10 A parking attendant tells you that you cannot park where you $\quad 0.43 \quad 0.47$ have just put the car. Would you ...

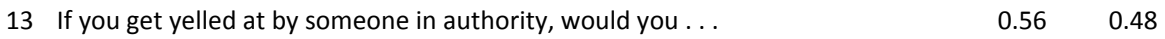

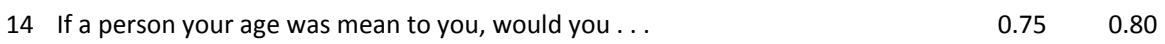

16 A charity will not accept you as a volunteer. Is your first reaction to . . $\quad 0.48 \quad 0.44$

18 If you ask a person at a party to dance with you who says 'no' without offering $\quad \begin{array}{lll}0.31 & 0.30\end{array}$ any explanation, would you...

Proactive rebelliousness

1 When you are told that you are breaking a rule (for example ' No smoking') is $\quad \begin{array}{lll}0.41 & 0.47\end{array}$ your first reaction to ...

4 "I enjoy the thrill I get from being difficult and awkward." Do you . . $\quad 0.46 \quad 0.51$

6 Do you find it exciting to do something 'shocking' ? $\quad 0.64 \quad 0.70$

7 If you are asked particularly NOT to do something, do you feel an urge to do it? $\quad 0.68 \quad 0.61$

9 Do you tease people unnecessarily just so as to have some fun at their expense? $\quad \begin{array}{lll}0.49 & 0.47\end{array}$

11 How often do you do something you shouldn't just to get some excitement? $\quad 0.65 \quad 0.68$

17 How often do others say that you are a difficult person? $\quad 0.510 .52$

$\begin{array}{lll}\text { Correlations between the two factors } & 0.42 & 0.41\end{array}$

\section{Internal consistency}

Cronbach's $\alpha$ 's for the subscales were modest (Table 2), ranging from 0.50 to 0.60 . Item-total correlations were fairly consistent across the samples. The increase in Cronbach's $\alpha$, when deleting any item, was negligible. 
Table 2 Internal consistency of the proactive and reactive rebelliousness subscales in two samples

\begin{tabular}{|c|c|c|c|c|}
\hline & Cronbach's $\alpha$ & $\begin{array}{l}\text { Min. item-total } \\
\text { correlation }\end{array}$ & $\begin{array}{l}\text { Max. item-total } \\
\text { correlation }\end{array}$ & $\begin{array}{l}\text { Increase } \alpha \text { if } \\
\text { any item deleted }\end{array}$ \\
\hline \multicolumn{5}{|l|}{ MAAS } \\
\hline $\mathrm{RR}^{\mathrm{a}}$ & 0.60 & Item $10(0.15)$ & Item $14(0.46)$ & 0.00 \\
\hline$P R^{a}$ & 0.50 & Item 9 (0.16) & Item $7(0.30)$ & 0.00 \\
\hline \multicolumn{5}{|l|}{ SMILE } \\
\hline $\mathrm{RR}^{\mathrm{a}}$ & 0.60 & Item $10(0.20)$ & Item $14(0.48)$ & 0.01 (items 10 and 18) \\
\hline$P R^{a}$ & 0.50 & Item $9(0.13)$ & Item $6(0.36)$ & 0.00 \\
\hline
\end{tabular}

${ }^{a}$ SRS = Social Reactivity Scale, theoretical range 0-28; PR = Proactive Rebelliousness, theoretical range 0-14; RR = Reactive Rebelliousness, theoretical range 0-14

\section{Sample comparison}

The mean scores on the subscales differed significantly across the two populations (Table 3). Men scored significantly higher than women on both subscales. The proactive rebelliousness scores were lower than the reactive rebelliousness scores. All means were low, when compared to the maximum scale scores, indicating that the respondents in general were not highly rebellious.

Table 3 Means (standard deviations) and between-sample mean comparison of reactive and proactive rebelliousness

\begin{tabular}{lllllll}
\hline Sample & & $\mathrm{N}^{\mathrm{d}}$ & $\mathrm{RR}^{\mathrm{a}}$ mean (SD) & $\begin{array}{l}\text { Gender mean } \\
\text { difference }\end{array}$ & $\mathrm{PR}^{\mathrm{a}}$ mean (SD) & $\begin{array}{l}\text { Gender mean } \\
\text { difference }\end{array}$ \\
\hline SMILE & total & 4485 & $3.89(2.92)$ & & $1.15(1.64)$ & \\
& men & 2132 & $4.24(3.05)$ & $p<.01$ & $1.30(1.78)$ & $p<.01$ \\
& women & 2353 & $3.58(2.77)$ & & $1.01(1.51)$ & \\
MAAS & total & 485 & $4.29(2.79)$ & & $0.91(1.52)$ & \\
& men & 242 & $4.57(3.02)$ & $p<.01$ & $1.13(1.67)$ & $p<.01$ \\
& women & 243 & $4.03(2.93)$ & & $0.65(1.27)$ & \\
$\begin{array}{l}\text { Sample mean } \\
\text { difference }\end{array}$ & & $p<.01$ & & $p<.01$ & \\
\hline
\end{tabular}

${ }^{\mathrm{a}} \mathrm{RR}=$ Reactive Rebelliousness, theoretical range 0-14, PR = Proactive Rebelliousness, theoretical range $0-14 ;{ }^{b}$ t-test statistic of mean differences between men and women; ${ }^{c}$ t-test statistic of sample mean differences between MAAS and SMILE; ${ }^{d}$ missings are listwise deleted 


\section{Construct validity}

Rebellious individuals (RR) were younger, they reported (both RR and PR) the lowest control and the highest hostility, they (both RR and PR) smoked and (RR) drank more, and they reported lower physical (PR) and mental functioning (both PR and RR) (Table 4). Unexpectedly, the reactive rebellious reported higher education and exercise was not related to rebelliousness at all. All correlations were relatively small.

Table 4 Pearson's correlations between reactive rebelliousness (RR), proactive rebelliousness (PR), and demographics, socioeconomic status, control, hostility, health behaviours, and health.

\begin{tabular}{|c|c|c|c|c|}
\hline & \multicolumn{2}{|c|}{ SMILE } & \multicolumn{2}{|c|}{ MAAS } \\
\hline & $\begin{array}{c}\text { Reactive } \\
\text { Rebelliousness }\end{array}$ & $\begin{array}{c}\text { Proactive } \\
\text { Rebelliousness }\end{array}$ & $\begin{array}{c}\text { Reactive } \\
\text { Rebelliousness }\end{array}$ & $\begin{array}{c}\text { Proactive } \\
\text { Rebelliousness }\end{array}$ \\
\hline \multicolumn{5}{|l|}{ Demographics } \\
\hline Age & $-0.12 * *$ & -0.01 & $-0.17 * *$ & -0.01 \\
\hline \multicolumn{5}{|l|}{ Socioeconomic status } \\
\hline Education & $0.13^{* *}$ & -0.01 & $0.17^{*}$ & 0.04 \\
\hline \multicolumn{5}{|l|}{ Psychological factors } \\
\hline Control & $-0.04 * *$ & $-0.11 * *$ & 0.01 & -0.11 \\
\hline Hostility & $0.09 * *$ & $0.16^{* *}$ & - & - \\
\hline \multicolumn{5}{|l|}{ Health Behaviours } \\
\hline Smoking & $0.07 * *$ & $0.19 * *$ & 0.03 & $0.16^{* *}$ \\
\hline Alcohol consumption & $0.12^{* *}$ & 0.03 & 0.00 & -0.03 \\
\hline Exercise & 0.04 & 0.01 & -0.02 & 0.10 \\
\hline \multicolumn{5}{|l|}{ Health } \\
\hline Physical functioning & 0.02 & $-0.08 * *$ & 0.09 & -0.02 \\
\hline Mental functioning & $-0.04 * *$ & $-0.15^{* *}$ & $-0.15^{*}$ & -0.09 \\
\hline
\end{tabular}

SMILE: $\mathrm{N} \leq 4,485$ MAAS: $\mathrm{N} \leq 492$, missing cases are pairwise deleted; ${ }^{*} p<.05 ;{ }^{*} \mathrm{p}<.01$

\section{Discussion}

Rebelliousness, as measured by the Social Reactivity Scale, was associated with demographic variables, health behaviours and health status in two elderly Dutch populations. Rebellious individuals were predominantly male and they were younger compared with less rebellious individuals. Rebellious individuals experienced lower control and reported more hostility; they tended to engage in adverse 
health behaviours and reported poorer physical and mental functioning, though correlations were relatively small. The previously found two-factor structure was confirmed, though internal consistency for subscales was modest. Hence, in our Dutch populations, there is moderate support for the reliability and validity of the Social Reactivity Scale and its two subscales.

We found in general that our older population was less rebellious (0.91 and 1.15 for proactive and 4.29 and 3.89 for reactive rebelliousness in MAAS and SMILE, respectively) than adolescents in previous studies, with reported means of 3.52 and 3.46 for proactive, and 4.10 and 5.22 for reactive rebelliousness in British and North American adolescents, respectively (McDermott \& Apter, 1987a). Plausibly, these mean differences between samples are related to age differences; our results support that the younger participants had higher rebelliousness scores than older participants. At the same time, we are unable to fully exclude an influence of socially desirable responding underlying the low rebelliousness scores, particularly in older persons. The low scores arguably are indicative of a homogeneous nonrebellious population. The consequence of such homogeneity might be that true variance is small, relative to error variance, leading to a lower $\alpha$ (Streiner, 2003). This age effect, thus, might be responsible also for the lower internal consistencies when compared to those found in studies among adolescents (Carpentier, et al., 2003; McDermott \& Apter, 1987a; Robinson, et al., 1996).

We found sufficient evidence that rebelliousness was associated with health behaviours (smoking and alcohol consumption). Similar to the findings in adolescents (Choi, et al., 2003; McDermott \& Apter, 1987a; Poikolainen, 1997; Spijkerman, et al., 2004; Turner \& Heskin, 1998; Tyc, et al., 2004), elderly rebellious individuals also tend to engage more in adverse health behaviours than their less rebellious counterparts. However, the results for exercise did not support our hypothesis that the rebellious would engage in sports less frequently. A possible explanation might be that rebellious states are patterned across different types of sport. For example, participants in risk and contact sports tend to be more rebellious than participants in safer sports (Vlaswinkel \& Kerr, 1990). Rebellious individuals further reported lower control and higher hostility and poorer physical and mental health. Thus, rebelliousness might, also in older persons, indeed be a mechanism to exert counter-influence and regain control (Brehm \& Brehm, 1981; Lee \& Chen, 2004). Engaging in adverse health behaviours might even reflect reactance to health education (Fogarty, 1997), given that it has been found that those high on reactance show resistance to persuasion (Imajo, 2002; Rains \& Mitchell-Turner, 2007) which in turn might lead to poorer health (Dowd, Pepper, \& Seibel, 2001). Further, reactance is found to be associated with hostility (Weathers, 1995), the latter being an established risk factor for all-cause mortality (Miller, Smith, Turner, Guijarro, \& Hallet, 1996), and coronary heart disease in particular (Kuper, Marmot, \& Hemingway, 2002). These pathways warrant further attention in future studies. The mod- 
est internal consistencies might have somewhat attenuated the correlations found in the examination of the construct validity.

Given the above mentioned associations, one would have expected more rebelliousness in lower socioeconomic status groups. Generally, lower socioeconomic status groups report more adverse health behaviours, worse health, and lower control beliefs (Bosma, 2006). However, in contrast with previous studies (Tacon \& Abner, 1993), our findings do not support the expected association between lower education and higher rebelliousness, making a role for rebelliousness in explaining socioeconomic health differences unlikely.

Finally, the concept of rebelliousness is embedded in Reversal Theory (Apter, 1982), which states that behaviours may vary between opposite experiential modes, with one mode being 'dominant' (the one in which most time is spent). In the study reported here, the opposite modes have been conceived of as rebelliousness and the absence of rebelliousness (the latter in Reversal Theory being referred to as 'conformity'). The Social Reactivity Scale measures such mode dominance. Extreme conformity may have negative consequences for health and health behaviours as well, a hypothesis for which some evidence has been found regarding unwanted health outcomes (Ratcliffe, Dawson, \& Walker, 1995), and adverse health risk behaviours in adolescents (Ratcliffe, et al., 1995). However, we did not find such bipolarity, when we re-examined the construct validity of the scale using a categorical representation of the rebelliousness measures (not tabulated).

\section{Conclusion}

The general conclusion is that moderate support was found for the association between rebelliousness and health behaviours and health outcomes in an elderly population. A pattern of associations emerges that is suggestive of rebelliousness, firstly, being associated with low control beliefs, secondly, being related to hostility, and, thirdly, also heightening the risk of engaging in unhealthy behaviours and that of poor health (perhaps through rebellious persons more often deliberately rejecting health education messages). Findings thus contribute to the ongoing emergence of an empirically defensible theoretical construct and advocate the application of the scale in future (longitudinal) studies examining associations and possible pathways of causality between psychological, social, and health-related factors.

\section{Acknowledgements}

The authors thank Dr. Math Candel for his valuable comments on the statistical procedures involved with the LISREL analyses. 


\section{References}

Aaronson, N. K., Acquadro, C., Alonso, J., Apolone, G., Bucquet, D., Bullinger, M., et al. (1992). International Quality of Life Assessment (IQOLA) Project. Qual Life Res, 1(5), 349-351.

Albers, A. B., \& Biener, L. (2002). The role of smoking and rebelliousness in the development of depressive symptoms among a cohort of Massachusetts adolescents. Prev Med, 34(6), 625-631.

Andriessen, J. H. T. H. (1972). Interne of externe beheersing. Nederlands Tijdschrift voor Psychologie, 27, 173-178.

Apter, M. J. (1982). The experience of motivation: the theory of psychological reversals. London: Academic Press.

Bentler, P. M., \& Bonett, D. G. (1980). Significance Tests and Goodness of Fit in the Analysis of Covariance Structures. Psychol Bull, 88(3), 588-606.

Bosma, H. (2006). Socio-economic differences in health: are control beliefs fundamental mediators? In J. Siegrist \& M. Marmot (Eds.), Social Inequalities in Health. New evidence and policy implications (pp. 153-166). Oxford: Oxford University Press.

Brehm, S. S., \& Brehm, J. W. (1981). Psychological Reactance: A Theory of Freedom and Control. New York: Academic Press.

Browne, M. W., \& Cudeck, R. (1993). Alternative Ways of Assessing Model Fit. In K. A. Bollen \& J. Scott Long (Eds.), Testing structural equation models (pp. 136-162). Newbury park, California: Sage Publications.

Buss, A. H., \& Perry, M. (1992). The aggression questionnaire. J Pers Soc Psychol, 63(3), 452-459.

Carpentier, F. D., Knobloch, S., \& Zillman, D. (2003). Rock, rap and rebellion: Comparisons of traits predicting selective exposure to defiant music. Pers Indiv Differ, 35(7), 1643-1655.

Choi, W. S., Harris, K. J., Okuyemi, K., \& Ahluwalia, J. S. (2003). Predictors of smoking initiation among college-bound high school students. Ann Behav Med, 26(1), 69-74.

Curran, P. J., Bollen, K. A., Chen, F., Paxton, P., \& Kirby, J. B. (2003). Finite Sampling Properties of the Point Estimates and Confidence Intervals of the RMSEA. Sociol Method Res, 32, 208-252.

Dowd, E. T., Pepper, H. F., \& Seibel, C. (2001). Developmental correlates of psychological reactance. J Cogn Psychother, 15(3), 239-252.

Fogarty, J. S. (1997). Reactance theory and patient noncompliance. Soc Sci Med, 45(8), 1277-1288.

Hamil-Luker, J., Land, K. C., \& Blau, J. (2004). Diverse trajectories of cocaine use through early adulthood among rebellious and socially conforming youth. Soc Sci Res, 33, 300-321.

Imajo, S. (2002). Reactance proneness, collectivism, uniqueness, and resistance to persuasion. Shinrigaku Kenkyu, 73(4), 366-372.[English abstract]

Jolles, J., Houx, P. J., Boxtel, M. P. J. v., \& Ponds, R. W. H. M. (Eds.). (1995). The Maastricht Aging Study. Determinants of cognitive aging. Maastricht: Neuropsych Publishers.

Jöreskog, K. G. (1990). New developments in LISREL: analysis of ordinal variables using polychoric correlations and weighted least squares. Qual Quant, 24, 387-404.

Jöreskog, K. G., \& Sörbom, D. (1985). PRELIS: A Program for Multivariate Data Screening and Data Summarization: A Preprocessor for LISREL. Uppsala, Sweden: University of Uppsala.

Kempen, G. I. J. M., van Heuvelen, M. J. G., van Sonderen, E., van den Brink, R. H. S., Kooijman, A. C., \& Ormel, J. (1999). The relationship of functional limitations to disability and the moderating effects of psychological attributes in community-dwelling older persons. Soc Sci Med, 48, 1161-1172.

Kuper, H., Marmot, M., \& Hemingway, H. (2002). Systematic review of prospective cohort studies of psychosocial factors in the etiology and prognosis of coronary heart disease. Semin Vasc Med, 2(3), 267-314.

Lee, M. J., \& Chen, Y. Y. (2004). Relationship between rebellious tendency and psychological reactance: Implications in effective health campaign message designs. Association for Education in Journalism and Mass Communication. Retrieved from http://list.msu.edu/archives/aejmc.html, March 31, 2005. 
McDermott, M. R. (2001). Rebelliousness. In M. J. Apter (Ed.), Motivational styles in everyday life: $A$ guide to Reversal Theory (pp. 167-185). Washington, DC: American Psychological Association.

McDermott, M. R., \& Apter, M. J. (1987a). An introduction \& guide to the Negativism Dominance Scale. In M. R. McDermott (Ed.), Rebelliousness in adolescence and young adulthood. Cardiff: University of Wales.

McDermott, M. R., \& Apter, M. J. (1987b). The Social Reactivity Scale. In M. R. McDermott (Ed.), Rebelliousness in adolescence and young adulthood. Cardiff: University of Wales.

Meesters, C., Muris, P., Bosma, H., Schouten, E., \& Beuving, S. (1996). Psychometric evaluation of the Dutch version of the Aggression Questionnaire. Behav Res Ther, 34(10), 839-843.

Miller, T. Q., Smith, T. W., Turner, C. W., Guijarro, M. L., \& Hallet, A. J. (1996). A meta-analytic review of research on hostility and physical health. Psychol Bull, 119(2), 322-348.

North, A. C., Desborough, L., \& Skarstein, L. (2005). Musical preference, deviance and attitudes towards music. Pers Indiv Differ, 38(8), 1903-1914.

O'Connell, K., Schwartz, J., Gerkovich, M., Bott, M., \& Shiffman, S. (2004). Playful and rebellious states vs. negative affect in explaining the occurrence of temptations and lapses during smoking cessation. Nicotine Tob Res, 6(4), 661-674.

O'Connell, K. A., Cook, M. R., Gerkovich, M. M., Potocky, M., \& Swan, G. E. (1990). Reversal theory and smoking: a state-based approach to ex-smokers' highly tempting situations. J Consult Clin Psychol, 58(4), 489-494.

Pearlin, L. I., \& Schooler, C. (1978). The structure of coping. J Health Soc Behav, 19(1), 2-21.

Poikolainen, K. (1997). Risk factors for alcohol dependence: a questionnaire survey. Alcohol Clin Exp Res, 21(6), 957-961.

Rains, S. A., \& Mitchell-Turner, M. (2007). Psychological reactance and persuasive health communication: a test and extension of the intertwined model

Hum Commun Res, 33, 241-269.

Ratcliffe, M. A., Dawson, A. A., \& Walker, L. G. (1995). Eysenk personality inventory L-scores in patients with Hodgkin's disease and non-Hodgkin's lymphoma. Psycho-oncol, 4, 39-45.

Robinson, T. O., Weaver, J. B., \& Zillmann, D. (1996). Exploring the relation between personality and the appreciation of rock music. Psychol Rep, 78(1), 259-269.

Rotter, J. (1966). Generalized expectancies fot internal versus external control of reinforcement. Psychol Monogr, 80, 1-28.

Sartori, J. (2003). A reversal theory approach to predicting and explaining university students' attitudes and use of marijuana. Unpublished Doctoral dissertation, University of Windsor, Canada.

Satorra, A., \& Bentler, P. M. (2001). A scaled difference chi-square test statistic for moment structure analysis. Psychometrika, 66(4), 507-514.

Spijkerman, R., van den Eijnden, R. J., Vitale, S., \& Engels, R. C. (2004). Explaining adolescents' smoking and drinking behavior: the concept of smoker and drinker prototypes in relation to variables of the theory of planned behavior. Addict Behav, 29(8), 1615-1622.

Streiner, D. L. (2003). Starting at the beginning: an introduction to coefficient alpha and internal consistency. J Pers Assess, 80(1), 99-103.

Tacon, P., \& Abner, B. (1993). Normative and other data for the telic dominance and negativism dominance scales. In J. H. Kerr, S. Murgatroyd \& M. J. Apter (Eds.), Advances in Reversal Theory (pp. 165175). Amsterdam: Swets \& Zeitlinger.

Turner, S., \& Heskin, K. (1998). Metamotivational dominance and use of tobacco and alcohol among adolescents. Psychol Rep, 83(1), 307-315.

Tyc, V. L., Hadley, W., Allen, D., Varnell, S., Ey, S., Rai, S. N., et al. (2004). Predictors of smoking intentions and smoking status among nonsmoking and smoking adolescents. Addict Behav, 29(6), 1143-1147.

Van den Akker, M., Spigt, M. G., De Raeve, L., van Steenkiste, B., Metsemakers, J. F., van Voorst, E. J., et al. (2008). The SMILE study: A Study of Medical Information and Lifestyles in Eindhoven, the rationale and contents of a large prospective dynamic cohort study. BMC Public Health, 8(1), 19. 


\section{CHAPTER 3}

Vlaswinkel, E. H., \& Kerr, J. H. (1990). Negativism dominance in risk and team sports. Percep Motor Skill, 70, 289-290.

Ware, J. E., Kosinski, M., \& Keller, S. D. (1994). SF-36 Physical \& Mental Health Summary Scales: a user's manual. Boston, MA: New England Medical Center, the Health Institute.

Weathers, P. L. (1995). A test of psychological reactance theory in a correctional setting. Dissertation Abstracts International, 56(3-B), 1714. 


\section{CHAPTER 4}

\section{Cognitive hostility predicts all-cause mortality}

irrespective of behavioural risk at late middle and older age

G. Klabbers, H. Bosma, M. van den Akker, G.I.J.M. Kempen, J.Th.M. van Eijk

Accepted for publication in the European Journal of Public Health. 


\section{Abstract}

Background: Most but not all evidence supports hostility-related attributes to increase mortality risk. However, studies usually include single attributes, their effects have been studied predominantly in younger populations and behavioural pathways explaining the mortality effect seem to differ by age. We examined the relationship between all-cause mortality and cognitive hostility, anger, aggression, and rebelliousness and their independence of health behaviours in a late middle-aged and older population.

Methods: Data were derived from the longitudinal Dutch SMILE study among 2,679 late middle-aged and older Dutch people. Psychological characteristics were self-reported in 2004/2005 and mortality was monitored from 2005 to 2010. Cox regression analyses were used to calculate the mortality risk by each unique psychological variable with additional adjustments for the other psychological variables, and for health behaviours. Baseline adjustments included age, sex, educational level and prevalent morbidity.

Results: Cognitive hostility was associated with all-cause mortality, independent of health behaviours (on a scale ranging from 6 to 30, the hazard ratio was $1.05 ; 95 \% \mathrm{Cl}: 1.01-1.09$ ). Anger, aggression and rebelliousness were not associated with mortality risk.

Conclusion: In diminishing excess mortality risks, hostile cognitions might be acknowledged separately and additionally to the risk posed by unhealthy lifestyles. 


\section{Introduction}

The importance of psychological risk factors for mortality is supported by evidence demonstrating the adverse influence of specific psychological attributes such as (cognitive) hostility, anger and aggression (Barefoot, Larsen, von der Lieth, \& Schroll, 1995; Eaker, Sullivan, Kelly-Hayes, D’Agostino, \& Benjamin, 2004; Everson et al., 1997; Miller, Smith, Turner, Guijarro, \& Hallet, 1996; Nabi et al., 2008; Tindle et al., 2009; Wilson, Bienias, Mendes de Leon, Evans, \& Bennett, 2003), though such associations have not been confirmed in all studies (Kuper, Marmot, \& Hemingway, 2002). Possible biological mechanisms by which these attributes may increase health risk include, amongst others, sustained psychophysiological reactivity (Adler \& Ostrove, 1999; Kristenson, Eriksen, Sluiter, Starke, \& Ursin, 2004; Rozanski, Blumenthal, \& Kaplan, 1999), and adverse health behaviours such as smoking, heavy drinking and physical inactivity (Everson, et al., 1997; Miller, Markides, Chiriboga, \& Ray, 1995; Siegler et al., 2003).

Cognitive hostility, anger and aggression can be regarded as different components of a multifaceted hostility-construct. Cognitive hostility can be defined as 'negative beliefs about and attitudes towards others' (e.g. cynicism and mistrust) (Smith, 1994). Anger is the emotional component and is defined as 'an unpleasant emotion ranging in intensity from irritation or annoyance to fury or rage' (Smith, 1994). Aggression involves a variety of verbal and physical behaviours, defined as 'attacking, destructive or hurtful actions' (Smith, 1994). Although these constructs are interrelated and often co-occur, they each refer to a unique part of the broader hostility-construct (Martin, Watson, \& Wan, 2000).

A similar psychological attribute, rebelliousness, was recently found to be associated with cognitive hostility (Klabbers et al., 2009). Being a rebellious person means that one wants to oppose a perceived requirement 'in order to obtain fun and excitement' (proactive rebelliousness) or 'because the requirement is judged to be unfair or unreasonable' (reactive rebelliousness) (McDermott \& Apter, 1987a). More than cognitive hostility, rebelliousness might be related to mortality via opposing and obstructing health campaigns. Previous studies already showed that a state of rebelliousness indeed was associated with maintaining maladaptive health behaviours as well as with refraining from adopting new health-promoting ones (Klabbers, et al., 2009; McDermott, 2001). Certainly, this warrants a further examination of the effect of rebelliousness on mortality; of whether or not this effect is in concordance with the adverse effects of cognitive hostility, anger, and aggression; and of the extent to which behavioural pathways contribute to mortality effects of these hostility-related attributes.

Both the effects on mortality of hostility-related attributes and behavioural contributions may be age-related. Although it is suggested that hostility decreases with age (Siegler, et al., 2003), the three studies that have specifically focused on 
older populations still found increased mortality risks among the most hostile or angry persons when compared to the least hostile or angry (Barefoot, et al., 1995; Tindle, et al., 2009; Wilson, et al., 2003). This might be explained by a longer duration of exposure to these adverse attributes in older people combined with the aging body becoming less able to repair damage (Kuh, Ben-Shlomo, Lynch, Hallqvist, \& Power, 2003). In contrast with findings in a younger (aged 42-60) male population (Everson, et al., 1997) showing that cynical hostility effects on mortality were primarily mediated by behavioural risk factors, the effects of hostility-related attributes on mortality in these older populations hardly changed after controlling for these risk factors, suggesting that explaining mechanisms might vary with age. However, methodological characteristics of these studies prevent from making strong inferences. Neither of these three studies included all the elements of the multifaceted hostility-construct, and two out of three were in specific samples: postmenopausal women aged 50-79 years (Tindle, et al., 2009) and catholic clergy members, aged 50 and followed-up until 77 years (Wilson, et al., 2003).

Dutch longitudinal data were used to address firstly whether these attributes induce premature mortality and secondly whether health behaviours contribute to these associations in a late middle-aged and older population.

\section{Methods}

\section{Design and participants}

Longitudinal self-report and medical data came from a dynamic cohort study: SMILE (Study of Medical Information and Lifestyles in the city of Eindhoven, in the Southeast of the Netherlands) (Van den Akker et al., 2008). Starting in 2002, individuals who were enrolled in one of the nine participating primary health care centres were invited to participate. The national compulsory medical insurance scheme leads to nearly every Dutch individual being registered with a general practitioner, offering SMILE an unselected practice population. Informed consent included self-report questionnaires and linkage of questionnaire data to medical records including mortality registration. The present study used data of the participants aged 55 years and older that were collected between November 2005 (baseline measures) and the end of the follow-up period, in November 2010. Within this subsample of the total SMILE population, a more extensive and detailed data collection took place, in particular of the psychosocial characteristics. Of the 5,001 participants aged 55 and older that consented to completion of the self-report questionnaires (response rate $44.8 \%$ ), 3,314 participants (66\%) also consented to linkage to their medical data. We excluded individuals with missing data on demographics $(N=82)$ and on health behaviours $(N=553)$. The final sample eligible for 
analysis comprised 2,679 participants (24.0\% of the target population). During follow-up 242 people died.

\section{Measures}

Rebelliousness, demographics, prevalent health status and health behaviours were measured at baseline in 2005. Cognitive hostility, anger and aggression were measured in 2004; these we assumed stable until 2005. Mortality was registered continuously from baseline (1 November 2005) until 1 November 2010.

Cognitive hostility, anger and aggression

Cognitive hostility, anger and aggression were measured by the Aggression Questionnaire (Buss \& Perry, 1992; Meesters, Muris, Bosma, Schouten, \& Beuving, 1996). Cognitive hostility (6 items), anger ( 7 items), and verbal aggression (4 items) were rated on a 5-point Likert scale, ranging from 1 ('totally disagree') to 5 ('totally agree') and summed to obtain subscale scores with higher scores indicating more cognitive hostility, anger and aggression, respectively. Example items are: 'Other people always seem to get the breaks' (cognitive hostility), 'I sometimes feel like a powder keg ready to explode' (anger), 'I can't help getting into arguments when people disagree with me' (verbal aggression). The Aggression Questionnaire has proven valid and reliable (Buss \& Perry, 1992; Harris, 1997; Meesters, et al., 1996).

\section{Rebelliousness}

Rebelliousness was measured by means of the self-report Social Reactivity Scale (SRS) with two subscale scores reflecting the degree of proactive rebelliousness and reactive rebelliousness (McDermott \& Apter, 1987b). Both subscales consist of seven items, each item is rated on a 3-point Likert scale with responses scored as: 0 (not rebellious), 1 (not sure), and, 2 (rebellious), which were summed to obtain subscale scores with higher scores indicating more proactive and reactive rebelliousness. An example item of proactive rebelliousness is: 'Do you find it exciting to do something 'shocking'?', with response options (2) yes, often, (0) no, hardly ever, (1) not sure. An example of a reactive rebelliousness item is: 'If people are unkind to you, do you feel you should be (2) unkind back, (0) understanding, (1) not sure?'. The SRS has been found moderately valid and reliable (Klabbers, et al., 2009).

\section{Health behaviours}

Data were obtained on: 1) smoking (never, former and current); 2) alcohol consumption, which was defined as number of alcoholic beverages per week and 3) physical activity, indicated by the hours spend per week on (different kinds of) sports, based on the SQUASH questionnaire, which has been judged fairly reliable and valid (Wendel-Vos, Schuit, Saris, \& Kromhout, 2003). 


\section{Mortality}

Time to event (death) was the outcome measure, which was defined as the time from baseline ( 1 November 2005 ) to the date of death $(n=242)$ or complete followup (1 November 2010, $n=2,437$ ).

\section{Covariates}

Age, sex, educational level and prevalent somatic morbidity were included in all analyses. Highest education completed was classified into high education (preuniversity secondary education, higher vocational education and university education), intermediate education (apprenticeship system, general secondary education and intermediate vocational education), and low education (primary and lower secondary vocational education). Prevalent somatic morbidity, diagnosed before 1 November 2005, was retrieved from GP registered medical records, which contain ICPC (International Classification of Primary Care) diagnose codes. Morbidity was dichotomised into being diagnosed (1) or not (0) with at least one of the four agerelated noncommunicable diseases (cardiovascular diseases, cancers, chronic respiratory diseases, diabetes) that are current spearheads of WHO policy (Mendis, 2010; Probst-Hensch, 2010; WHO, 2008).

\section{Data analyses}

Missing values on the cognitive hostility, anger, aggression or rebelliousness subscales $(\mathrm{N}=506)$ were imputed by means of multiple imputation methods in SPSS 17.0 , in which the missing value is predicted by regression analyses of the complete cases (Sterne et al., 2009; Van Buuren, 2007). Age, sex, and educational level were entered as predictor variables of the missing values. We created 5 sets of imputed data (Rubin, 1987), and those estimations were combined into one set of pooled data. The analyses described below are based on the pooled dataset.

Bivariate correlations were performed to determine associations among psychological attributes and health behaviours. The prediction of mortality by cognitive hostility, anger, aggression, and proactive and reactive rebelliousness was studied by means of Cox proportional hazard models; adjusted for age, sex, educational level and prevalent somatic morbidity (model 1 ), additionally adjusted for the other four psychological attributes under study (model 2) and for the health behaviours (model 3). The analyses in model 3 were repeated with the significant psychological predictors categorised in tertiles for purpose of examining the group effect. The proportional hazard assumption was examined by calculating the interaction between each psychological variable and the logarithm of time, which should result in the interaction term being non-significant. We tested for multicollinearity of the psychological variables by means of calculating the variation inflations factors (VIFs). As a rule of thumb, these VIFs are not allowed to exceed 10 
(Myers, 1990). Curvilinearity was examined in all three models by additionally including the quadratic terms of the psychological attributes in the models. Interactions of the psychological attributes with each other, as well as interactions of the psychological attributes with the covariates in their association with mortality were also examined in models 2 and 3 . In order to check the robustness of the findings, the results based on the imputed data were compared with the results of the complete case analyses.

\section{Results}

Of the 5001 respondents that filled out the questionnaires, $34 \%$ did not consent to the use of their medical data, and not all data were complete. We examined the differences in socio-demographics and hostility-related attributes between the people who consented and those who did not consent to the linkage with medical data. The people who consented did not differ by age, sex, or educational level from the persons who did not consent. The people who consented had lower mean levels of hostility and proactive rebelliousness ( 11.7 versus 12.2 for hostility, $p=.02$ and 1.1 versus $1.3, p<.01$ for proactive rebelliousness respectively). Further, the respondents with missing data on the psychological variables $(\mathrm{N}=506)$ measured at baseline did not differ with regard to age, sex, educational level and mortality from the participants with complete data at baseline.

A total of 242 participants (9\%) died during the observation period, and 985 (37\%) were diagnosed with at least one somatic disease before baseline (Table 1 ). The mean scores on the psychological measures were relatively low when compared with the possible range of the scales. About one fifth of the population smoked, one tenth was abstinent from alcohol and 7\% drank excessively. About half of the participants did not engage in any kind of sports at all. Survivors were younger; they reported lower levels of cognitive hostility and anger; they were more likely to be male; less likely to smoke; more likely to engage in sports; and they were diagnosed less frequently with a somatic disease compared with the people who died during follow-up. 
Table 1 Demographic, personality and lifestyle characteristics $(n=2,679)$ for the total population and by survival status

\begin{tabular}{|c|c|c|c|c|}
\hline Characteristic & $\begin{array}{l}\text { Total } \\
\text { population }\end{array}$ & $\begin{array}{l}\text { Survivors } \\
\mathrm{N}=2437\end{array}$ & $\begin{array}{l}\text { Non survivors } \\
\mathrm{N}=242\end{array}$ & $p$-value* \\
\hline & Mean (SD) & Mean (SD) & Mean (SD) & \\
\hline Age (range $55-92$ years) & $68.7(8.3)$ & $68.1(8.0)$ & $75.4(8.4)$ & $<.01$ \\
\hline Cognitive hostility (theoretical range 6-30) & $11.7(4.7)$ & $11.4(4.7)$ & $12.9(5.1)$ & $<.01$ \\
\hline Anger (theoretical range $7-35$ ) & $14.7(5.2)$ & $14.5(5.2)$ & $15.3(5.6)$ & .04 \\
\hline Verbal aggression (theoretical range 4-20) & $8.4(2.6)$ & $8.3(2.6)$ & $8.7(2.9)$ & .07 \\
\hline Proactive rebelliousness (theoretical range 0-14) & $1.1(1.5)$ & $1.0(1.5)$ & $1.2(1.6)$ & .17 \\
\hline \multirow[t]{2}{*}{ Reactive rebelliousness (theoretical range 0-14) } & $3.9(2.9)$ & $3.9(2.9)$ & $4.0(3.2)$ & .69 \\
\hline & $\mathrm{n}(\%)$ & $\mathrm{n}(\%)$ & $\mathrm{n}(\%)$ & \\
\hline Men & $1268(47)$ & $1124(46)$ & $144(60)$ & $<.01$ \\
\hline Current smoking & $507(19)$ & 451 (19) & $56(23)$ & $<.01$ \\
\hline Abstinence & $280(11)$ & $245(10)$ & $35(15)$ & .10 \\
\hline $\begin{array}{l}\text { Excessive alcohol consumption (>21 glasses per } \\
\text { week) }{ }^{(\mathrm{WHO}, 2004)}\end{array}$ & $196(7)$ & $178(7)$ & $18(7)$ & \\
\hline Physical inactivity (no sports) & $1467(55)$ & $1297(53)$ & $170(70)$ & $<.01$ \\
\hline Prevalent morbidity & $985(37)$ & $819(34)$ & $166(69)$ & $<.01$ \\
\hline
\end{tabular}

* for the continuous variables the $p$-value is based on t-testing, for the categorical variables the $p$-value is based on chi-square testing

All psychological attributes correlated positively and significantly with each other, with the strongest correlations found between cognitive hostility and anger (Pearson's $r=.51$ ), and between anger and verbal aggression $(r=.49)$ (Table 2). Smoking correlated (based on Spearman's rho correlations) positively and significantly with all five psychological variables; the number of alcoholic beverages week was significantly associated with anger and reactive rebelliousness; and no psychological variable correlated significantly with sports. 
Table 2 Bivariate correlations among personality variables and health behaviours

\begin{tabular}{|c|c|c|c|c|c|c|}
\hline Anger $^{a}$ & $\begin{array}{l}\text { Verbal } \\
\text { aggression }^{\mathrm{a}}\end{array}$ & $\begin{array}{l}\text { Proactive } \\
\text { rebelliousness }^{\mathrm{a}}\end{array}$ & $\begin{array}{l}\text { Reactive } \\
\text { rebelliousness }^{\mathrm{a}}\end{array}$ & Smoking $^{\mathrm{b}}$ & $\begin{array}{l}\text { Alcohol } \\
\text { use }^{a}\end{array}$ & Sports $^{a}$ \\
\hline Cognitive hostility $.51^{* *}$ & $.42^{* *}$ & $.12^{* *}$ & $.09^{* *}$ & $.05^{*}$ & .01 & -.02 \\
\hline Anger & $.49^{* *}$ & $.17^{* *}$ & $.19^{* *}$ & $.08^{* *}$ & $.04^{* *}$ & .01 \\
\hline Verbal aggression & & $.16^{* *}$ & $.14^{* *}$ & $.05^{*}$ & .02 & .03 \\
\hline $\begin{array}{l}\text { Proactive } \\
\text { rebelliousness }\end{array}$ & & & $.20^{* *}$ & $.14^{* *}$ & .03 & -.01 \\
\hline $\begin{array}{l}\text { Reactive } \\
\text { rebelliousness }\end{array}$ & & & & $.07^{* *}$ & $.11^{* *}$ & .03 \\
\hline Smoking ${ }^{\mathrm{b}}$ & & & & & $.20^{* *}$ & $-.08^{* *}$ \\
\hline Alcohol use & & & & & & $.07^{* *}$ \\
\hline
\end{tabular}

${ }^{a}$ Pearson's r correlations; ${ }^{b}$ Spearman's rho correlations; ${ }^{*} \mathrm{p}<.05, * * \mathrm{p}<.01$

People who reported more cognitive hostility had an increased risk of all-cause mortality (Table 3 ). This effect remained even after additional adjustments for the other psychological variables (model 2 ) and for health behaviours (model 3 ). With each unit increase in cognitive hostility (1 point on a scale of 6-30) the mortality risk was raised by $5 \%(\mathrm{HR}=1.05, \mathrm{p}<.01$, model 3$)$. Neither anger, verbal aggression, nor rebelliousness predicted all-cause mortality. We examined the group effect of cognitive hostility by categorising this variable into tertiles; the highest scoring $33 \%$ of this sample had a $57 \%$ higher risk $(95 \% \mathrm{Cl} 1.06-2.32, \mathrm{p}=.03)$ of premature mortality when compared with the lowest scoring tertile (not tabulated). The models satisfied the proportional hazard function; all interaction terms were nonsignificant. The VIFs of the personality characteristics in these models did not exceed 2 , indicating there were no collinear effects (not tabulated).

Prevalent morbidity hardly affected the associations between the psychological characteristics and mortality; without adjustment for prevalent morbidity the hazard ratios for cognitive hostility, anger and rebelliousness were 0.01 higher, for verbal aggression it remained the same. Further, the results neither differed between men and women, nor across different age groups, nor across different educational levels nor for people with or without prevalent somatic disease, for there were no statistically significant interactions between the psychological variables and these covariates in predicting mortality (results not shown). Neither were there significant interactions between the psychological variables. None of the quadratic terms were statistically significant indicating the absence of curvilinear associations. Robustness of the findings based on the imputed data set was checked by comparing these findings to the results from the analyses including complete cases 
only $(N=2,173)$; the results were similar. In order to exclude reversed causation, we reran the analyses by excluding deaths in the first two years of follow-up. This left us with 150 deaths. The hazard ratio for cognitive hostility in the fully controlled model (Table 3, model 3) remained significant: HR 1.06, 95\% Cl 1.01-1.11, $p=.01$.

Table 3 Hazard ratios (95\% confidence intervals) of all-cause mortality by cognitive hostility, anger, aggression and rebelliousness, adjusted for age, sex, educational level and prevalent somatic disease (model 1), additionally adjusted for the other four personality variables (model 2 ) and for the health behaviours (model 3)

\begin{tabular}{|c|c|c|c|}
\hline & \multicolumn{3}{|l|}{ All-cause mortality } \\
\hline & $\begin{array}{l}\text { Model 1: } \\
\text { Age, sex, education, } \\
\text { prevalent morbidity }\end{array}$ & $\begin{array}{l}\text { Model 2: } \\
\text { Age, sex, education, } \\
\text { prevalent morbidity and } \\
\text { other personality } \\
\text { variables }\end{array}$ & $\begin{array}{l}\text { Model 3: } \\
\text { Age, sex, education, } \\
\text { prevalent morbidity, other } \\
\text { personality variables, and } \\
\text { health behaviours }^{a}\end{array}$ \\
\hline & $\mathrm{HR}(95 \% \mathrm{Cl})$ & $\mathrm{HR}(95 \% \mathrm{Cl})$ & $\mathrm{HR}(95 \% \mathrm{Cl})$ \\
\hline & $p$-value & $\mathrm{p}$-value & $p$-value \\
\hline \multirow[t]{2}{*}{ Cognitive hostility } & 1.04 (1.01-1.07) & 1.05 (1.02-1.09) & 1.05 (1.01-1.09) \\
\hline & $p<.01$ & $\mathrm{p}<.01$ & $\mathrm{p}<.01$ \\
\hline \multirow[t]{2}{*}{ Anger } & 1.01 (0.98-1.03) & $0.99(0.95-1.02)$ & $0.99(0.95-1.02)$ \\
\hline & $p=.62$ & $p=.50$ & $p=.48$ \\
\hline \multirow[t]{2}{*}{ Verbal aggression } & $1.00(0.96-1.05)$ & $0.97(0.92-1.03)$ & $0.97(0.92-1.03)$ \\
\hline & $\mathrm{p}=.88$ & $\mathrm{p}=.34$ & $p=.35$ \\
\hline Proactive & 1.05 (0.97-1.14) & $1.04(0.96-1.13)$ & $1.02(0.93-1.11)$ \\
\hline rebelliousness & $p=.23$ & $\mathrm{p}=.37$ & $p=.71$ \\
\hline Reactive & 1.03 (0.99-1.08) & $1.03(0.98-1.07)$ & $1.03(0.98-1.07)$ \\
\hline rebelliousness & $p=.17$ & $p=.30$ & $p=.31$ \\
\hline
\end{tabular}

\footnotetext{
${ }^{a}$ sports and alcohol consumption were entered into the analyses as continuous variables
} 


\section{Discussion}

The results showed a positive relationship between cognitive hostility and mortality in this late middle-aged and older population, irrespective of unhealthy lifestyles or the other related psychological variables. Anger, aggression and rebelliousness were not associated with the risk of mortality in this population.

Our findings that expressed adverse psychological responses are less harmful for longevity than adverse cognitions among older people are in line with previous findings on expressed psychological responses being less harmful than internally experienced psychological responses in an older population (Wilson, et al., 2003). A possible explanation could be that the low mean values of the expressed responses anger, aggression and rebelliousness within this population are simply not high or 'toxic' enough to provoke an untimely death. Previous studies providing descriptives for these psychological characteristics reported higher mean values', albeit in much younger populations (McDermott \& Apter, 1987a; Meesters, et al., 1996). However, also in younger populations hostile cognitions, rather than the behavioural and emotional components of hostility, were found to be significantly predictive of all-cause mortality, as was shown in a recent large-scale observational study with a 12.7 year follow-up by Nabi et al (Nabi, et al., 2008). Although we cannot entirely rule out that the null-findings for anger, aggression and rebelliousness are caused by low mean levels of these characteristics, it seems more likely that only hostile cognitions are of importance for longevity, not only in our population of late middle-aged and older people, but also in the general population.

We expected that the effect of cognitive hostility on mortality would be attenuated by the health behaviours, as cognitive hostility has been found predictive of smoking, excessive drinking and avoidance of exercise in previous studies (Miller, et al., 1995; Siegler, et al., 2003), which lifestyles in turn increase the mortality risk (Khaw et al., 2008). Everson and colleagues (Everson, et al., 1997) found that the behavioural risk factors substantially attenuated the association between hostility and all-cause and CVD mortality in a younger population (men aged 42-60 years). In the present study, relatively high hostile people were significantly more often current smokers as compared to low hostile people (Table 2), and smoking predicted mortality as well (not tabulated). However, we found neither attenuation, nor any significant interaction between smoking and cognitive hostility. Apparently, the adverse effects of both cognitive hostility and smoking on mortality are unique effects. Our findings are consistent with the observation that behavioural risk factors did not influence the hostility-mortality association in the three other studies in older populations either (Barefoot, et al., 1995; Tindle, et al., 2009; Wilson, et al., 2003).

Some methodological limitations need to be acknowledged. Cognitive hostility, anger and aggression were measured in 2004, but they were treated in the analy- 
ses as though they were measured at baseline (2005), for we assumed stability of these variables for this one year. Although there is meta-analytic evidence that personality might change, even in old age (Roberts, Walton, \& Viechtbauer, 2006), we believe that, considering the relatively short time period of 1 year, it is unlikely this has caused our results to be biased.

A substantial part of the respondents (34\%) did not consent to the use of their medical data, and not all data were complete. We cannot rule out selection bias due to consent to the use of medical data in our results, but since data for comparison on the outcome were not available to us, it is unknown whether and how this selection might have biased our findings. The respondents with missing data on the psychological variables measured at baseline did not differ on sociodemographics and mortality from the participants with complete data at baseline. The results from the multiple imputation analyses also did not differ from analyses using the complete cases only. Therefore, we do not expect our findings to be substantially biased by these missing data.

Possibly, the effects of hostility on the outcome might have been different if we had used cause-specific mortality. Unfortunately, these data were not available. Hostility has in previous studies often been associated with cardiac mortality, both in the etiology of (Everson, et al., 1997) and prognosis (Boyle et al., 2005; Chida \& Steptoe, 2009) with cardiac disease (mortality). Proposed mechanisms specifically for cardiac health include lifestyle factors (Everson, et al., 1997) though not in all studies (Barefoot, et al., 1995); blood pressure (Helmers \& Krantz, 1996); atherosclerosis (Julkunen, Salonen, Kaplan, Chesney, \& Salonen, 1994); obesity and insulin resistance (Niaura et al., 2000); and autonomic control (Sloan et al., 2001). The present results show that hostility probably also exerts broader effects on survival. In future studies, we need to include other causes of death and consider alternative pathways.

\section{Conclusion}

Premature mortality in late middle-aged and older people is not only induced by unhealthy behaviours, but psychological attributes, specifically cognitive hostility, account for a part of the excess risk as well. In diminishing this excess risk, hostile cognitions in older people might be acknowledged separately and additionally to the risk posed by unhealthy lifestyles. 


\section{References}

Adler, N. E., \& Ostrove, J. M. (1999). Socioeconomic status and health: what we know and what we don't. Ann N Y Acad Sci, 896, 3-15.

Barefoot, J. C., Larsen, S., von der Lieth, L., \& Schroll, M. (1995). Hostility, incidence of acute myocardial infarction, and mortality in a sample of older Danish men and women. Am J Epidemiol, 142(5), 477484.

Boyle, S. H., Williams, R. B., Mark, D. B., Brummett, B. H., Siegler, I. C., \& Barefoot, J. C. (2005). Hostility, age, and mortality in a sample of cardiac patients. Am J Cardiol, 96(1), 64-66.

Buss, A. H., \& Perry, M. (1992). The aggression questionnaire. J Pers Soc Psychol, 63(3), 452-459.

Chida, Y., \& Steptoe, A. (2009). The association of anger and hostility with future coronary heart disease: a meta-analytic review of prospective evidence. J Am Coll Cardiol, 53(11), 936-946.

Eaker, E. D., Sullivan, L. M., Kelly-Hayes, M., D’Agostino, R. B., Sr., \& Benjamin, E. J. (2004). Anger and hostility predict the development of atrial fibrillation in men in the Framingham Offspring Study. Circulation, 109(10), 1267-1271.

Everson, S. A., Kauhanen, J., Kaplan, G. A., Goldberg, D. E., Julkunen, J., Tuomilehto, J., et al. (1997). Hostility and increased risk of mortality and acute myocardial infarction: the mediating role of behavioral risk factors. Am J Epidemiol, 146(2), 142-152.

Harris, J. A. (1997). A further evaluation of the Aggression Questionnaire: issues of validity and reliability. Behav Res Ther, 35(11), 1047-1053.

Helmers, K. F., \& Krantz, D. S. (1996). Defensive hostility, gender and cardiovascular levels and responses to stress. Ann Behav Med, 18(4), 246-254.

Julkunen, J., Salonen, R., Kaplan, G. A., Chesney, M. A., \& Salonen, J. T. (1994). Hostility and the progression of carotid atherosclerosis. Psychosom Med, 56(6), 519-525.

Khaw, K. T., Wareham, N., Bingham, S., Welch, A., Luben, R., \& Day, N. (2008). Combined impact of health behaviours and mortality in men and women: the EPIC-Norfolk prospective population study. PLoS Med, 5(1), e12.

Klabbers, G., Bosma, H., van den Akker, M., van Boxtel, M. P., Kempen, G. I., McDermott, M. R., et al. (2009). Measuring rebelliousness and predicting health behaviour and outcomes: an investigation of the construct validity of the social reactivity scale. J Health Psychol, 14(6), 771-779.

Kristenson, M., Eriksen, H. R., Sluiter, J. K., Starke, D., \& Ursin, H. (2004). Psychobiological mechanisms of socioeconomic differences in health. Soc Sci Med, 58(8), 1511-1522.

Kuh, D., Ben-Shlomo, Y., Lynch, J., Hallqvist, J., \& Power, C. (2003). Life course epidemiology. J Epidemiol Community Health, 57(10), 778-783.

Kuper, H., Marmot, M., \& Hemingway, H. (2002). Systematic review of prospective cohort studies of psychosocial factors in the etiology and prognosis of coronary heart disease. Semin Vasc Med, 2(3), 267-314.

Martin, R., Watson, D., \& Wan, C. K. (2000). A three-factor model of trait anger: dimensions of affect, behavior, and cognition. J Pers, 68(5), 869-897.

McDermott, M. R. (2001). Rebelliousness. In M. J. Apter (Ed.), Motivational styles in everyday life: $A$ Guide to Reversal Theory (pp. 167-185). Washington, DC: American Psychological Association.

McDermott, M. R., \& Apter, M. J. (1987a). An Introduction \& Guide to the Negativism Dominance Scale. In M. R. McDermott (Ed.), Rebelliousness in adolescence and young adulthood. Cardiff: University of Wales.

McDermott, M. R., \& Apter, M. J. (1987b). The Social Reactivity Scale. In M. R. McDermott (Ed.), Rebelliousness in adolescence and young adulthood. Cardiff: University of Wales.

Meesters, C., Muris, P., Bosma, H., Schouten, E., \& Beuving, S. (1996). Psychometric evaluation of the Dutch version of the Aggression Questionnaire. Behav Res Ther, 34(10), 839-843.

Mendis, S. (2010). The policy agenda for prevention and control of non-communicable diseases. Br Med Bull, 96, 23-43. 
Miller, T. Q., Markides, K. S., Chiriboga, D. A., \& Ray, L. A. (1995). A test of the psychosocial vulnerability and health behavior models of hostility: results from an 11-year follow-up study of Mexican Americans. Psychosom Med, 57(6), 572-581.

Miller, T. Q., Smith, T. W., Turner, C. W., Guijarro, M. L., \& Hallet, A. J. (1996). A meta-analytic review of research on hostility and physical health. Psychol Bull, 119(2), 322-348.

Myers, R. (1990). Classical and modern regression with applications (2nd ed.). Boston, MA: Duxbury.

Nabi, H., Kivimaki, M., Zins, M., Elovainio, M., Consoli, S. M., Cordier, S., et al. (2008). Does personality predict mortality? Results from the GAZEL French prospective cohort study. Int J Epidemiol, 37(2), 386-396.

Niaura, R., Banks, S. M., Ward, K. D., Stoney, C. M., Spiro, A., 3rd, Aldwin, C. M., et al. (2000). Hostility and the metabolic syndrome in older males: the normative aging study. Psychosom Med, 62(1), 716.

Probst-Hensch, N. M. (2010). Chronic age-related diseases share risk factors: do they share pathophysiological mechanisms and why does that matter? Swiss Med Wkly, 140, w13072.

Roberts, B. W., Walton, K. E., \& Viechtbauer, W. (2006). Patterns of mean-level change in personality traits across the life course: a meta-analysis of longitudinal studies. Psychol Bull, 132(1), 1-25.

Rozanski, A., Blumenthal, J. A., \& Kaplan, J. (1999). Impact of Psychological Factors on the Pathogenesis of Cardiovascular Disease and Implications for Therapy. Circulation, 99, 2192-2217.

Rubin, D. B. (1987). Multiple imputation for nonresponse in surveys. New York: Wiley \& Sons.

Siegler, I. C., Costa, P. T., Brummett, B. H., Helms, M. J., Barefoot, J. C., Williams, R. B., et al. (2003). Patterns of change in hostility from college to midlife in the UNC Alumni Heart Study predict highrisk status. Psychosom Med, 65(5), 738-745.

Sloan, R. P., Bagiella, E., Shapiro, P. A., Kuhl, J. P., Chernikhova, D., Berg, J., et al. (2001). Hostility, gender, and cardiac autonomic control. Psychosom Med, 63(3), 434-440.

Smith, T. W. (1994). Concepts and methods in the study of anger, hostility, and health. In A. W. Siegman \& T. W. Smith (Eds.), Anger, hostility and the heart (pp. 23-42). Hillsdale, NJ: Lawrence Erlbaum.

Sterne, J. A., White, I. R., Carlin, J. B., Spratt, M., Royston, P., Kenward, M. G., et al. (2009). Multiple imputation for missing data in epidemiological and clinical research: potential and pitfalls. BMJ, 338, b2393.

Tindle, H. A., Chang, Y. F., Kuller, L. H., Manson, J. E., Robinson, J. G., Rosal, M. C., et al. (2009). Optimism, cynical hostility, and incident coronary heart disease and mortality in the Women's Health Initiative. Circulation, 120(8), 656-662.

Van Buuren, S. (2007). Multiple imputation of discrete and continuous data by fully conditional specification. Stat Methods Med Res, 16(3), 219-242.

Van den Akker, M., Spigt, M. G., de Raeve, L., van Steenkiste, B., Metsemakers, J. F., van Voorst, E. J., et al. (2008). The SMILE study: A Study of Medical Information and Lifestyles in Eindhoven, the rationale and contents of a large prospective dynamic cohort study. BMC Public Health, 8(1), 19.

Wendel-Vos, G. C., Schuit, A. J., Saris, W. H., \& Kromhout, D. (2003). Reproducibility and relative validity of the short questionnaire to assess health-enhancing physical activity. J Clin Epidemiol, 56(12), 1163-1169.

WHO. (2004). Global status report on alcohol 2004. Geneva: World Health Organisation, Department of mental health and substance abuse.

WHO. (2008). 2008-2013 Action Plan for the Global Strategy for the Prevention and Control of Noncommunicable diseases: World Health Organization.

Wilson, R. S., Bienias, J. L., Mendes de Leon, C. F., Evans, D. A., \& Bennett, D. A. (2003). Negative Affect and Mortality in Older Persons. Am J Epidemiol, 158(9), 827-835. 


\section{CHAPTER 5}

Predicting health in late middle-aged and older persons: the comparison of a new psychosocial health risk approach with individual psychosocial characteristics

G. Klabbers, H. Bosma, G.I.J.M. Kempen, M. Benzeval, M. van den Akker, J.Th.M. van Eijk

Under review. 


\section{Abstract}

A psychosocial profile that combines potentially synergistic effects between different psychosocial characteristics, including psychological attributes and functioning, coping styles and social support, might be a stronger predictor of health compared to individual psychosocial characteristics. Prospective, longitudinal data from 1912 Dutch participants aged 55-91 years were used to determine distinct psychosocial profiles by means of two-step cluster analysis. The predictive power of these profiles over a five-year follow-up was determined by the Schwarz Bayesian Information Criterion (BIC) for Cox regression models for GP-diagnosed somatic morbidity and all-cause mortality, and logistic regression models for self-rated health. Three distinct psychosocial risk profiles emerged: an adverse, an average and a beneficial profile. These profiles strongly predicted self-rated health but not morbidity or mortality. Based on the BICs, the cluster (profile) model proved to be a stronger predictor than the model comprising individual psychosocial characteristics in predicting self-rated health, suggesting synergistic effects. 


\section{Introduction}

There is a substantial body of evidence which demonstrates that individual psychosocial factors affect (somatic) health and longevity (Egan, Tannahill, Petticrew, \& Thomas, 2008; Kroenke, 2007; Kuper, Marmot, \& Hemingway, 2002; Stansfeld, Bosma, Hemingway, \& Marmot, 1998). The evidence includes a wide range of psychosocial characteristics, such as psychological attributes (hostility, anger, neuroticism and low control beliefs), mental functioning (depression and anxiety), and low social support and social isolation (Bosma, Schrijvers, \& Mackenbach, 1999; Chapman, Fiscella, Kawachi, \& Duberstein, 2009; Chida \& Steptoe, 2009; Egan, et al., 2008; Kubzansky, Cole, Kawachi, Vokonas, \& Sparrow, 2006; Kuper, et al., 2002; Nabi et al., 2008; Penninx et al., 2001; Rugulies, 2002; Stansfeld, 2006; Stansfeld, et al., 1998; Van den Akker, Buntinx, Metsemakers, van der Aa, \& Knottnerus, 2001). However, the strength of these associations varies across different psychosocial characteristics and the health outcomes considered (Chida \& Steptoe, 2009; Egan, et al., 2008; Surtees, Wainwright, Luben, Day, \& Khaw, 2005). A possible, yet under-researched, reason for these differences might be that a person's psychosocial makeup is inadequately represented by just one psychosocial characteristic; health risk might be more accurately predicted by a more complete psychosocial profile.

Additional predictive power might be found by taking into account the covariation of certain psychosocial factors and their potentially synergistic effects on health and longevity. Many psychological attributes correlate with each other: for example hostility, neuroticism, anger and aggressiveness are all inter-related (Martin, Watson, \& Wan, 2000; Miller, Smith, Turner, Guijarro, \& Hallet, 1996). In addition these attributes correlate with mental functioning, e.g. hostility and anger are both associated with depression (Boyle, Jackson, \& Suarez, 2007; Felsten, 1996). Similarly, psychological attributes and mental functioning are inter-related with social circumstances; with depressive and hostile people often experiencing deteriorating social networks and even social isolation (Koster et al., 2006; Smith, 1992; Smith, Glazer, Ruiz, \& Gallo, 2004). The reverse, that poor social networks result in depression, has also been found (Brown, Andrews, Harris, Adler, \& Bridge, 1986). Theoretically these empirically established associations are underpinned by interpersonal theory, which suggests that personality influences social relationships because more agreeable or hostile personalities can lead to more or less close social relationships, which can in turn enhance personality (Pincus \& Ansell, 2003). Further, personality determines whether situations will be evaluated more positively or negatively, whether a person feels more in control or out of control, thus affecting coping styles (Kiesler, 1996).

Although the potentially synergistic effect of different psychosocial factors on health is relatively understudied, some findings suggest that a combined psychosocial profile might be more strongly associated with health than separate character- 
istics are. For instance, the interaction between hostility, anger and depression was found to be a stronger predictor of long term health risk - through inflammatory processes - than the individual characteristics (Boyle, et al., 2007). Taking into account the additive and possibly synergistic effect of psychosocial factors might lead to a more systematic, accurate and robust, and therefore more valid, psychosocial prediction of morbidity and mortality. This paper firstly explores whether psychosocial profiles can be developed from a set of individual psychosocial risk factors; and secondly, whether a combined psychosocial risk profile, compared to a set of individual psychosocial risk factors, better predicts poor self-rated health, somatic morbidity and mortality risk in a population of late middle-aged and older men and women.

\section{Methods}

\section{Design and participants}

Self-reported data on psychosocial characteristics and health as well as registered medical data including mortality were gathered in a prospective cohort study: the SMILE study (Study of Medical Information and Lifestyles in the city of Eindhoven (Southeast of the Netherlands)). The design of this study has been described in detail elsewhere (Van den Akker et al., 2008). Briefly, starting in 2002, individuals who were enrolled in one of the nine participating primary health care centres, involving 32 general practitioners (GPs) in Eindhoven were invited to participate in the SMILE study. In the Netherlands, nearly every individual is registered with a GP and basic medical care is covered by the compulsory national medical insurance scheme. Informed consent was sought for the self-report questionnaires including information about psychosocial characteristics and self-rated health, and linkage of questionnaire data with medical information (morbidity, mortality, and health care use) extracted from electronic medical records. Of the 5001 participants aged 55 years and older consenting to the questionnaires, 3022 participants (60.4\%) consented to the linkage with medical data. The SMILE study protocol was approved by the medical ethical committee of the Maastricht Academic Hospital. The present study used baseline data collected between 2003 and 2005 (since not every characteristic was measured every year), and five-year follow-up data (2010) on the health outcomes.

\section{Measures}

\section{Psychosocial characteristics}

The 13 different psychosocial characteristics available in the study are outlined in Table 1. All psychosocial characteristics were recoded so that higher scores indi- 
cated more of that particular characteristic. All questionnaires asked for responses 'in general' except for one: the Hospital Anxiety and Depression Scale which deals with 'recent' mood.

\section{Morbidity and mortality}

Morbidity and (all-cause) mortality are, in GP-registration data, defined according to ICPC (International Classification of Primary Care) diagnostic codes. These are derived from the diagnostic criteria as provided by the guidelines of the Dutch College of GP's and/or the diagnosis of a medical specialist. Incident somatic morbidity was defined as a patient being diagnosed (or not) with at least one of four age-related non-communicable diseases (cardiovascular diseases, cancers, chronic respiratory diseases, diabetes) during the follow-up period between November 2005 and November 2010. These diseases were chosen as they are current priorities for WHO policy (Mendis, 2010; Probst-Hensch, 2010; WHO, 2008). Specific diagnoses for these four disease categories are:

- cardiovascular diseases: angina, acute myocardial infarction or other ischaemic heart disease, cardiac failure, pulmonary heart disease, and stroke;

- cancers: all malignancies in circulatory, digestive, respiratory, and urogenital tract or in the nervous system or endocrine glands;

- chronic respiratory diseases: tuberculosis, emphysema, chronic obstructive pulmonary disease, and asthma;

- diabetes, type I and II.

Diseases that were diagnosed before 1 November 2005 were considered prevalent and they were adjusted for in the longitudinal analyses. The outcome variables were included in the analyses as time until occurrence of the event. The GPregistered somatic morbidity and all-cause mortality will hereafter be referred to as 'morbidity' and 'mortality'. 


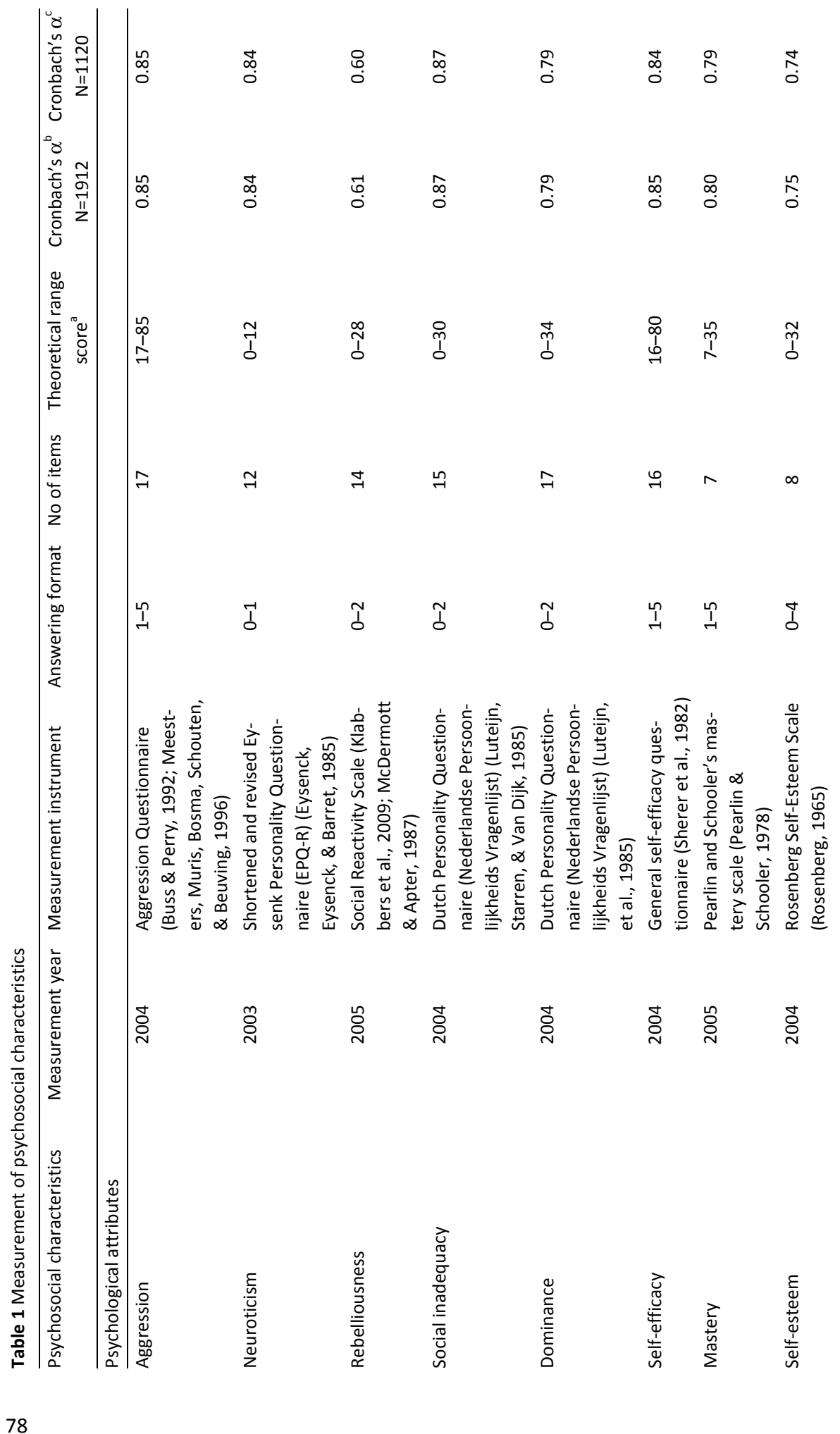




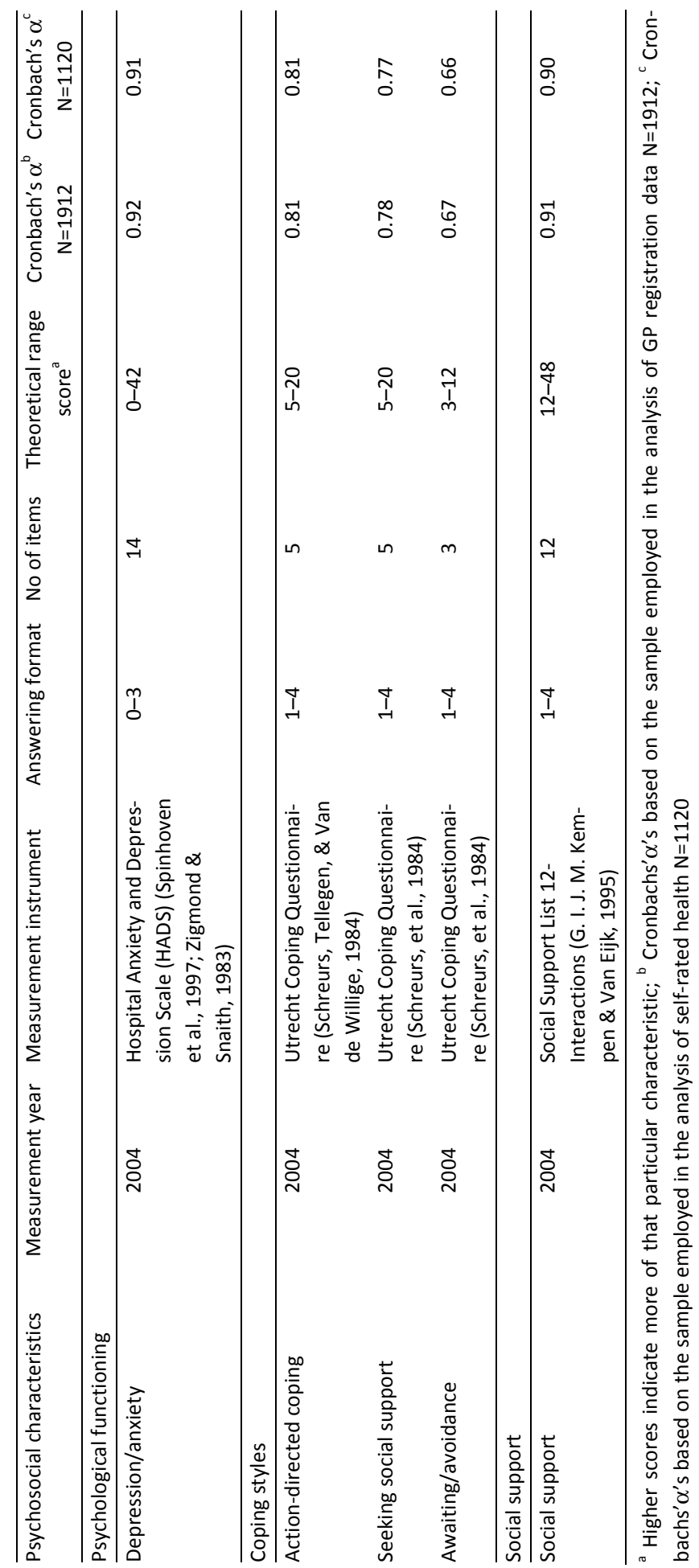




\section{Self-rated health}

Self-rated health was operationalised as a dichotomous variable: less-than-good health (1) versus good health (0), based on the question: 'How would you rate your health in general?' with five answer categories: very good; good; fair; sometimes good and sometimes poor; poor. It was measured in 2005 and 2010.

\section{Sociodemographic variables}

The sociodemographic variables were measured in 2002 and included age, sex and educational level. Education was classified into low (primary and lower secondary vocational), intermediate (apprenticeship system, general secondary and senior secondary vocational), and high (pre-university, higher professional and university).

\section{Data analysis}

First, we determined distinct psychosocial profiles based on the psychosocial characteristics described in Table 1 by means of a two-step cluster analysis in SPSS 17 (Norušis, 2010). Clustering enables the formation of groups of individuals that are similar to each other but different from others. Cases are assigned to a specific cluster based on distance measures, in this case using the log-likelihood criterion. In the first step of the procedure, preclusters are formed that are merged successively with similar preclusters in the second step. The continuous variables are standardised in this procedure (by default). Cluster analysis is an explorative procedure and there is no prescribed decision criterion available for choosing the final number of clusters (Norušis, 2010). The automated cluster solution (where the number of clusters is determined by the statistical package) is based on the Schwarz Bayesian Information Criterion (BIC), but the qualitative evaluation of content, interpretation and stability of the different cluster solutions is equally important. We used the automated option as well as imposing specific numbers of clusters (four, five and six) in order to determine the 'right' number of clusters. To account for both sample fluctuations and sequence (since cluster analysis depends on the sequence of the data (Norušis, 2010)) we ran ten runs of split half analyses in different random case orders as a form of stability testing. We further examined the associations between the cluster pattern and sex, age and educational level.

Cox proportional hazard models were employed for the main analyses estimating the hazards of morbidity and mortality for the psychosocial profiles. The survival time for morbidity was defined as the time from 1 November 2005 to the date of first diagnosis of one of the abovementioned diseases with the other cases censored by death, drop-out of the study or complete follow up (1 November 2010) as appropriate. The survival time for mortality was defined as the time from baseline to date of death, with the other cases censored by date of drop-out of the study or complete follow up (1 November 2010). For the analyses with self-rated health we 
used logistic regression models to calculate the odds ratios for less-than-goodhealth by psychosocial profile. All models were adjusted for age, sex, educational level, and prevalent morbidity or self-rated health at baseline depending on the health outcome. Interactions of age, sex and educational level individually with psychosocial profile were also tested.

We compared the models predicting health by psychosocial profile with those employing the individual psychosocial characteristics from which the profiles were derived. The comparison was based on the BIC, which is a criterion for model selection among parametric models with different numbers of parameters (Schwarz, 1987). The $\mathrm{BIC}$ is calculated by: $-2 \mathrm{LL}+k \ln (n)$, in which $-2 \mathrm{LL}$ is the maximum likelihood estimator of the estimated model, $k$ is the number of free parameters to be estimated, and $\mathrm{n}$ is the sample size. Given any two estimated models, the one with the lower BIC value has the better statistical fit.

\section{Results}

Individuals who died before 1 November $2005(\mathrm{~N}=10)$, and those who had missing data on the demographic $(\mathrm{N}=58)$ and psychosocial $(\mathrm{N}=1042)$ variables were excluded from the analysis. The final sample eligible for analyses with the medical data comprised 1912 participants, with a mean age of 66.3 years, (SD 7.7); 47.7\% male (Table 2). Compared with the total sample of 3022 giving informed consent for linkage to medical data, the analysis sample comprised more men ( $47.7 \%$ versus $41.9 \%$ in the total sample, $\chi^{2}=9.55, p<.01$ ) and was on average 2.1 years younger $(t=6.64, p<.01)$.

For the analysis with self-rated health an additional 622 people with missing data on self-rated health were excluded and 170 people died between November 2005 and November 2010, leaving 1120 people eligible for analysis (mean age 65.2 years (SD 7.0), 47.9\% male). The sample based on self-rated health was on average 2.6 years younger than the sample based on GP-registered data $(t=7.26, p<.05)$. The two samples used in the analyses did not differ on sex $(p=.82)$, education $(p=.06)$ or on prevalent $(p=.81)$ or incident $(p=.22)$ morbidity. During follow-up (November 2005-November 2010), 22.1\% ( $N=422$ ) of the participants were diagnosed with incident morbidity and $37 \%(\mathrm{~N}=720)$ had prevalent morbidity (diagnosed before November 2005). In 2005 17.0\% of the participants reported lessthan-good health and $19.8 \%$ did so in 2010. 
Table 2 Sample descriptives of the two analysis samples

\begin{tabular}{|c|c|c|c|c|c|}
\hline & & $\mathrm{N}=1912^{\mathrm{a}}$ & & $\mathrm{N}=1120^{\mathrm{b}}$ & \\
\hline & Variables (theoretical range) & $\operatorname{Mean}^{\mathrm{C}}(\mathrm{SD})$ & Prevalence & $\operatorname{Mean}^{c}(S D)$ & Prevalence \\
\hline \multirow[t]{5}{*}{ Sociodemographics } & Age (55.0-91.0) & $66.3(7.7)$ & & $65.2(7.0)$ & \\
\hline & Men & & $47.7 \%$ & & $47.9 \%$ \\
\hline & Education low & & $30.4 \%$ & & 31.3 \\
\hline & intermediate & & $36.2 \%$ & & 37.7 \\
\hline & high & & $33.4 \%$ & & 31.0 \\
\hline \multirow{13}{*}{$\begin{array}{l}\text { Psychosocial } \\
\text { characteristics }\end{array}$} & Aggression (17-85) & $34.2(10.3)$ & & $33.9(10.4)$ & \\
\hline & Neuroticism (0-12) & $2.4(2.9)$ & & $2.3(2.8)$ & \\
\hline & Rebelliousness (0-28) & $4.9(3.6)$ & & $4.8(3.5)$ & \\
\hline & Social inadequacy (0-30) & $9.7(7.1)$ & & $9.4(7.0)$ & \\
\hline & Dominance (0-34) & $15.0(6.2)$ & & $15.2(6.2)$ & \\
\hline & Self-efficacy (16-80) & $56.7(7.3)$ & & $57.2(6.9)$ & \\
\hline & Mastery (7-35) & $24.4(4.8)$ & & $24.7(4.7)$ & \\
\hline & Self-esteem (0-32) & $22.6(3.6)$ & & $22.7(3.6)$ & \\
\hline & Depression/anxiety (0-42) & $22.8(6.9)$ & & $22.1(6.6)$ & \\
\hline & Action-directed coping (5-20) & $13.6(2.5)$ & & $13.7(2.4)$ & \\
\hline & Seeking social support (5-20) & $10.8(2.6)$ & & $10.9(2.6)$ & \\
\hline & Awaiting/avoidance (3-12) & $6.0(1.6)$ & & $5.9(1.6)$ & \\
\hline & Social support (12-48) & $27.3(6.1)$ & & $27.3(5.9)$ & \\
\hline \multirow[t]{2}{*}{ GP-registered morbidity } & $\begin{array}{l}\text { Prevalent morbidity } \\
(<1 \text { Nov 2005) }\end{array}$ & & $37.7 \%$ & & $37.4 \%$ \\
\hline & $\begin{array}{l}\text { Incident Morbidity } \\
\text { (1Nov 2005-1 Nov 2010) }\end{array}$ & & $22.1 \%$ & & $21.1 \%$ \\
\hline All-cause mortality & $\begin{array}{l}\text { All- cause mortality } \\
\text { (1Nov 2005-1 Nov 2010) }\end{array}$ & & $8.9 \%$ & & - \\
\hline \multirow[t]{2}{*}{ Self-rated health } & $\begin{array}{l}\text { Prevalent self-rated less-than- } \\
\text { good health ( } 2005)\end{array}$ & & & & $17.0 \%$ \\
\hline & $\begin{array}{l}\text { Incident self-rated less-than- } \\
\text { good health (2010) }\end{array}$ & & & & $19.8 \%$ \\
\hline
\end{tabular}

\footnotetext{
${ }^{a}$ the sample employed in the analysis of GP registration data $\mathrm{N}=1912{ }^{\mathrm{b}}{ }^{\text {the }}$ the sample employed in the analysis of self-rated health $\mathrm{N}=1120$; $^{\mathrm{C}}$ Higher scores indicate more of that particular characteristic
}

The first stage of the analysis was to examine the clustering of respondents across a range of psychosocial factors outlined in Table 1. Using the autoclustering func- 
tion based on the BIC, and the BIC change, the sample was split into three distinct clusters, based on the larger sample of $\mathrm{N}=1912$ (Table 3). Cluster 1 ( $18.1 \%$ of the sample) consisted of participants with the most adverse scores on all psychosocial characteristics, and mainly consisted of neurotic, depressed/anxious persons with low control beliefs. Cluster 2 (41.6\%) consisted of participants with average scores on the psychosocial characteristics. Cluster 3 (40.3\%), consisted of participants with the most beneficial scores: they felt socially adequate, had high control beliefs, and reported positive affect. The column 'contribution to cluster formation' shows how important the psychosocial attributes are for the formation of the cluster ( 1 is most important, 13 is least important). Notably, the psychological attributes (neuroticism, social inadequacy, self-efficacy, mastery and self-esteem) and mental functioning, rather than the coping styles and social support variables, contributed to the formation of both the adverse as well as beneficial clusters.

Table 3 Three-cluster solution, total sample (N=1912): unstandardized variable means per cluster

\begin{tabular}{|c|c|c|c|c|c|c|c|}
\hline & & $\begin{array}{c}\text { Cluster } 1 \\
\text { adverse } \\
18.1 \%\end{array}$ & & $\begin{array}{c}\text { Cluster } 2 \\
\text { average } \\
41.6 \%\end{array}$ & & $\begin{array}{c}\text { Cluster } 3 \\
\text { beneficial } \\
40.3 \%\end{array}$ & \\
\hline & & Means & $\begin{array}{l}\text { Contribution } \\
\text { to cluster } \\
\text { formation* }\end{array}$ & Means & $\begin{array}{c}\text { Contribution } \\
\text { to cluster } \\
\text { formation* }\end{array}$ & Means & $\begin{array}{c}\text { Contribution } \\
\text { to cluster } \\
\text { formation* }\end{array}$ \\
\hline \multirow{8}{*}{$\begin{array}{l}\text { Psychological } \\
\text { attributes }\end{array}$} & Aggression & 44.0 & 7 & 34.6 & ns & 29.5 & 8 \\
\hline & Neuroticism & 6.5 & 1 & 2.0 & 6 & 1.0 & 3 \\
\hline & Rebelliousness & 6.1 & 12 & 4.8 & 11 & 4.5 & ns \\
\hline & Social inadequacy & 16.4 & 6 & 11.3 & 4 & 4.9 & 1 \\
\hline & Dominance & 11.7 & 10 & 13.3 & 2 & 18.4 & 10 \\
\hline & Self efficacy & 48.3 & 2 & 55.1 & 1 & 62.2 & 2 \\
\hline & Mastery & 19.4 & 4 & 23.7 & 7 & 27.4 & 6 \\
\hline & Self-esteem & 18.9 & 5 & 21.9 & 3 & 25.0 & 4 \\
\hline $\begin{array}{l}\text { Mental } \\
\text { functioning }\end{array}$ & Depression/Anxiety & 31.5 & 3 & 22.6 & ns & 19.0 & 5 \\
\hline \multirow[t]{3}{*}{ Coping styles } & Action directed coping & 11.9 & 9 & 13.2 & 5 & 14.9 & 7 \\
\hline & Seeking social support & 10.3 & 13 & 10.4 & 9 & 11.4 & 12 \\
\hline & Awaiting/avoidance & 7.2 & 8 & 6.2 & 8 & 5.2 & 9 \\
\hline Social support & Social support & 25.3 & 11 & 26.5 & 10 & 29.0 & 11 \\
\hline
\end{tabular}

*order of contribution to the formation of this cluster , 1= most significantly contributing, 13 = least significant contributing, ns = not significantly contributing to the formation of this cluster 
Subsequent runs of the cluster analysis with different numbers of clusters (three, four, five and six), revealed more detailed and subtle patterns. However, the corresponding stability analyses (ten runs of two split half analyses) showed only the three-cluster solution to be stable; 16 out of 20 reruns had the same solution. This procedure was repeated in the smaller sample (for the analyses with self-rated health) with similar results.

Chi-square testing for sociodemographic differences within the three-cluster solution revealed that women, older participants and people who were less educated were more often members of the 'adverse' cluster than men, younger participants and those with higher educational levels (Table 4).

Table 4 Distribution of sex, age and educational level across the three clusters

\begin{tabular}{llllll}
\hline & $\begin{array}{l}\text { Cluster } 1 \\
\text { adverse }\end{array}$ & $\begin{array}{l}\text { Cluster } 2 \\
\text { average }\end{array}$ & $\begin{array}{l}\text { Cluster } 3 \\
\text { beneficial }\end{array}$ & $\chi^{2}$ & p value \\
\hline men & $129(14.1 \%)$ & $380(41.7 \%)$ & $403(44.2 \%)$ & 22.0 & $<.01$ \\
women & $218(21.8 \%)$ & $415(41.5 \%)$ & $367(36.7 \%)$ & & $<.01$ \\
$\leq 65.15$ yrs & $162(16.9 \%)$ & $351(36.7 \%)$ & $444(46.4 \%)$ & 22.0 & \\
$>64.15$ yrs & $185(19.4 \%)$ & $444(46.5 \%)$ & $326(34.1 \%)$ & & $<.01$ \\
high education & $62(10.6 \%)$ & $200(34.4 \%)$ & $320(55.0 \%)$ & 118.5 & \\
intermediate & $121(17.5 \%)$ & $284(41.1 \%)$ & $286(41.4 \%)$ & & \\
education & $164(25.7 \%)$ & $311(48.6 \%)$ & $164(25.7 \%)$ & & \\
low education & & & & \\
\hline
\end{tabular}

The results for the psychosocial clusters predicting morbidity, mortality and selfrated health are shown in Table 5. Cluster membership did not predict morbidity. The adverse cluster had an increased risk of mortality (HR 1.56, $p=.04$ ) compared with the beneficial cluster; adjusting for prevalent morbidity attenuated this risk to $H R=1.40, p=.13$. The risk of self-rated less-than-good health, however, was higher in both the average and the adverse clusters showing a dose-response association and this risk, although attenuated, remained statistically significant after adjusting for self-rated health at baseline $\left(O \mathrm{OR}_{\text {average }} 1.74,95 \% \mathrm{Cl} 1.15-2.64\right.$ and $\mathrm{OR}$ adverse 2.66, $95 \% \mathrm{Cl} 1.58-4.46)$. There were no statistically significant interactions of age, sex or education with cluster membership in their effect on morbidity, mortality and selfrated health (not tabulated).

We compared the BICs for the cluster models with those of the models comprising the set of individual psychosocial characteristics. The lower BICs for the 
cluster models showed that these models had a better statistical fit than the models comprising the individual characteristics (Table 5). The BIC of the cluster model predicting self-rated health was $862.78(-2 \mathrm{LL}=813.6 ; \mathrm{k}=7 ; \mathrm{N}=1120)$, and that for the set of individual characteristics was $917.72(-2 \mathrm{LL}=791.33 ; \mathrm{k}=18 ; \mathrm{N}=1120)$. Notably, in the model including all psychosocial characteristics, only aggression and depression/anxiety were significantly associated with self-rated health (OR 1.03, $p<$ .01 and OR 1.06, $\mathrm{p}<.01$ respectively).

Table 5 Risk estimators of morbidity (HR), mortality (HR) and self-rated health (OR) by cluster membership, adjusted for age, sex, educational level, and additionally for the prevalent health status

\begin{tabular}{|c|c|c|c|c|c|c|}
\hline & \multicolumn{2}{|l|}{ Morbidity } & \multicolumn{2}{|l|}{ Mortality } & \multicolumn{2}{|l|}{ Self-rated health } \\
\hline & $\begin{array}{l}\text { Adjusted for } \\
\text { age, sex and } \\
\text { education }\end{array}$ & $\begin{array}{l}+ \text { prevalent } \\
\text { morbidity }\end{array}$ & $\begin{array}{l}\text { Adjusted for } \\
\text { age, sex and } \\
\text { education }\end{array}$ & $\begin{array}{l}\text { +prevalent } \\
\text { morbidity }\end{array}$ & $\begin{array}{l}\text { Adjusted for } \\
\text { age, sex and } \\
\text { education }\end{array}$ & $\begin{array}{l}+ \text { prevalent } \\
\text { self-rated health }\end{array}$ \\
\hline & $\mathrm{N}=1912$ & & $\mathrm{~N}=1912$ & & $\mathrm{~N}=1120$ & \\
\hline & $\begin{array}{l}\mathrm{HR}(95 \% \mathrm{Cl}) \\
\text { p-value }\end{array}$ & $\begin{array}{l}\mathrm{HR}(95 \% \mathrm{Cl}) \\
\mathrm{p} \text {-value }\end{array}$ & $\begin{array}{l}\mathrm{HR}(95 \% \mathrm{Cl}) \\
\mathrm{p} \text {-value }\end{array}$ & $\begin{array}{l}\mathrm{HR}(95 \% \mathrm{Cl}) \\
\text { p-value }\end{array}$ & $\begin{array}{l}\text { OR }(95 \% \mathrm{Cl}) \\
\text { p-value }\end{array}$ & $\begin{array}{l}\text { OR }(95 \% \mathrm{Cl}) \\
\text { p-value }\end{array}$ \\
\hline \multicolumn{7}{|l|}{ Cluster } \\
\hline 1 beneficial & 1.00 & 1.00 & 1.00 & 1.00 & 1.00 & 1.00 \\
\hline \multirow[t]{2}{*}{ average } & $0.87(0.69-1.08)$ & $0.84(0.67-1.05)$ & $1.15(0.80-1.65)$ & $1.11(0.77-1.59)$ & $2.24(1.54-3.27)$ & $1.74(1.15-2.64)$ \\
\hline & .20 & .12 & .46 & .59 & $<.001$ & .01 \\
\hline \multirow[t]{2}{*}{3 adverse } & $1.17(0.89-1.53)$ & $1.10(0.84-1.45)$ & $1.56(1.02-2.38)$ & $1.40(0.91-2.15)$ & $5.67(3.62-8.88)$ & $2.66(1.58-4.46)$ \\
\hline & .26 & .48 & .04 & .13 & $<.001$ & $<.001$ \\
\hline BIC cluster model & 6148.30 & 6114.39 & 2450.32 & 2430.60 & 1032.09 & 862.78 \\
\hline $\begin{array}{l}\text { BIC combined } \\
\text { psychosocial } \\
\text { characteristics } \\
\text { model* }\end{array}$ & 6218.10 & 6185.94 & 2512.25 & 2494.13 & 1050.05 & 917.72 \\
\hline
\end{tabular}

* Results of the regression analyses not shown, available from the author

In addition, replication of the analyses on morbidity and mortality in the smaller $(\mathrm{N}=1120)$ sample generated similar results to those in the full sample (not tabulated) suggesting the strong association for self-rated health was not the result of a different sample being employed. We also replicated the analyses with self-rated health, adjusting for prevalent morbidity (rather than prior self-rated health); in this case the results also held (not tabulated). Both additional analyses underpin the consistency of our findings. 


\section{Discussion}

We set out to explore whether psychosocial risk profiles would be a valid tool to predict the risk of morbidity, mortality and self-rated health in this population of late middle-aged and older men and women. We found three distinct psychosocial profiles, which can be characterised as 1) beneficial, 2) average, and 3) adverse. Having an adverse profile raised the risk of all-cause mortality, although this did not reach statistical significance at $95 \%$ level after adjustments for prevalent morbidity. However, (change in) self-rated health was strongly predicted by the average and adverse psychosocial profiles in a dose-response relation: the average cluster showed an increased risk of $74 \%$, and the adverse cluster showed an increased risk of $166 \%$ for self-rated less-than-good health, compared with the beneficial cluster. Comparing the BICs of the cluster model with those of the models comprising all the psychosocial characteristics showed that the cluster models had a better statistical fit for all three outcomes, which was of particular importance for the prediction of self-rated health. Hence, the profile approach, taking into account both additive and possible synergistic effects, adds to the predictive power of psychosocial characteristics for self-rated health.

For the prediction of somatic morbidity and all-cause mortality, the profiles seemed less important than for self-rated health. The association with self-rated health might be stronger than that for morbidity, as self-rated health is both strongly associated with psychosocial distress (Cano et al., 2003) and is a subjective measure, whereas morbidity is objective and more somatic (the way we measured it). Similarly, the association for self-rated health might be stronger than that for mortality because although they both capture physical and mental health conditions, self-rated health might possibly be influenced by negative affect, i.e. that negative mood correlates with self-rated poor health and negative reports of the psychosocial characteristics (Benyamini, Idler, Leventhal, \& Leventhal, 2000; Benyamini \& Roziner, 2008; Kempen, Miedema, van den Bos, \& Ormel, 1998). However, controlling for baseline self-rated health addresses this potential reporting bias. On the other hand controlling for baseline health might lead to an underestimation of the effects, since baseline health may itself have been affected by prior psychosocial factors (Astin \& Fortys, 2004; Denton, Prus, \& Walters, 2004), controlling for baseline health might therefore result in overadjustment. This might explain why the adverse profile did not predict mortality after adjustments for baseline morbidity. Given that we do not know the causal ordering of the association between psychosocial factors and (prevalent) disease, we presented the findings both before and after adjustment. Future longitudinal research should unravel the two-way pathways between psychosocial profiles and health.

We found significant sociodemographic differences across the three psychosocial profiles of which the most striking was that less educated people are more 
often members of the adverse cluster than their higher educated counterparts. Taking into account that people in lower socioeconomic positions more often report health problems (Breeze et al., 2001) and have a higher mortality rate (Huisman et al., 2004) than their better-off counterparts, our findings indicate that psychosocial profiling could potentially explain socioeconomic health inequalities, as has been previously suggested (Taylor \& Seeman, 1999). Further investigation of this pathway is required.

\section{Methodological limitations}

Firstly, the findings indicating that the profile approach is more valid in case of predicting self-rated health as compared to the prediction by the individual psychosocial characteristics are based on the comparison of the BICs. However, there is no statistical test available for the comparison of BICs, which is a common difficulty in the comparison of non-nested models. But given this is an explorative study, both conceptually and analytically, we feel we have provided enough evidence for studying psychosocial profiling in more detail in future research. Secondly, the nullresults for morbidity might be caused by the 'no disease' group having other diseases that could be related to psychosocial clusters. For instance, other serious diseases such as epilepsy, musculoskeletal diseases and psychiatric diagnoses (DSM-IV) such as major depressive disorder, which were not classified here as morbidity, have all been found to be associated with one or more psychosocial characteristics (Gotlib, Lewinsohn, \& Seeley, 1995; Nahit et al., 2003; Suurmeijer, Reuvekamp, \& Aldenkamp, 2001). This would bias our findings for this measure towards null. Thirdly, non-response (i.e. not consenting to linkage with medical data) was almost $40 \%$. However, those who did not consent did not differ significantly with regard to age, sex and education from those who did. We, therefore, do not believe selection bias would influence these results, although we cannot rule out this possibility for other characteristics not measured. Further, the eligible sample for the analysis with self-rated health was even smaller due to attrition between 2005 and 2010. The former sample was on average 2.6 years younger than the latter. Although it has been shown before that longitudinal studies are not as severely affected by attrition as has often been assumed, particularly in old age (Deeg, 2002; Kempen \& van Sonderen, 2002; Kho, Duffett, Willison, Cook, \& Brouwers, 2009), we cannot rule out bias by these age differences as the loss to followup was substantial. Fourthly, the five-year follow-up period might be too short to see the true effects on mortality. Finally, psychosocial characteristics are prone to change over the lifecourse, depending on the life stage a person is in (Roberts, Walton, \& Viechtbauer, 2006), and morbidity patterns are also age-related. It is 
necessary therefore to cross-validate the cluster structure and its effect on health in other populations across the life-course.

\section{Conclusions}

Given the above, we suggest that profiling people based on their psychosocial characteristics is a useful approach for predicting self-rated health in this population of late-middle aged and older participants. However, we could not confirm this hypothesis with regard to morbidity or all-cause mortality. Further research should seek to refine the psychosocial clusters to better define high-risk groups, explore the potential pathways between psychosocial factors and health, and - given the strong educational patterning - examine the extent to which these clusters might explain socioeconomic inequalities in health. 


\section{References}

Astin, J. A., \& Fortys, K. (2004). Psychosocial determinants of health and illness: reintegrating mind, body, and spirit. In B. Kligler \& R. A. Lee (Eds.), Integrative Medicine. Principles for practice (pp. 2536): McGraw-Hill Companies.

Benyamini, Y., Idler, E. L., Leventhal, H., \& Leventhal, E. A. (2000). Positive Affect and Function as Influences on Self-Assessments of Health. J Gerontol B Psychol Sci Soc Sci, 55(2), P107-P116.

Benyamini, Y., \& Roziner, I. (2008). The Predictive Validity of Optimism and Affectivity in a Longitudinal Study of Older Adults. Pers Indiv Differ, 44(4), 853-864.

Bosma, H., Schrijvers, C., \& Mackenbach, J. P. (1999). Socioeconomic inequalities in mortality and importance of perceived control: cohort study. BMJ, 319(7223), 1469-1470.

Boyle, S. H., Jackson, W. G., \& Suarez, E. C. (2007). Hostility, anger, and depression predict increases in C3 over a 10-year period. Brain Behav Immun, 21(6), 816-823.

Breeze, E., Fletcher, A. E., Leon, D. A., Marmot, M. G., Clarke, R. J., \& Shipley, M. J. (2001). Do socioeconomic disadvantages persist into old age? Self-reported morbidity in a 29-year follow-up of the Whitehall Study. Am J Public Health, 91(2), 277-283.

Brown, G. W., Andrews, B., Harris, T., Adler, Z., \& Bridge, L. (1986). Social support, self-esteem and depression. Psychol Med, 16(04), 813-831.

Buss, A. H., \& Perry, M. (1992). The aggression questionnaire. J Pers Soc Psychol, 63(3), 452-459.

Cano, A., Scaturo, D. J., Sprafkin, R. P., Lantinga, L. J., Fiese, B. H., \& Brand, F. (2003). Family Support, Self-Rated Health, and Psychological Distress. Prim Care Companion J Clin Psychiatry, 5(3), 111-117.

Chapman, B. P., Fiscella, K., Kawachi, I., \& Duberstein, P. R. (2009). Personality, socioeconomic status, and all-cause mortality in the United States. Am J Epidemiol, 171(1), 83-92.

Chida, Y., \& Steptoe, A. (2009). The association of anger and hostility with future coronary heart disease: a meta-analytic review of prospective evidence. J Am Coll Cardiol, 53(11), 936-946.

Deeg, D. J. H. (2002). Attrition in longitudinal population studies: Does it affect the generalizability of the findings? An introduction to the series. J Clin Epidemiol, 55, 213-215.

Denton, M., Prus, S., \& Walters, V. (2004). Gender differences in health: a Canadian study of the psychosocial, structural and behavioural determinants of health. Soc Sci Med, 58(12), 2585-2600.

Egan, M., Tannahill, C., Petticrew, M., \& Thomas, S. (2008). Psychosocial risk factors in home and community settings and their associations with population health and health inequalities: a systematic meta-review. BMC Public Health, 8, 239.

Eysenck, S. B. G., Eysenck, H. J., \& Barret, P. A. (1985). A revised version of the psychoticism scale. Pers Indiv Differ, 6, 21-29.

Felsten, G. (1996). Hostility, Stress and symptoms of depression. Pers Indiv Differ, 21(4), 461-467.

Gotlib, I. H., Lewinsohn, P. M., \& Seeley, J. R. (1995). Symptoms versus a diagnosis of depression: Differences in psychosocial functioning. J Consul Clin Psych, 63(1), 90-100.

Huisman, M., Kunst, A. E., Andersen, O., Bopp, M., Borgan, J. K., Borrell, C., et al. (2004). Socioeconomic inequalities in mortality among elderly people in 11 European populations. J Epidemiol Community Health, 58(6), 468-475.

Kempen, G. I., Miedema, I., van den Bos, G. A., \& Ormel, J. (1998). Relationship of domain-specific measures of health to perceived overall health among older subjects. J Clin Epidemiol, 51(1), 11-18.

Kempen, G. I., \& van Sonderen, E. (2002). Psychological attributes and changes in disability among lowfunctioning older persons: does attrition affect the outcomes? J Clin Epidemiol, 55(3), 224-229.

Kempen, G. I. J. M., \& Van Eijk, L. M. (1995). The psychometric properties of the SSL12-I, a short scale for measuring social support in the elderly. Soc Indic Res, 35, 303-312.

Kho, M. E., Duffett, M., Willison, D. J., Cook, D. J., \& Brouwers, M. C. (2009). Written informed consent and selection bias in observational studies using medical records: systematic review. BMJ, 338, b866.

Kiesler, D. J. (1996). Contemporary interpersonal theory and research: Personality, psychpathology, and psychotherapy. New York: John Wiley \& Sons. 
Klabbers, G., Bosma, H., van den Akker, M., van Boxtel, M. P., Kempen, G. I., McDermott, M. R., et al. (2009). Measuring rebelliousness and predicting health behaviour and outcomes: an investigation of the construct validity of the social reactivity scale. J Health Psychol, 14(6), 771-779.

Koster, A., Bosma, H., Kempen, G. I., Penninx, B. W., Beekman, A. T., Deeg, D. J., et al. (2006). Socioeconomic differences in incident depression in older adults: the role of psychosocial factors, physical health status, and behavioral factors. J Psychosom Res, 61(5), 619-627.

Kroenke, C. (2008). Socioeconomic status and health: Youth development and neomaterialist and psychosocial mechanisms. Soc Sci Med, 66(1), 31-42.

Kubzansky, L. D., Cole, S. R., Kawachi, I., Vokonas, P., \& Sparrow, D. (2006). Shared and unique contributions of anger, anxiety, and depression to coronary heart disease: a prospective study in the normative aging study. Ann Behav Med, 31(1), 21-29.

Kuper, H., Marmot, M., \& Hemingway, H. (2002). Systematic review of prospective cohort studies of psychosocial factors in the etiology and prognosis of coronary heart disease. Semin Vasc Med, 2(3), 267-314.

Luteijn, F., Starren, J., \& Van Dijk, H. (1985). Handleiding bij de NPV: Swets en Zeitlinger BV.

Martin, R., Watson, D., \& Wan, C. K. (2000). A three-factor model of trait anger: dimensions of affect, behavior, and cognition. J Pers, 68(5), 869-897.

McDermott, M. R., \& Apter, M. J. (1987). An introduction \& guide to the Negativism Dominance Scale. In M. R. McDermott (Ed.), Rebelliousness in adolescence and young adulthood. Cardiff: University of Wales.

Meesters, C., Muris, P., Bosma, H., Schouten, E., \& Beuving, S. (1996). Psychometric evaluation of the Dutch version of the Aggression Questionnaire. Behav Res Ther, 34(10), 839-843.

Mendis, S. (2010). The policy agenda for prevention and control of non-communicable diseases. Br Med Bull, 96, 23-43.

Miller, T. Q., Smith, T. W., Turner, C. W., Guijarro, M. L., \& Hallet, A. J. (1996). A meta-analytic review of research on hostility and physical health. Psychol Bull, 119(2), 322-348.

Nabi, H., Kivimaki, M., Zins, M., Elovainio, M., Consoli, S. M., Cordier, S., et al. (2008). Does personality predict mortality? Results from the GAZEL French prospective cohort study. Int J Epidemiol, 37(2), 386-396.

Nahit, E. S., Hunt, I. M., Lunt, M., Dunn, G., Silman, A. J., \& Macfarlane, G. J. (2003). Effects of psychosocial and individual psychological factors on the onset of musculoskeletal pain: common and sitespecific effects. Ann Rheum Dis, 62(8), 755-760.

Norušis, M. J. (2010). PASW Statistics 18 Statistical Procedures Companion: Prentice Hall.

Pearlin, L. I., \& Schooler, C. (1978). The structure of coping. J Health Soc Behav, 19(1), 2-21.

Penninx, B. W., Beekman, A. T., Honig, A., Deeg, D. J., Schoevers, R. A., van Eijk, J. T., et al. (2001). Depression and cardiac mortality: results from a community-based longitudinal study. Arch Gen Psychiatry, 58(3), 221-227.

Pincus, A. L., \& Ansell, E. B. (2003). Interpersonal theory of personality. In T. Millon, M. J. Lerner \& I. B. Weiner (Eds.), Handbook of psychology. Personality and social psychology. (Vol. 5, pp. 209-229). New York: John Wiley \& Sons, Inc.

Probst-Hensch, N. M. (2010). Chronic age-related diseases share risk factors: do they share pathophysiological mechanisms and why does that matter? Swiss Med Wkly, 140, w13072.

Roberts, B. W., Walton, K. E., \& Viechtbauer, W. (2006). Patterns of mean-level change in personality traits across the life course: a meta-analysis of longitudinal studies. Psychol Bull, 132(1), 1-25.

Rosenberg, M. (1965). Society and the adolescent self-image. Princeton, NJ: Princeton University Press.

Rugulies, R. (2002). Depression as a predictor for coronary heart disease. a review and meta-analysis. Am J Prev Med, 23(1), 51-61.

Schreurs, P. J. G., Tellegen, B., \& Van de Willige, G. (1984). Gezondheid, stress en coping; de ontwikkeling van de Utrechtse Copinglijst. Tijdschr Psychol, 12, 101-117.

Schwarz, G. E. (1987). Estimating the dimension of a model. Ann Stat, 6(2), 461-464. 
Sherer, M., Maddux, J. E., Mercandante, B., Prentice-Dunn, S., Jacobs, B., \& Rogers, R. W. (1982). The Self-efficacy Scale: Construction and validation. Psychol Rep(51), 663-671.

Smith, T. W. (1992). Hostility and health: current status of a psychosomatic hypothesis. Health Psychol, 11(3), 139-150.

Smith, T. W., Glazer, K., Ruiz, J. M., \& Gallo, L. C. (2004). Hostility, anger, aggressiveness, and coronary heart disease: an interpersonal perspective on personality, emotion, and health. J Pers, 72(6), 1217-1270.

Spinhoven, P., Ormel, J., Sloekers, P. P., Kempen, G. I., Speckens, A. E., \& van Hemert, A. M. (1997). A validation study of the Hospital Anxiety and Depression Scale (HADS) in different groups of Dutch subjects. Psychol Med, 27(2), 363-370.

Stansfeld, S. A. (2006). Social support and social cohesion. In M. Marmot \& R. G. Wilkinson (Eds.), Social determinants of health. (Second ed., pp. 148-171). Oxford: Oxford University Press.

Stansfeld, S. A., Bosma, H., Hemingway, H., \& Marmot, M. G. (1998). Psychosocial work characteristics and social support as predictors of SF-36 health functioning: the Whitehall II study. Psychosom Med, 60(3), 247-255.

Surtees, P. G., Wainwright, N. W., Luben, R., Day, N. E., \& Khaw, K. T. (2005). Prospective cohort study of hostility and the risk of cardiovascular disease mortality. Int J Cardiol, 100(1), 155-161.

Suurmeijer, T. P. B. M., Reuvekamp, M. F., \& Aldenkamp, B. P. (2001). Social functioning, psychological functioning, and quality of life in epilepsy. Epilepsia, 42(9), 1160-1168.

Taylor, S. E., \& Seeman, T. E. (1999). Psychosocial resources and the SES-health relationship. Ann $N Y$ Acad Sci, 896, 210-225.

Van den Akker, M., Buntinx, F., Metsemakers, J. F. M., van der Aa, M., \& Knottnerus, J. A. (2001). Psychosocial patient characteristics and GP-registered chronic morbidity: A prospective study. J Psychosom Res, 50(2), 95-102.

Van den Akker, M., Spigt, M. G., De Raeve, L., van Steenkiste, B., Metsemakers, J. F., van Voorst, E. J., et al. (2008). The SMILE study: A Study of Medical Information and Lifestyles in Eindhoven, the rationale and contents of a large prospective dynamic cohort study. BMC Public Health, 8(1), 19.

WHO. (2008). 2008-2013 Action Plan for the Global Strategy for the Prevention and Control of Noncommunicable diseases: World Health Organization.

Zigmond, A. S., \& Snaith, R. P. (1983). The Hospital Anxiety and Depression Scale. Acta Psychiatr Scand, 67(6), 361-370. 



\section{CHAPTER 6}

Early life poverty associated with poor self-rated health in late middle and old age: a pathway through psychosocial profiles

G. Klabbers, H. Bosma, G.I.J.M. Kempen, M. van den Akker, J.Th.M. van Eijk

Submitted. 


\section{Abstract}

Early life socioeconomic status has been associated with health status in later life, either through, or independent of, adulthood socioeconomic status. Apart from health behavioural risk, psychosocial functioning might be an important explanatory factor, being related not only to early life circumstances but also to health status. We set out to determine whether early life poverty was associated with self-rated health independently of adulthood socioeconomic status, and the extent to which the psychosocial profile contributed to this association. We used cross-sectional data on socio-demographics, early life poverty, psychosocial profile, health behaviours and self-rated health collected among 1688 late middle and older aged participants of the Dutch SMILE study. Data were collected between 2003 and 2005. Three psychosocial profiles were distinguished: those with an adverse, an average and a beneficial psychosocial profile. Logistic regression analyses were applied to calculate the association between early life poverty and self-rated health; we compared this with models separately and simultaneously including adulthood education, psychosocial profile, and health behaviours, adjusted for age and sex. Individuals who had experienced poverty in early life reported more often less than good health (OR $=1.52,95 \%$ $\mathrm{Cl}$ 1.06-2.18) than their better off counterparts, partially independent of adulthood educational level. The psychosocial profile explained a substantial part of the excess risk of early life poverty for less than good health, while health behaviours hardly contributed at all. These results suggest that health status in later life results from pathways starting in early life, with adverse socioeconomic conditions in that critical period sensitising people towards more adverse psychosocial functioning, leading in turn to poorer self-rated health compared with people who had a better start in life. 


\section{Introduction}

Early life socioeconomic circumstances have often been associated with health and life expectancy in adult life (Bosma, van de Mheen, \& Mackenbach, 1999; Danese et al., 2009; Hemmingsson \& Lundberg, 2005; Power et al., 2007; Power \& Hertzman, 1997). For instance, childhood disadvantage was found to significantly predict coronary heart disease and cardiac and all-cause mortality during adulthood in a population of 49,000 Swedish men (Hemmingsson \& Lundberg, 2005), and to poor self-rated health in a sample of 2,174 of a Dutch general population (Bosma, van de Mheen, et al., 1999), compared with people growing up in more favourable circumstances. Physical risk factors such as high inflammation levels, clustering of metabolic risk markers (Danese, et al., 2009; Power, et al., 2007), and adverse health behaviours (smoking, alcohol consumption and overweight) (Hemmingsson \& Lundberg, 2005; Power, et al., 2007; van de Mheen, Stronks, Looman, \& Mackenbach, 1998) were all found to be predicted by socioeconomic disadvantage during childhood and contributing to poorer adult health and premature mortality, compared to people who were better off during childhood. Whether or not these early life effects on health can be explained through adulthood socioeconomic status remains unclear, as evidence has been found for both independent (Bosma, van de Mheen, et al., 1999; Danese, et al., 2009) and dependent effects (Addo, Smeeth, \& Leon, 2009; Ben-Shlomo \& Smith, 1991; Ferrie, Martikainen, Shipley, \& Marmot, 2005) of childhood circumstances. Understanding of the timeframe in which future disease risk develops might contribute to improvement of the timing of interventions (Kuh, Ben-Shlomo, Lynch, Hallqvist, \& Power, 2003). Early life might be a 'critical period' for future health status.

Potentially underlying the adverse biological and behavioural make-up in later life (Brunner, 1997), adverse circumstances during upbringing might leave a definite psychological imprint on individuals, causing health problems at a later age. Parents might have to deal with poverty, a lack of basic goods, and unfavourable housing and working conditions; such circumstances are bound to cause depressive symptoms (Stansfeld, Head, Fuhrer, Wardle, \& Cattell, 2003), low control beliefs (Bosma, Schrijvers, \& Mackenbach, 1999), hostility (Carroll, Davey Smith, Sheffield, Shipley, \& Marmot, 1997; Klabbers et al., 2009), and unhealthy coping styles (Bosma, van de Mheen, Borsboom, \& Mackenbach, 2001), not only in the parents, but also in their children (Lynch, 1997; McEwen \& Seeman, 1999). Socioeconomic adversity in early life has been found to cause unhealthy personality change (Hart, Atkins, \& Matsuba, 2008), depressive and anxiety symptoms (Power, et al., 2007), external locus of control, neuroticism, and an avoidant coping style during adulthood (Bosma, van de Mheen, et al., 1999).

A combination of all the abovementioned psychosocial attributes might be even more health damaging than the separate attributes, and they might simulta- 
neously better characterize the cultural and psychosocial context in lower socioeconomic status groups; this context might leave a long-term psychosocial imprint in the offspring. In previous work, Klabbers et al. found evidence for possible synergism between different psychosocial characteristics by the formation of psychosocial profiles in their prediction of health (Klabbers et al, submitted, manuscript available upon request). Such a profile includes interrelated types of psychosocial attributes, such as aggressiveness and neuroticism, control beliefs, mood (depressed/anxious), coping styles, and social support. The adverse profile better predicted poor self-rated health than the separate characteristics did. It is likely, but not yet examined, that a person's psychosocial profile and makeup partially originate in childhood circumstances and that such profile is on the pathway between these circumstances and adulthood health status (Bosma, van de Mheen, et al., 1999; Chapman, Fiscella, Duberstein, Kawachi, \& Coletta, 2009).

Using cross-sectional data of the Dutch SMILE study in late middle-aged and older persons, we set out to determine whether early life poverty (as a proxy measurement for socioeconomic status) was associated with self-rated health independently of adulthood socioeconomic status. We further examined whether psychosocial profiles contributed to this association. To determine whether the effects of early life poverty and psychosocial profile are unique effects, contributions of health behaviours were taken into account.

\section{Methods}

\section{Design and participants}

We carried out a retrospective cohort study using cross-sectional data from the Dutch SMILE study: the Study of Medical Information and Lifestyles in Eindhoven (a city in the Southeast of the Netherlands) (Van den Akker et al., 2008). The SMILE study protocol was approved by the medical ethical committee of the Maastricht Academic Hospital. Starting in 2002, individuals (adolescents and adults) registered in one of the 9 participating health care centres (including 32 general practitioners, GPs) were asked to participate in this dynamic cohort study collecting self-reported data annually next to medical data. The participants aged 55 years and older are considered a specific subsample of the SMILE population; extensive data on psychosocial characteristics are collected in this subsample. Our psychosocial profiles were based on psychosocial data collection between 2003 and 2005 (for an extensive description see Klabbers et al, submitted, manuscript available upon request). In 2003, 4745 individuals aged 55 years and older filled out the questionnaires; 2635 (47\% men, mean age 69.1 years, SD=8.1) of whom participated in all three questionnaires $(2003,2004,2005)$ containing necessary data for this study. We 
subsequently excluded from the analyses those who had missing data on early life and adulthood socioeconomic status ( $\mathrm{N}=291)$, on any of the psychosocial variables $(\mathrm{N}=602)$, on health behaviours $(\mathrm{N}=50)$, and on self-rated health $(\mathrm{N}=4)$, leaving 1688 people eligible for analysis (mean age 67.8 years (SD 7.5), $49.2 \%$ male).

\section{Measures}

Early life socioeconomic status

Early life poverty, being a proxy for childhood socioeconomic status, was a 1-item measurement: 'During your childhood, was there ever a time when there was not enough money to buy food or replace worn-out clothes or shoes?' with answering categories (1) no, never, (2) yes, occasionally, (3) yes, often, and (4) yes, all the time. For purpose of clearly distinguishing structural poverty from occasional financial strain, we dichotomised this measure into (0) never or occasionally, and (1) often or all the time.

\section{Adulthood socioeconomic status}

Educational level was used as a proxy for socioeconomic status in adulthood, for it is a generic measure of socioeconomic status that is relevant to people regardless of age and therefore fits within a life-course perspective (Galobardes, Shaw, Lawlor, Lynch, \& Davey Smith, 2006). Education was classified into low (primary and lower secondary vocational), intermediate (apprenticeship system, general secondary and senior secondary vocational), and high (pre-university secondary, higher vocational, and university).

\section{Psychosocial profile}

Previous clustering based upon different psychosocial variables revealed three distinct groups of people. Cluster 1 had the most adverse scores on all psychosocial characteristics; this cluster primarily consisted of neurotic, depressed/anxious persons with low control beliefs. Cluster 2 had average scores on the psychosocial characteristics, and cluster 3 had the most beneficial scores; this group felt socially adequate, had high control beliefs, and reported positive affect (Klabbers et al, submitted, manuscript available upon request).

\section{Self-rated health}

Self-rated health was operationalised as a dichotomous variable: less than good health (1) versus good or very good health (0), based on the item: 'How would you rate your health in general?' with five answer categories: very good; good; fair; sometimes good and sometimes poor; poor. Good or very good health will hereafter be referred to as good health. 


\section{Covariates}

Age, sex, and health behaviours (smoking and alcohol consumption) were included as covariates in the analyses. Smoking was categorised as never, former and current smoking, alcohol consumption was defined as number of alcoholic beverages per week, and categorised into abstinence, normal consumption (1-21 beverages per week), excessive consumption (> 21 glasses per week) (WHO, 2004).

\section{Analyses}

First, the associations of early life poverty with adulthood education, psychosocial profile, health behaviours and self-rated health were determined by means of multinomial and binary logistic regression, depending on the measurement level of the dependent variable (Table 1). Second, binary logistic regression analyses were used to calculate the associations of adulthood education, psychosocial cluster, and health behaviours with self-rated health (Table 2). Third, the basic model predicting self-rated health from early life poverty was compared with models including adulthood education (model 2), psychosocial profile (model 3 ), health behaviours (model 4-5), and with a model including all variables simultaneously (model 6) and the attenuation of the odds ratio for self-rated health by early life poverty was calculated (Table 3). All analyses were adjusted for age and sex.

\section{Results}

People who experienced poverty during childhood were more likely to be less educated $(O R=2.71,95 \%$ confidence interval $(\mathrm{Cl}) 1.76-4.18)$, more likely to be a member of the adverse psychosocial cluster (OR $=1.87,95 \% \mathrm{Cl} 1.22-2.87)$, and more likely to report less than good health $(\mathrm{OR}=1.52,95 \% \mathrm{Cl} 1.06-2.18)$ compared with their better off counterparts (Table 1 ), adjusted for age and sex. The health behaviours were not significantly associated with early life poverty. 
Table 1 Associations between early life poverty (independent variable) and adulthood education, psychosocial clusters, health behaviours, and self-rated health (dependent variables) adjusted for age and sex: results of multinomial and binary regression analyses

\begin{tabular}{|c|c|c|c|c|c|}
\hline dependent variables & & $N=1688$ & Early life poverty \% & OR $(95 \% \mathrm{Cl})$ & $p$-value \\
\hline \multirow[t]{3}{*}{ adulthood education $^{a}$} & high & 530 & 6.2 & 1.00 & \\
\hline & intermediate & 625 & 8.8 & $1.41(0.90-2.22)$ & .14 \\
\hline & Low & 533 & 15.4 & $2.71(1.76-4.18)$ & $<.01$ \\
\hline \multirow[t]{3}{*}{ psychosocial clusters $^{\mathrm{a}}$} & beneficial & 623 & 7.9 & 1.00 & \\
\hline & average & 719 & 10.3 & $1.39(0.95-2.03)$ & .09 \\
\hline & adverse & 346 & 13.6 & $1.87(1.22-2.87)$ & $<.01$ \\
\hline \multirow[t]{3}{*}{ smoking $^{a}$} & never & 476 & 10.9 & 1.00 & \\
\hline & former & 896 & 8.5 & $0.82(0.56-1.21)$ & .32 \\
\hline & current & 316 & 13.3 & $1.32(0.85-2.07)$ & .22 \\
\hline \multirow[t]{3}{*}{ alcohol consumption $^{a}$} & normal use & 1304 & 10.0 & 1.00 & \\
\hline & abstinence & 148 & 12.8 & $1.31(0.78-2.21)$ & .31 \\
\hline & excessive use & 236 & 8.9 & $0.90(0.55-1.46)$ & .66 \\
\hline \multirow[t]{2}{*}{ self-rated health ${ }^{b}$} & good & 1326 & 9.3 & 1.00 & \\
\hline & less than good & 362 & 13.0 & $1.52(1.06-2.18)$ & .02 \\
\hline
\end{tabular}

${ }^{a}$ results of multinomial logistic regression modelling; classifying participants in the more unfavourable 2 categories with the most favourable category (reference); ${ }^{b}$ results of binary logic regression modelling

Being a member of the average or adverse psychosocial clusters was significantly associated with less than good health in a dose-response manner, OR $=2.90,95 \%$ $\mathrm{Cl}$ 2.05-4.10 and $\mathrm{OR}=9.93,95 \% \mathrm{Cl}$ 6.90-14.28 for average and adverse cluster membership respectively (Table 2). Further, low educational level was also associated with less than good health, $\mathrm{OR}=1.71,95 \% \mathrm{Cl} 1.26-2.31$. Smoking and excessive alcohol consumption were not associated with self rated health; abstinence was marginally significantly $(p<.10)$ associated with less than good health. 
Table 2 Associations between psychosocial cluster, adulthood education and health behaviours (independent variables) and self-rated health (dependent variable): results of binary logistic regression analyses

\begin{tabular}{|c|c|c|c|}
\hline \multicolumn{2}{|l|}{ independent variables } & \multirow{2}{*}{$\begin{array}{l}\mathrm{OR}(95 \% \mathrm{Cl}) \\
1.00\end{array}$} & \multirow[t]{2}{*}{$p$-value } \\
\hline adulthood education & high & & \\
\hline & intermediate & $1.22(0.90-1.66)$ & .20 \\
\hline & low & $1.71(1.26-2.31)$ & $<.01$ \\
\hline \multirow[t]{3}{*}{ psychosocial cluster } & beneficial & 1.00 & \\
\hline & average & $2.90(2.05-4.10)$ & $<.01$ \\
\hline & adverse & 9.93 (6.90-14.28) & $<.01$ \\
\hline \multirow[t]{3}{*}{ smoking } & never & 1.00 & \\
\hline & former & $1.21(0.90-1.61)$ & .20 \\
\hline & current & $1.30(0.91-1.87)$ & .15 \\
\hline \multirow[t]{3}{*}{ alcohol consumption } & normal use & 1.00 & \\
\hline & abstinence & $1.39(0.95-2.05)$ & .09 \\
\hline & excessive use & $0.98(0.69-1.41)$ & .93 \\
\hline
\end{tabular}

To determine the attenuation of the odds ratio for risk of less than good self-rated health by early life poverty, all variables were additionally included in the model, first separately, then simultaneously (Table 3 ). The odds ratios for early life poverty in baseline model 1 decreased by $21 \%$ after inclusion of adulthood education (model 2 ), leaving the odds ratio marginally significant $(p=.07)$. After including the psychosocial profile (model 3 ) the odds ratio for early life poverty decreased by $40 \%$ and lost statistical significance $(p=.17)$. Health behaviours hardly contributed to the model predicting less than good health from early life poverty. After simultaneous inclusion of all variables the reduction in odds ratio was $44 \%$. The attenuation and significance levels of the odds ratios suggest that psychosocial profiles explained a substantial part of the risk of less than good health for those who experienced early life poverty, independent of adulthood education. 
Table 3 Attenuation of the odds ratio of early life poverty for self-rated health by adulthood education (model 2), psychosocial profile (model 3), health behaviours (models $4-5$ ) separately, and by all variables simultaneously (model 6)

\begin{tabular}{|c|c|c|c|}
\hline Models & $\begin{array}{l}\text { OR ( } 95 \% \text { confidence } \\
\text { interval) }\end{array}$ & p-value & $\begin{array}{l}\text { Reduction in } \\
\text { odds ratio }^{a}(\%)\end{array}$ \\
\hline 1. early life poverty, age, sex & $1.52(1.06-2.18)$ & .02 & \\
\hline 2. early life poverty, age, sex, adulthood education & $1.41(0.98-2.03)$ & .07 & 21 \\
\hline 3. early life poverty, age, sex, psychosocial profile & $1.31(0.89-1.93)$ & .17 & 40 \\
\hline 4. early life poverty, age, sex, smoking & $1.51(1.05-2.17)$ & .03 & 2 \\
\hline 5. early life poverty, age, sex, alcohol consumption & $1.52(1.06-2.18)$ & .02 & 0 \\
\hline 6. early life poverty, age, sex, all variables & $1.29(0.87-1.90)$ & .20 & 44 \\
\hline
\end{tabular}

${ }^{a}$ calculated as: OR restricted model - OR extended model / OR extended model - 1(Lynch, Kaplan, Cohen, Tuomilehto, \& Salonen, 1996)

Further examination of the association between adulthood education and psychosocial profile by means of multinomial regression analyses showed that the odds for being a member of the average or adverse cluster increased as educational level decreased: $\mathrm{OR}=1.47,95 \% \mathrm{Cl} 1.28-1.69, \mathrm{p}<.01$ for average cluster and $\mathrm{OR}=2.21$, $95 \% \mathrm{Cl} 1.86-2.64, \mathrm{p}<.01$ for adverse cluster membership respectively (not tabulated).

\section{Discussion}

A substantial part of the unhealthy effects of early life poverty can be attributed to psychosocial adversities in later life, independent of adulthood education. Health behaviours hardly contributed in explaining the early life poverty risk of less than good health.

These results underscore the importance of a life-course perspective which interprets adult health status as directly originating from exposures in early life (latency model), or as originating in early life accumulating with life events throughout the life cycle, causing disease in later life (pathways model) (Braveman \& Barclay, 2009; Kuh, et al., 2003; Power \& Hertzman, 1997). We have not measured environmental stressors or life events (usually referred to when describing the pathways model), but the finding that adulthood education attenuated the risk of poor health as a consequence of early life poverty also supports the pathways model towards poor health in later life. Simultaneously, it is unclear where the contribution of the psychosocial profile should exactly be positioned along the lifecourse. Part of its contribution might be through psychosocial characteristics influ- 
encing educational attainment in adolescence and young adulthood (Bosma, 2006; Pulkkinen, Ohranen, \& Tolvanen, 1999), another part might be through educational attainment having an additional influence on the development of the psychosocial profile (Mickelson \& Kubzansky, 2003). This should be examined in more depth. Our study shows that, also independent of where a person ends up in educational terms, being raised in (relative) poverty tends to position him on a pathway to an "unhealthy" psychosocial profile. In a minimal interpretation, assuming psychosocial profile and adult education operate completely independently, the contribution of the psychosocial profile would be at least $21 \%$ (44\%-21\%-2\%, assuming smoking would have an independent effect as well). Given the finding they are associated, this contribution is probably even higher.

Poverty during early life appears to sensitise the individual to the development of a less advantageous psychosocial profile and less than good health; this is supported by previous results (Bosma, van de Mheen, et al., 1999; Danese, et al., 2009; Power \& Hertzman, 1997) regarding childhood as a critical period for adult psychosocial functioning and health. Small and colleagues (Small, Harding, \& Lamont, 2010) elaborating on the concept of "the culture of poverty", argued that there is no such thing as a uniform set of responses to poverty; in fact, heterogeneity is common. However, in our data, the way individuals perceive themselves and act upon it (the psychosocial profile) follows a clear social pattern: varying "unhealthy" psychosocial characteristics cluster within persons and are more prevalent in poor people (Klabbers et al., submitted, manuscript available upon request). To be able to prevent such adverse pathways, future longitudinal research should be designed to find out what exactly triggers the onset of an adverse psychosocial profile and at what life phase. A greater understanding might provide useful and tailored tools and - in order to diminish socioeconomic health inequalities - might optimise the timepoint (life stage) of using these tools. Awaiting these future studies, the present results could increase the awareness among professionals involved in child development (e.g. paediatricians and school doctors) of unhealthy psychosocial characteristics especially among children living in deprived circumstances.

Compared with the wealthy setting of the present study, in developing countries the prevalence of poverty probably is higher, poverty is likely to be more severe, and its health consequences probably worse. The question is whether the same mechanisms (psychosocial) contribute to health inequalities in developing countries. Although variations among developing countries must be acknowledged, it is likely that more direct health consequences should be added to the pathways underlying the poverty in childhood - health in adulthood association. Hunger and infectious diseases are more common and, next to short-term effects, might also have long-term effects on health (WHO, 2009). On the other hand, also in developing countries poverty is associated with anxiety, fear, feelings of insecurity and hopelessness, and lack of social relationships (Patel \& Kleinman, 2003) which sup- 
ports the relevance of the psychosocial pathway, also in developing countries. Hence, in developing countries, the relative contribution of psychosocial factors might be smaller, but still be of relevance. This is in need of further examination.

\section{Methodological limitations}

A study design like ours, based on retrospective and partially cross-sectional data, used to unravel associations, comes with several limitations. First, the simultaneous measurement of predictor (early life poverty), intermediate (psychosocial profile) and independent (self-rated health) variables, does not allow us to draw inferences on the sequence of the presumed pathways (health following psychosocial profile following early life poverty).

Second, the results might be biased by an unmeasured underlying variable, such as negative affectivity, which might have affected the scoring on both the psychosocial variables and the perception of health. However, in previous work we did establish the association between psychosocial profile and health at five years follow-up, independently of baseline health, which at least partially confirms a sequential order between psychosocial profile and health, and at the same time partially excludes the confounding influence of unmeasured negative affect (Klabbers et al., submitted, manuscript available upon request). Further, recall bias might have influenced the results as well, for the current health or psychosocial status might have affected the recollection of past poverty. Whether and to what extent these types of bias might have influenced our results remains uncertain. Future studies should unravel longitudinal pathways.

Third, the measurement of the health behaviours was not complete; data on exercise were not included in our analyses, since very few respondents completed this particular part of the questionnaire $(\mathrm{N}=970)$. Including this exercise variable did not contribute to the main association, nor did it change the pattern of the contributions of adulthood education and psychosocial profile. Therefore, we do not think that omitting exercise from the analyses has affected our results in any serious way.

Fourth, the number of respondents eligible for the analyses was smaller $(\mathrm{N}=1688)$ than the sample we started out with $(\mathrm{N}=4745)$ caused by attrition $(44 \%)$ and missing data. We compared the sample we used for the analyses with those who were lost to follow-up on age, sex, early life poverty and self-rated health. Individuals not included in the analyses were older (mean age difference 2.8 years, $p<.01)$ and less likely to be male $(43 \%$ versus $49 \%$ among those included, $p<.01$ ). Further, the (incomplete) data indicated poorer health $(p<.01)$ among nonparticipants, but no early life poverty differentials. Given the latter, it is unlikely that the effect of poverty is over- or underestimated in our analyses. 


\section{Conclusion}

The present results suggest that health status in later life results from pathways starting in early life, with adverse socioeconomic conditions in that critical period sensitising people towards a more adverse psychosocial profile, leading in the end to poorer health compared with people who had a better start in life. This effect of early life is independent of adulthood socioeconomic status and of health behaviours. Preferably, these results need be confirmed in future longitudinal research providing tailored tools for diminishing socioeconomic health inequalities. For now, the present study could increase the awareness among professionals involved in child development towards unhealthy psychosocial characteristics in those who grow up in deprived neighbourhoods. 


\section{References}

Addo, J., Smeeth, L., \& Leon, D. A. (2009). Socioeconomic position and hypertension: a study of urban civil servants in Ghana. J Epidemiol Community Health, 63(8), 646-650.

Ben-Shlomo, Y., \& Smith, G. D. (1991). Deprivation in infancy or in adult life: which is more important for mortality risk? Lancet, 337(8740), 530-534.

Bosma, H. (2006). Socio-economic differences in health: are control beliefs fundamental mediators? In J. Siegrist \& M. Marmot (Eds.), Social Inequalities in Health. New evidence and policy implications (pp. 153-166). Oxford: Oxford University Press.

Bosma, H., Schrijvers, C., \& Mackenbach, J. P. (1999). Socioeconomic inequalities in mortality and importance of perceived control: cohort study. BMJ, 319(7223), 1469-1470.

Bosma, H., van de Mheen, H. D., Borsboom, G. J., \& Mackenbach, J. P. (2001). Neighborhood socioeconomic status and all-cause mortality. Am J Epidemiol, 153(4), 363-371.

Bosma, H., van de Mheen, H. D., \& Mackenbach, J. P. (1999). Social class in childhood and general health in adulthood: questionnaire study of contribution of psychological attributes. BMJ, 318(7175), 1822.

Braveman, P., \& Barclay, C. (2009). Health disparities beginning in childhood: a life-course perspective. Pediatrics, 124 Suppl 3, S163-175.

Brunner, E. (1997). Stress and the biology of inequality. BMJ, 314(7092), 1472-1476.

Carroll, D., Davey Smith, G., Sheffield, D., Shipley, M. J., \& Marmot, M. G. (1997). The relationship between socioeconomic status, hostility, and blood pressure reactions to mental stress in men: data from the Whitehall II study. Health Psychol, 16(2), 131-136.

Chapman, B. P., Fiscella, K., Duberstein, P., Kawachi, I., \& Coletta, M. (2009). Can the influence of childhood socioeconomic status on men's and women's adult body mass be explained by adult socioeconomic status or personality? Findings from a national sample. Health Psychol, 28(4), 419-427.

Danese, A., Moffitt, T. E., Harrington, H., Milne, B. J., Polanczyk, G., Pariante, C. M., et al. (2009). Adverse childhood experiences and adult risk factors for age-related disease: depression, inflammation, and clustering of metabolic risk markers. Arch Pediatr Adolesc Med, 163(12), 1135-1143.

Ferrie, J. E., Martikainen, P., Shipley, M. J., \& Marmot, M. G. (2005). Self-reported economic difficulties and coronary events in men: evidence from the Whitehall II study. Int J Epidemiol, 34(3), 640-648.

Galobardes, B., Shaw, M., Lawlor, D. A., Lynch, J. W., \& Davey Smith, G. (2006). Indicators of socioeconomic position (part 2). J Epidemiol Community Health, 60(2), 95-101.

Hart, D., Atkins, R., \& Matsuba, M. K. (2008). The association of neighborhood poverty with personality change in childhood. J Pers Soc Psychol, 94(6), 1048-1061.

Hemmingsson, T., \& Lundberg, I. (2005). How far are socioeconomic differences in coronary heart disease hospitalization, all-cause mortality and cardiovascular mortality among adult Swedish males attributable to negative childhood circumstances and behaviour in adolescence? Int J Epidemiol, 34(2), 260-267.

Klabbers, G., Bosma, H., van Lenthe, F. J., Kempen, G. I., van Eijk, J. T., \& Mackenbach, J. P. (2009). The relative contributions of hostility and depressive symptoms to the income gradient in hospitalbased incidence of ischaemic heart disease: 12-Year follow-up findings from the GLOBE study. Soc Sci Med, 69(8), 1272-1280.

Kuh, D., Ben-Shlomo, Y., Lynch, J., Hallqvist, J., \& Power, C. (2003). Life course epidemiology. J Epidemiol Community Health, 57(10), 778-783.

Lynch, J. W., Kaplan, G. A., \& Salonen, J. T. (1997). Why do poor people behave poorly? Variation in adult health behaviours and psychosocial characteristics by stages of the socioeconomic lifecourse. Soc Sci Med, 44(6), 809-819.

Lynch, J. W., Kaplan, G. A., Cohen, R. D., Tuomilehto, J., \& Salonen, J. T. (1996). Do cardiovascular risk factors explain the relation between socioeconomic status, risk of all-cause mortality, cardiovascular mortality, and acute myocardial infarction? Am J Epidemiol, 144(10), 934-942. 
McEwen, B. S., \& Seeman, T. (1999). Protective and damaging effects of mediators of stress. Elaborating and testing the concepts of allostasis and allostatic load. Ann N Y Acad Sci, 896, 30-47.

Mickelson, K. D., \& Kubzansky, L. D. (2003). Social distribution of social support: the mediating role of life events. Am J Community Psychol, 32(3-4), 265-281.

Patel, V., \& Kleinman, A. (2003). Poverty and common mental disorders in developing countries. Bull World Health Organ, 81(8), 609-615.

Power, C., Atherton, K., Strachan, D. P., Shepherd, P., Fuller, E., Davis, A., et al. (2007). Life-course influences on health in British adults: effects of socio-economic position in childhood and adulthood. Int J Epidemiol, 36(3), 532-539.

Power, C., \& Hertzman, C. (1997). Social and biological pathways linking early life and adult disease. $\mathrm{Br}$ Med Bull, 53(1), 210-221.

Pulkkinen, L., Ohranen, M., \& Tolvanen, A. (1999). Personality Antecedents of Career Orientation and Stability among Women Compared to Men. J Vocat Behav, 54(1), 37-58.

Small, M. L., Harding, D. J., \& Lamont, M. I. (2010). Reconsidering Culture and Poverty. Ann Am Acad Polit SS, 629(1), 6-27.

Stansfeld, S. A., Head, J., Fuhrer, R., Wardle, J., \& Cattell, V. (2003). Social inequalities in depressive symptoms and physical functioning in the Whitehall II study: exploring a common cause explanation. J Epidemiol Community Health, 57(5), 361-367.

Van de Mheen, H., Stronks, K., Looman, C., \& Mackenbach, J. (1998). Does childhood socioeconomic status influence adult health through behavioural factors? Int J Epidemiol, 27(3), 431-437.

Van den Akker, M., Spigt, M. G., de Raeve, L., van Steenkiste, B., Metsemakers, J. F., van Voorst, E. J., et al. (2008). The SMILE study: A Study of Medical Information and Lifestyles in Eindhoven, the rationale and contents of a large prospective dynamic cohort study. BMC Public Health, 8(1), 19.

WHO. (2004). Global status report on alcohol 2004. Geneva: World Health Organisation, Department of mental health and substance abuse.

WHO. (2009). Global health risks: Mortality and burden of disease attributable to selected major risks. Geneva, Switzerland: WHO. 


\section{CHAPTER 7}

The educational patterning of health-related adversities in individuals with major depression.

G. Klabbers, H. Bosma, A.J.W. van der Does, N. Vogelzangs, G.I.J.M. Kempen, J.Th.M. van Eijk, B.W.J.H. Penninx

Journal of Affective Disorders, 2010, 126, 96-102. 


\section{Abstract}

Background: Major depressive disorder and depression severity are socially patterned, disfavouring individuals from lower socioeconomic groups. Depressive disorders are associated with several adverse health-related outcomes. We examined the educational patterning of somatic health, lifestyles, psychological function and treatment modalities in individuals suffering from major depressive disorder.

Methods: We used cross-sectional medical and psychiatric data from 992 participants of the Netherlands Study of Depression and Anxiety (NESDA) with a diagnosed current major depressive disorder. Associations of education with somatic, lifestyle-related, and psychological outcomes, and with treatment modalities, adjusted for depression severity, were examined by means of (multinomial and binary) logistic and linear regression analyses.

Results: In addition to and independent of major depressions being more severe in the less educated patients, metabolic syndrome, current smoking, low alcohol consumption, hopelessness and low control were more prevalent in a group of less educated individuals suffering from major depression, compared with their more highly educated peers. The less educated persons were more likely to be treated with antidepressant medication and less likely to receive psychotherapy treatment. None of these observations were explained by a higher depression severity in the less educated group.

Limitations: The cross-sectional design does not allow us to make direct causal inferences regarding the mutual influences of the different healthrelated outcomes.

Conclusions: Further research should explore the necessity and feasibility of routine screening for additional health risk, particularly among less educated depressed individuals. 


\section{Introduction}

Compelling evidence exists for a social patterning of major depressive disorders, disfavouring the poor and those with lower educational levels (Bruce, Takeuchi, \& Leaf, 1991; Lorant et al., 2003; Mojtabai \& Olfson, 2004). It is unknown, however, whether the adverse health-threatening conditions that are associated with major depression also follow a social gradient. The higher risk of persistence of the depression (Lorant, et al., 2003), as well as the higher rates of suicide and the shorter life-expectancy in socioeconomically disadvantaged depressed patients (Cuijpers \& Schoevers, 2004; Qin, Agerbo, \& Mortensen, 2003) may be related to the greater severity of the disorder in these patients. Inequalities in associated somatic morbidity (Meeks, Murrell, \& Mehl, 2000) and in particular an increased cardiac risk (Capuron et al., 2008; Kinder, Carnethon, Palaniappan, King, \& Fortmann, 2004; Raikkonen, Matthews, \& Kuller, 2002; Vogelzangs et al., 2007), unhealthier lifestyles (Van Gool et al., 2003), and poorer psychological function (Van der Does \& Williams, 2003; Van der Does, 2002) might also contribute, especially since these adversities also follow a socioeconomic gradient in the general population (Anda et al., 1993; Lynch, Kaplan, \& Salonen, 1997; Mackenbach, Kunst, Cavelaars, Groenhof, \& Geurts, 1997; Prescott, Godtfredsen, Osler, Schnohr, \& Barefoot, 2007). Previous studies also found inequalities in treatment (undertreatment with pharmacotherapy in those with lower socioeconomic status) (Kivimaki et al., 2007) and in the response to treatment (both pharmacotherapy and psychotherapy being less effective in those with the lowest socioeconomic status) (Falconnier, 2009). This possible accumulation of adversities in low socioeconomic status groups with depressive disorders warrants a detailed examination of the social patterning of somatic diseases, unhealthy lifestyles, poor psychological function and treatment modalities, in order to identify opportunities to tailor their treatment.

We used cross-sectional data from The Netherlands Study of Depression and Anxiety (NESDA) to examine the educational patterning of somatic health, lifestyles, psychological function and treatment modalities in individuals suffering from major depressive disorder.

Education was used as a proxy measure of socioeconomic status. We also examined the extent to which the educational patterning of adversities depends on the severity of the depression. 


\section{Method}

\section{Design and participants}

Participants were selected from those of the Netherlands Study of Depression and Anxiety (NESDA), which was designed to study the long-term course of depression and anxiety disorders in a naturalistic longitudinal cohort, and includes 2,981 respondents aged 18 to 65 years. These respondents were recruited from different health care settings, and include individuals in different stages of the developmental history of depressive and anxiety disorders. Exclusion criteria were a primary clinical diagnosis of a psychiatric disorder not subject of NESDA (e.g. psychotic or bipolar disorders), and not being fluent in Dutch. Recruitment lasted from 2004 until 2007, and the study will have an 8-year follow-up. A detailed description of the sampling procedure can be found elsewhere (Penninx et al., 2008).

The present study used psychiatric data; medical data; interview data on demographics, mental health care use and medication; and questionnaire data on lifestyles, presence of somatic diseases and psychological function. Inclusion criteria for the present analyses were a current (past 6 months) major depressive disorder and age 24 years or older. There were no further exclusion criteria. Our final sample comprised 992 participants. Major depressive disorders were diagnosed with the Composite Interview Diagnostic Instrument (CIDI, version 2.1) which classifies diagnoses according to the DSM-IV criteria (Association, 2001). Depression severity was classified as mild, moderate or severe according to CIDI guidelines. The age criterion was necessary for a more accurate assessment of completed education.

\section{Measures}

\section{Education}

Education was categorised into three levels. The high education group had completed higher vocational education or university education, the intermediate group had completed general secondary education or intermediate vocational education, and the low education group included participants who had not completed elementary education, or had completed only elementary, lower vocational or junior general secondary education.

\section{Somatic health}

Somatic health was measured by a standard self-report questionnaire on the number of somatic diseases (out of a list of 17 most common somatic conditions, e.g. stroke and rheumatic conditions) and by the presence of the metabolic syndrome, the latter being an established risk factor for cardiovascular disease (Dekker et al., 
2005). The metabolic syndrome was defined according to the revised guidelines of the National Cholesterol Education Program (NCEP) Adult Treatment panel III (ATP III) (Grundy et al., 2005; NCEP, 2001). The ATP III definition is based on the number of abnormalities, with the presence of three or more of the following abnormalities defining a case (yes/no) of the metabolic syndrome: waist circumference $>102 \mathrm{~cm}$ in men and $>88 \mathrm{~cm}$ in women, triglycerides $\geq 1.7 \mathrm{mmol} / \mathrm{L}$ or drug treatment for elevated trigyceride levels, high-density lipoprotein (HDL) cholesterol $<1.0 \mathrm{mmol} / \mathrm{L}$ in men and $<1.3 \mathrm{mmol} / \mathrm{L}$ in women or drug treatment for reduced $\mathrm{HDL}$-cholesterol levels, systolic blood pressure $\geq 130 \mathrm{~mm} \mathrm{Hg}$ or diastolic blood pressure $\geq 85 \mathrm{~mm} \mathrm{Hg}$ or drug treatment for hypertension, and fasting glucose $\geq 5.6 \mathrm{mmol} / \mathrm{L}$ or drug treatment for elevated glucose. The metabolic syndrome components were entered as dichotomous variables in the analyses, using the above cut-offs. Waist circumference was measured to the nearest $0.1 \mathrm{~cm}$ midway between the lower rib margin and the iliac crest following a normal expiration, over light clothing. A 50$\mathrm{mL}$ blood sample was drawn after an overnight fast, and was immediately transferred to a local lab to start processing within the hour. Serum glucose, HDL cholesterol and triglycerides were measured by standard laboratory methods. Systolic and diastolic blood pressure was measured twice on the right arm in a supine position using an electronic Omron sphygmomanometer, and averaged. Medication use in the past month was measured by drug container observation, and coded using the Anatomical Therapeutic Chemical (ATC) system to ascertain anti-dyslipidemic (C10AB, C10AD), anti-hypertensive (C02, C03, C07, C08, C09) and anti-diabetic (A10) medication use.

\section{Lifestyles}

Lifestyles included self-reported smoking (never, former or current), alcohol consumption and physical activity. Alcohol consumption was classified into low consumption ( $<1$ alcoholic beverage a week), moderate consumption (1-21 alcoholic beverages a week) and high to excessive consumption ( $>21$ alcoholic beverages a week) according to the WHO classification (WHO, 2004). Physical activity was measured by the International Physical Activity Questionnaire (short form), which calculates energy expenditure based on sports and other daily activities during the week (Craig et al., 2003). The total energy expenditure was calculated by summing the products of metabolic equivalent (MET value) per hour of activity, and the number of hours spent on that particular activity. This was classified into three levels of activity: low, moderate or high physical activity, based on the summary algorithms in the scoring protocol (IPAQ, 2005).

\section{Psychological function}

Psychological function was assessed by cognitive reactivity to sad mood, which was measured with the Leiden Index of Depression Sensitivity-Revised (LEIDS-R) (Van 
der Does \& Williams, 2003). The 34-item LEIDS-R scale was developed to assess the effects of sad mood on cognition and is related to an adverse course of the depression and suicidal ideation and behaviour (Segal, Gemar, \& Williams, 1999; Segal et al., 2003; Williams, van der Does, Barnhofer, Crane, \& Segal, 2008). The scale covers six domains: hopelessness (5 items), acceptance ( 5 items), aggression ( 6 items), perfectionism/control ( 6 items), risk aversion ( 6 items) and rumination ( 6 items) (Van der Does, 2002). Items were rated on a 5-point Likert scale, ranging from 0 (not at all) to 4 (very strongly), and summed per subscale. Example items are: 'When I feel down, I more often feel hopeless about everything' (hopelessness); and 'When in a sad mood, I more often think about how my life could have been different' (rumination). The LEIDS-R total scale score, indicating cognitive reactivity, is the sum of the subscale scores.

\section{Depression treatment}

Depression treatment was defined as any form of psychotherapy in the past six months (yes/no) and the use of psychotropic medication. Psychotherapy was defined as 'conversations about causes of and dealing with emotional problems' with a psychologist or psychiatrist. Psychotropic medication use (yes/no) was measured by drug container observation, and coded using the ATC system. We distinguished antidepressant medication, including selective serotonin reuptake inhibitors (SSRI, N06AB), tricyclic antidepressants (TCA, N06AA) and other antidepressants (N06AX, N06AG, and N06AF), as well as benzodiazepine derivatives (N05BA, N05CF, N05CD, and NO3AE).

\section{Statistical analyses}

Analyses of variance for age, number of somatic diseases and cognitive reactivity, and chi-square testing for all other variables provided insight into the educational patterning of somatic health, lifestyles, psychological function and depression treatment. Multinomial logistic regression modelling with educational level as the independent variable was used to study its associations with depression severity and with the lifestyle variables. Binary logistic regression modelling was used to study the associations between educational level (as an independent variable) and the metabolic syndrome and depression treatment. The association between educational level (as an independent variable) and the number of somatic diseases and psychological function were examined by means of linear regression modelling. The basic confounders age, sex and ethnicity were included in all regression analyses and depression severity was separately controlled for. Participants with missing values on a specific variable were excluded from the analyses which included that particular variable. 


\section{Results}

The sample comprised 341 men (34.4\%) and 651 women (65.6\%) (Table 1). Mean age was 43.2 yrs $(S D=10.5)$, and $92.1 \%$ of the sample were of Northern European ancestry. Individuals with a low educational level were older (44.6 years) than the more highly educated individuals (42.4 years). Most cases of severe major depression were found among the less educated individuals (42.9\%). These individuals also had more somatic diseases than their more highly educated peers ( 2.3 versus 1.9), and had the highest prevalence of the metabolic syndrome (30.9\% versus $16.2 \%)$ and its components, although the difference was not significant for glucose levels. Most current smokers were found among the less educated (53.6\% versus $33.2 \%$ among the highly educated respondents), and they were also most likely to report low physical activity levels, although this association was not statistically significant. Low alcohol consumption was more common among the less educated group than among the highly educated group ( $45.4 \%$ and $29.1 \%$, respectively), and excessive drinking was more common among the highly educated $(9.1 \%$ versus $6.0 \%$ among the less educated group). Hopelessness and acceptance reactivity were highest among the less educated. Psychotherapy was least prevalent among the less educated individuals (46.1\% versus $54.2 \%$ ), although the difference was not significant, whereas antidepressant medication use and benzodiazepine use were highest in this group (50.9\% and $19.7 \%$ versus $39.5 \%$ and $12.3 \%$, respectively).

Examination of the educational patterning of depression severity by means of multinomial regression, controlling for the basic confounders (results not tabulated), showed that less educated individuals had higher odds of moderate depression (OR=1.84; 95\% Cl 1.23-2.75), as well as higher odds of severe depression (OR=1.66; 95\% $\mathrm{Cl} 1.14-2.41$ ) than the more highly educated respondents. 
Table 1 Educational differences in sociodemographics, depression severity, somatic health, lifestyles, psychological function and depression treatment $(n=992)$

\begin{tabular}{|c|c|c|c|c|c|c|c|}
\hline & & $\begin{array}{c}\text { Sample } \\
\text { means } \\
\text { (SD) }\end{array}$ & $\begin{array}{c}\% \text { of total } \\
\text { sample }\end{array}$ & $\begin{array}{c}\text { high } \\
\text { education } \\
(\mathrm{N}=301)\end{array}$ & $\begin{array}{l}\text { intermediate } \\
\text { education } \\
(\mathrm{N}=320)\end{array}$ & $\begin{array}{c}\text { low } \\
\text { education } \\
(\mathrm{N}=371)\end{array}$ & $p$ value \\
\hline \multirow[t]{3}{*}{ Demographics } & Mean age ${ }^{a}$ & $43.2(10.5)$ & & 42.4 & 42.4 & 44.6 & .01 \\
\hline & Sex female & & 65.6 & 70.1 & 58.4 & 68.2 & $<.001$ \\
\hline & $\begin{array}{l}\text { Ethnicity North- } \\
\text { European ancestry }\end{array}$ & & 92.1 & 91.7 & 91.3 & 93.3 & .58 \\
\hline \multirow[t]{3}{*}{ Depression severity } & mild & & 28.2 & 34.6 & 27.5 & 23.7 & .02 \\
\hline & moderate & & 31.8 & 26.6 & 34.7 & 33.4 & \\
\hline & severe & & 40.0 & 38.9 & 37.8 & 42.9 & \\
\hline \multirow[t]{7}{*}{ Somatic health } & Mean no. of diseases ${ }^{a}$ & $2.0(1.6)$ & & 1.9 & 1.9 & 2.3 & $<.01$ \\
\hline & Metabolic syndrome & & 24.2 & 16.2 & 24.1 & 30.9 & $<.01$ \\
\hline & Waist circumference & & 37.8 & 26.2 & 36.7 & 48.2 & $<.001$ \\
\hline & Triglycerides & & 23.2 & 18.6 & 22.4 & 27.7 & .02 \\
\hline & HDL-cholesterol & & 14.5 & 12.1 & 12.1 & 18.6 & .02 \\
\hline & Blood pressure & & 61.8 & 53.2 & 63.6 & 67.4 & $<.001$ \\
\hline & Glucose & & 22.7 & 19.5 & 22.8 & 25.3 & .21 \\
\hline \multirow[t]{12}{*}{ Lifestyles } & Smoking status & & & & & & \\
\hline & current & & 45.8 & 33.2 & 48.4 & 53.6 & $<.001$ \\
\hline & former & & 29.6 & 37.2 & 27.8 & 25.1 & \\
\hline & never & & 24.6 & 29.6 & 23.8 & 21.3 & \\
\hline & Alcohol consumption & & & & & & \\
\hline & low & & 37.6 & 29.1 & 36.5 & 45.4 & $<.001$ \\
\hline & moderate & & 49.9 & 61.8 & 57.7 & 48.6 & \\
\hline & excessive & & 12.5 & 9.1 & 5.8 & 6.0 & \\
\hline & Physical activity & & & & & & \\
\hline & low & & 21.6 & 16.9 & 22.5 & 24.7 & .16 \\
\hline & moderate & & 36.4 & 40.2 & 35.3 & 34.1 & \\
\hline & high & & 42.0 & 42.9 & 42.2 & 41.2 & \\
\hline
\end{tabular}




\begin{tabular}{|c|c|c|c|c|c|c|c|}
\hline & & $\begin{array}{c}\text { Sample } \\
\text { means } \\
(\mathrm{SD})\end{array}$ & $\begin{array}{l}\% \text { of total } \\
\text { sample }\end{array}$ & $\begin{array}{c}\text { high } \\
\text { education } \\
(\mathrm{N}=301)\end{array}$ & $\begin{array}{l}\text { intermediate } \\
\text { education } \\
(\mathrm{N}=320)\end{array}$ & $\begin{array}{c}\text { low } \\
\text { education } \\
(\mathrm{N}=371)\end{array}$ & $\mathrm{p}$ value \\
\hline \multirow[t]{7}{*}{$\begin{array}{l}\text { Psychological } \\
\text { function }\end{array}$} & $\begin{array}{l}\text { Mean total cognitive } \\
\text { reactivity }^{a}\end{array}$ & $45.8(17.7)$ & & 45.9 & 45.6 & 46.1 & .95 \\
\hline & Mean hopelessness ${ }^{a}$ & $7.5(5.0)$ & & 7.0 & 7.4 & 8.0 & .05 \\
\hline & Mean acceptance ${ }^{a}$ & $2.0(2.4)$ & & 2.0 & 1.6 & 2.2 & .02 \\
\hline & Mean aggression ${ }^{a}$ & $6.2(4.8)$ & & 6.0 & 6.1 & 6.6 & .32 \\
\hline & Mean control ${ }^{a}$ & $6.8(4.0)$ & & 7.2 & 6.7 & 6.4 & .07 \\
\hline & Mean risk aversion ${ }^{a}$ & $11.1(4.5)$ & & 11.1 & 11.2 & 11.0 & .91 \\
\hline & Mean rumination ${ }^{\mathrm{a}}$ & $12.2(4.5)$ & & 12.6 & 12.4 & 11.8 & .09 \\
\hline \multirow{6}{*}{$\begin{array}{l}\text { Depression } \\
\text { treatment }\end{array}$} & Any psychotherapy & & 49.6 & 54.2 & 49.4 & 46.1 & .12 \\
\hline & Any antidepressant use & & 45.2 & 39.5 & 43.8 & 50.9 & .01 \\
\hline & TCA use & & 4.2 & 2.0 & 5.0 & 5.4 & .07 \\
\hline & SSRI use & & 30.2 & 27.6 & 28.8 & 33.7 & .18 \\
\hline & $\begin{array}{l}\text { Other antidepressant } \\
\text { use }\end{array}$ & & 11.8 & 10.6 & 10.9 & 13.5 & .44 \\
\hline & Benzodiazepine use & & 15.9 & 12.3 & 15.0 & 19.7 & .03 \\
\hline
\end{tabular}

${ }^{a}$ mean age, number of somatic diseases and cognitive reactivity are presented per educational category, with the mean differences tested by means of analysis of variance. For all other categorical variables, percentages within the three educational groups are presented, the differences being tested by chisquare statistic

The associations between educational level and the categorical outcome measures of metabolic syndrome, lifestyle and depression treatment were assessed using binary and multinomial logistic regression analyses. The educational patterning of the metabolic syndrome remained significant even after additionally adjusting for depression severity: $\mathrm{OR}=2.15 ; 95 \% \mathrm{Cl}$ 1.45-3.20 (Table 2A, models 1 and 2). This was true for each of the components of metabolic syndrome, although not significantly so for glucose levels. Current smoking was highly associated with educational level, even after controlling for depression severity $(\mathrm{OR}=2.25,95 \% \mathrm{Cl} 1.52-$ 3.33 for low educational level). Low alcohol consumption, but not excessive consumption, was associated with educational level (OR=2.06; $95 \% \mathrm{Cl} 1.46-2.90$ for the less educated), after controlling for depression severity. Physical activity was not significantly associated with educational level. Less educated individuals were less likely to receive psychotherapy, though this association was only marginally significant (OR=0.74; 95\% Cl 0.54-1.00). In contrast, these respondents were more likely to use any antidepressant medication (OR=1.48; $95 \% \mathrm{Cl} 1.08-2.02)$ than their more 
highly educated counterparts, independent of the severity of the depression. TCA use was higher among respondents with intermediate educational level (OR=2.67; 95\% $\mathrm{Cl} 1.03-6.95)$ and tended to be higher among the less educated individuals (OR=2.49, 95\% Cl 0.98-6.31), even after controlling for depression severity.

Table 2A Odds ratios (95\% confidence interval) of adverse dichotomous and categorical outcomes by education (highest educational level being the reference category) adjusted for age, sex and ethnicity in model 1 and additionally for depression severity in model 2

\begin{tabular}{|c|c|c|c|c|c|}
\hline \multirow[b]{2}{*}{ Health-related outcomes } & \multirow[b]{2}{*}{$N^{a}$} & \multicolumn{2}{|c|}{$\begin{array}{l}\text { Model } 1 \\
\text { Education + basic confounders }\end{array}$} & \multicolumn{2}{|c|}{$\begin{array}{l}\text { Model } 2 \\
\text { Education + basic confounders + } \\
\text { depression severity }\end{array}$} \\
\hline & & $\begin{array}{l}\text { Intermediate } \\
\text { education } \\
\text { OR }(95 \% \mathrm{Cl})\end{array}$ & $\begin{array}{l}\text { Low education } \\
\text { OR }(95 \% \mathrm{Cl})\end{array}$ & $\begin{array}{l}\text { Intermediate } \\
\text { education } \\
\text { OR }(95 \% \mathrm{Cl})\end{array}$ & $\begin{array}{l}\text { Low education } \\
\text { OR }(95 \% \mathrm{Cl})\end{array}$ \\
\hline \multicolumn{6}{|l|}{ Somatic health ${ }^{b}$} \\
\hline Metabolic syndrome & 972 & $1.60(1.06-2.43)$ & $2.24(1.51-3.32)$ & $1.58(1.04-2.40)$ & $2.15(1.45-3.20)$ \\
\hline Waist circumference & 989 & $1.75(1.23-2.50)$ & $2.53(1.81-3.54)$ & $1.74(1.22-2.49)$ & $2.46(1.75-3.45)$ \\
\hline Triglycerides & 970 & $1.14(0.75-1.72)$ & $1.63(1.11-2.41)$ & $1.11(0.73-1.68)$ & $1.56(1.06-2.31)$ \\
\hline HDL-cholesterol & 971 & $1.09(0.67-1.79)$ & $1.73(1.11-2.70)$ & $1.08(0.66-1.77)$ & $1.66(1.06-2.60)$ \\
\hline Blood pressure & 988 & $1.40(0.98-2.01)$ & $1.66(1.18-2.35)$ & $1.40(0.98-2.00)$ & $1.64(1.16-2.32)$ \\
\hline Glucose & 974 & $1.17(0.78-1.76)$ & $1.31(0.89-1.94)$ & $1.16(0.77-1.75)$ & $1.29(0.87-1.90)$ \\
\hline \multicolumn{6}{|l|}{ Lifestyles $^{c}$} \\
\hline \multicolumn{6}{|l|}{ Smoking } \\
\hline former & 992 & $0.90(0.59-1.37)$ & $0.85(0.56-1.29)$ & $0.91(0.60-1.39)$ & $0.87(0.57-1.32)$ \\
\hline current & & $1.79(1.20-2.67)$ & $2.28(1.55-3.37)$ & $1.78(1.19-2.66)$ & $2.25(1.52-3.33)$ \\
\hline \multicolumn{6}{|l|}{ Alcohol consumption } \\
\hline low & 974 & $1.46(1.02-2.08)$ & $2.11(1.50-2.97)$ & $1.45(1.01-2.07)$ & $2.06(1.46-2.90)$ \\
\hline excessive & & $0.60(0.31-1.13)$ & $0.79(0.43-1.44)$ & $0.59(0.31-1.12)$ & $0.77(0.42-1.42)$ \\
\hline \multicolumn{6}{|l|}{ Physical activity } \\
\hline moderate & 990 & $0.89(0.63-1.27)$ & $0.87(0.62-1.23)$ & $0.89(0.62-1.26)$ & $0.86(0.61-1.21)$ \\
\hline low & & $1.32(0.85-2.04)$ & $1.51(0.99-2.30)$ & $1.31(0.85-2.02)$ & $1.48(0.97-2.25)$ \\
\hline \multicolumn{6}{|l|}{ Depression treatment ${ }^{b}$} \\
\hline Any psychotherapy & 992 & $0.83(0.60-1.14)$ & $0.73(0.55-1.02)$ & $0.82(0.60-1.13)$ & $0.74(0.54-1.00)$ \\
\hline Any antidepressant use & 992 & $1.20(0.87-1.65)$ & $1.54(1.13-2.10)$ & $1.18(0.85-1.63)$ & $1.48(1.08-2.02)$ \\
\hline TCA use & 992 & $2.68(1.03-6.96)$ & $2.54(1.00-6.45)$ & $2.67(1.03-6.95)$ & $2.49(0.98-6.31)$ \\
\hline SSRI use & 992 & $1.08(0.76-1.54)$ & $1.34(0.96-1.87)$ & $1.07(0.75-1.53)$ & $1.32(0.94-1.84)$ \\
\hline Other antidepressant use & 992 & $0.99(0.60-1.66)$ & $1.26(0.78-2.02)$ & $0.97(0.58-1.62)$ & $1.18(0.73-1.91)$ \\
\hline Benzodiazepine use & 992 & $1.29(0.81-2.07)$ & $1.58(1.02-2.44)$ & $1.28(0.79-2.05)$ & $1.50(0.97-2.34)$ \\
\hline
\end{tabular}

${ }^{a}$ missings were listwise deleted; ${ }^{b}$ odds ratios for the metabolic syndrome and depression treatment are based on logistic regression analyses; ${ }^{c}$ odds ratios for the lifestyle factors are based on multinomial regression analyses, the reference category being the most healthy category (never smoker, moderate alcohol consumption and high physical activity, respectively) 
The results of the linear regression analyses show that the higher number of diseases in less educated individuals was no longer significant after adjusting for depression severity (Table 2B, models 1 and 2). The higher hopelessness reactivity remained marginally significant among respondents with a low educational level after depression severity was included $(b=0.80, p=0.05)$. Lower acceptance was found among the respondents with an intermediate educational level $(b=-0.42$, $p=0.04)$. Control and rumination reactivity were lower among the less educated respondents $(b=-0.76, p=0.03$ and $b=-0.88, p=0.02$ respectively).

Linear regression analyses were also applied to the continuous measures of the metabolic syndrome components, in order to examine the consistency of the results (not tabulated). These analyses resulted in a pattern similar to that presented in Table 2A, with higher risks for the less educated respondents. Again, glucose levels were not significantly associated with educational levels and neither were the individual measures of systolic and diastolic blood pressure.

Table 2B b coefficients of adverse continuous outcomes by education (highest educational level being the reference category) adjusted for age, sex and ethnicity in model 1 and additionally for depression severity in model 2

\begin{tabular}{|c|c|c|c|c|c|}
\hline \multirow[b]{2}{*}{ Health-related outcomes } & \multirow[b]{2}{*}{$N^{a}$} & \multicolumn{2}{|c|}{$\begin{array}{l}\text { Model } 1 \\
\text { Education + basic confounders }\end{array}$} & \multicolumn{2}{|c|}{$\begin{array}{l}\text { Model } 2 \\
\text { Education + basic confounders + } \\
\text { depression severity }\end{array}$} \\
\hline & & $\begin{array}{l}\text { Intermediate } \\
\text { education } \\
\text { b coefficient }\end{array}$ & $\begin{array}{l}\text { Low } \\
\text { education } \\
\text { b coefficient }\end{array}$ & $\begin{array}{l}\text { Intermediate } \\
\text { education } \\
\text { b coefficient }\end{array}$ & $\begin{array}{l}\text { Low } \\
\text { education } \\
\text { b coefficient }\end{array}$ \\
\hline \multicolumn{6}{|l|}{ Somatic health } \\
\hline No. of somatic diseases & 987 & $-0.07(-0.32-0.19)$ & $0.27(0.03-0.51)$ & $-0.08(-0.33-0.17)$ & $0.24(-0.01-0.48)$ \\
\hline \multicolumn{6}{|l|}{ Psychological function } \\
\hline Total cognitive reactivity & 826 & $-0.61(-3.61-2.39)$ & $0.54(-2.45-3.53)$ & $-0.88(-3.78-2.02)$ & $-0.34(-3.24-2.57)$ \\
\hline Hopelessness & 827 & $0.43(-0.42-1.27)$ & $1.08(0.24-1.93)$ & $0.34(-0.47-1.15)$ & $0.80(-0.02-1.61)$ \\
\hline Acceptance & 826 & $-0.41(-0.81--0.01)$ & $0.15(-0.25-0.54)$ & $0.42(-0.82--0.02)$ & $0.11(-0.29-0.51)$ \\
\hline Aggression & 827 & $-0.10(-0.90-0.70)$ & $0.71(-0.09-1.51)$ & $-0.16(-0.94-0.63)$ & $0.53(-0.26-1.31)$ \\
\hline Control & 828 & $-0.49(-1.16-0.19)$ & $-0.69(-1.36--0.01)$ & $-0.51(-1.18-0.16)$ & $-0.76(-1.43--0.09)$ \\
\hline Risk aversion & 829 & $0.03(-0.73-0.79)$ & $-0.04(-0.80-0.72)$ & $-0.02(-0.77-0.73)$ & $-0.18(-0.93-0.58)$ \\
\hline Rumination & 827 & $-0.17(-0.93-0.59)$ & $-0.71(-1.47-0.05)$ & $-0.23(-0.97-0.52)$ & $-0.88(-1.63--0.13)$ \\
\hline
\end{tabular}

\footnotetext{
${ }^{\mathrm{a}}$ missings were listwise deleted
} 


\section{Discussion}

Among individuals with major depressive disorder, health-related adversities accumulated in the less educated. To our knowledge, this is the first study to examine the educational patterning of multiple health-related outcomes in a group of individuals with major depression. We confirmed previous findings about depression severity being higher among the less educated (Mojtabai \& Olfson, 2004). We also found substantially higher levels of health-related adversities across somatic (metabolic syndrome), lifestyle (current smoking and low alcohol consumption), and psychological (hopelessness, control) domains in this group, independent of depression severity. Finally, the less educated individuals were more likely to use antidepressant medication and tended to receive less psychotherapy. These results also remained significant after controlling for the higher depression severity levels in less educated individuals.

A possible explanation for the higher levels of health-related adversities in the group of less educated persons with major depression may be that these individuals are more susceptible to all kinds of adversity than those with higher socioeconomic status. For instance, elevated inflammatory markers have also been reported in these groups (Gimeno et al., 2007; Koster et al., 2006). The different adversities might also add up, leading to an ever-increasing health risk over the course of life (Kop, 1999, 2003; Kuh, Ben-Shlomo, Lynch, Hallqvist, \& Power, 2003; Lynch, Kaplan, \& Shema, 1997). For instance, major depression and daily smoking reinforce each other (Breslau, Peterson, Schultz, Chilcoat, \& Andreski, 1998). Smoking has been found to increase the risk of developing metabolic syndrome (Wannamethee, Shaper, \& Whincup, 2006), the metabolic syndrome is associated with hopelessness (Valtonen et al., 2008), and antidepressant use is associated with hypertension (Licht et al., 2009). These complex mechanisms also relate to the potential accumulation of negative vicious cycles and reciprocal associations during the whole course of life of individuals from lower socioeconomic backgrounds. However, the cross-sectional design of the current study does not allow us to make any direct causal inferences regarding the mutual influences of the adverse outcomes.

The low alcohol consumption among the less educated respondents is in line with the findings of previous studies, which showed that individuals with the lowest educational attainment were more likely to abstain than more highly educated individuals (Bloomfield, Grittner, Kramer, \& Gmel, 2006). It has been suggested that, compared to moderate drinking, total abstinence is less beneficial to cardiovascular health, as it results in lower concentrations of HDL cholesterol (Marmot \& Brunner, 1991). Both increased cardiac risk (through higher prevalence of the metabolic syndrome) and lower HDL cholesterol concentrations were found among the less educated respondents in our study. Although major depression is associ- 
ated with heavy alcohol use in the general population (Grant \& Harford, 1995), excessive drinking was not educationally patterned in our population of individuals with major depression.

Our results did not confirm undertreatment with antidepressants among the less educated group (Kivimaki, et al., 2007); antidepressant use was in fact higher in this group, independent of the severity of the depression. Rather, the inequalities reflect previous findings that people of lower socioeconomic status tend to prefer medication, whereas patients from higher socioeconomic status groups generally prefer psychotherapy (Angermeyer \& Matschinger, 1999; McKeon \& Carrick, 1991; Van Schaik et al., 2004). Our finding that less educated individuals were less likely to receive psychotherapy - though the difference was only marginally significant seems to confirm these preferences. It seems unlikely that this educational patterning is explained by differential access to mental health care, since psychotherapy is covered by the compulsory national medical insurance scheme in the Netherlands. However, although antidepressant therapy and psychotherapy have proved to be equally effective (Mynors-Wallis, Gath, Day, \& Baker, 2000), negative cognitions, which increase the risk of recurrence of depression after remission (Van der Does, 2002), remain untargeted in pharmacotherapy. Less educated individuals indeed had the highest scores for hopelessness and the lowest control reactivity scores, although their rumination scores were lower. If these hopelessness scores persist into remission, they might predict higher rates of relapse. In view of the less favourable responses to both psychotherapy and pharmacotherapy in the lowest socioeconomic categories of depressed individuals (Falconnier, 2009), further study is needed to identify how the educational differences in treatment might affect the course of major depression.

Some remaining issues regarding our measurements need to be addressed. The data for most of the variables were complete, except for the psychological data, which had 164 to 166 missing scores (16.5\%-16.7\%). The reason is that these data were derived from questionnaires filled in by participants at home after the assessments at the hospital, and not all participants returned the questionnaire. To check the robustness of our findings, we repeated all analyses in a sub-sample of participants with complete data $(\mathrm{N}=792)$. These analyses basically yielded similar results. Further, the use of a structured clinical interview for diagnosing major depressive disorder, the availability of medical data and the relatively large number of participants in this study add to the validity of its findings.

\section{Conclusion}

Among less educated individuals with major depression, there was a strikingly consistent higher prevalence of health-related adversities across multiple domains, 
which could not be explained by greater depression severity in the less educated group. Independent of depression severity, less educated individuals were more likely to use antidepressant medication, and tended to receive less psychotherapy than the more highly educated respondents. Further research is needed to examine the implications of these educational inequalities in the treatment of depression, and to explore the necessity and feasibility of routine screening for additional health risk among less educated depressed individuals. 


\section{References}

Anda, R., Williamson, D., Jones, D., Macera, C., Eaker, E., Glassman, A., et al. (1993). Depressed affect, hopelessness, and the risk of ischemic heart disease in a cohort of U.S. adults. Epidemiology, 4(4), 285-294.

Angermeyer, M. C., \& Matschinger, H. (1999). Lay beliefs about mental disorders: a comparison between the western and the eastern parts of Germany. Soc Psychiatry Psychiatr Epidemiol, 34(5), 275-281.

American Psychiatric Association (2001). Diagnostic and statistical manual of mental disorders, fourth edition. Washington.

Bloomfield, K., Grittner, U., Kramer, S., \& Gmel, G. (2006). Social inequalities in alcohol consumption and alcohol-related problems in the study countries of the EU concerted action 'Gender, Culture and Alcohol Problems: a Multi-national Study'. Alcohol Alcohol Suppl, 41(1), i26-36.

Breslau, N., Peterson, E. L., Schultz, L. R., Chilcoat, H. D., \& Andreski, P. (1998). Major depression and stages of smoking. A longitudinal investigation. Arch Gen Psychiatry, 55(2), 161-166.

Bruce, M. L., Takeuchi, D. T., \& Leaf, P. J. (1991). Poverty and psychiatric status. Longitudinal evidence from the New Haven Epidemiologic Catchment Area study. Arch Gen Psychiatry, 48(5), 470-474.

Capuron, L., Su, S., Miller, A. H., Bremner, J. D., Goldberg, J., Vogt, G. J., et al. (2008). Depressive symptoms and metabolic syndrome: Is inflammation the underlying link? Biol Psychiatry, 64(10), 896900.

Craig, C. L., Marshall, A. L., Sjostrom, M., Bauman, A. E., Booth, M. L., Ainsworth, B. E., et al. (2003). International Physical Activity Questionnaire: 12-country reliability and validity. Med Sci Sports Exerc, 35(8), 1381-1395.

Cuijpers, P., \& Schoevers, R. A. (2004). Increased mortality in depressive disorders: a review. Curr Psychiatry Rep, 6(6), 430-437.

Dekker, J. M., Girman, C., Rhodes, T., Nijpels, G., Stehouwer, C. D., Bouter, L. M., et al. (2005). Metabolic syndrome and 10-year cardiovascular disease risk in the Hoorn Study. Circulation, 112(5), 666-673.

Falconnier, L. (2009). Socioeconomic status in the treatment of depression. Am J Orthopsychiatry, 79(2), 148-158.

Gimeno, D., Brunner, E. J., Lowe, G. D., Rumley, A., Marmot, M. G., \& Ferrie, J. E. (2007). Adult socioeconomic position, C-reactive protein and interleukin-6 in the Whitehall II prospective study. Eur J Epidemiol.

Grant, B. F., \& Harford, T. C. (1995). Comorbidity between DSM-IV alcohol use disorders and major depression: results of a national survey. Drug Alcohol Depend, 39(3), 197-206.

Grundy, S. M., Cleeman, J. I., Daniels, S. R., Donato, K. A., Eckel, R. H., Franklin, B. A., et al. (2005). Diagnosis and management of the metabolic syndrome: an American Heart Association/National Heart, Lung, and Blood Institute Scientific Statement. Circulation, 112(17), 2735-2752.

IPAQ (Cartographer). (2005). Guidelines for data processing and analysis of the International Physical Activity Questionnaire (IPAQ). Short and long forms.

Kinder, L. S., Carnethon, M. R., Palaniappan, L. P., King, A. C., \& Fortmann, S. P. (2004). Depression and the metabolic syndrome in young adults: findings from the Third National Health and Nutrition Examination Survey. Psychosom Med, 66(3), 316-322.

Kivimaki, M., Gunnell, D., Lawlor, D. A., Davey Smith, G., Pentti, J., Virtanen, M., et al. (2007). Social inequalities in antidepressant treatment and mortality: a longitudinal register study. Psychol Med, 37(3), 373-382.

Kop, W. J. (1999). Chronic and acute psychological risk factors for clinical manifestations of coronary artery disease. Psychosom Med, 61(4), 476-487.

Kop, W. J. (2003). The integration of cardiovascular behavioral medicine and psychoneuroimmunology: new developments based on converging research fields. Brain Behav Immun, 17(4), 233-237.

Koster, A., Bosma, H., Penninx, B. W., Newman, A. B., Harris, T. B., van Eijk, J. T., et al. (2006). Association of inflammatory markers with socioeconomic status. J Gerontol A Biol Sci Med Sci, 61(3), 284-290. 
Kuh, D., Ben-Shlomo, Y., Lynch, J., Hallqvist, J., \& Power, C. (2003). Life course epidemiology. J Epidemiol Community Health, 57(10), 778-783.

Licht, C. M., de Geus, E. J., Seldenrijk, A., van Hout, H. P., Zitman, F. G., van Dyck, R., et al. (2009). Depression is associated with decreased blood pressure, but antidepressant use increases the risk for hypertension. Hypertension, 53(4), 631-638.

Lorant, V., Deliege, D., Eaton, W., Robert, A., Philippot, P., \& Ansseau, M. (2003). Socioeconomic inequalities in depression: a meta-analysis. Am J Epidemiol, 157(2), 98-112.

Lynch, J. W., Kaplan, G. A., \& Salonen, J. T. (1997). Why do poor people behave poorly? Variation in adult health behaviours and psychosocial characteristics by stages of the socioeconomic lifecourse. Soc Sci Med, 44(6), 809-819.

Lynch, J. W., Kaplan, G. A., \& Shema, S. J. (1997). Cumulative impact of sustained economic hardship on physical, cognitive, psychological, and social functioning. N Engl J Med, 337(26), 1889-1895.

Mackenbach, J. P., Kunst, A. E., Cavelaars, A. E., Groenhof, F., \& Geurts, J. J. (1997). Socioeconomic inequalities in morbidity and mortality in western Europe. The EU Working Group on Socioeconomic Inequalities in Health. Lancet, 349(9066), 1655-1659.

Marmot, M., \& Brunner, E. (1991). Alcohol and cardiovascular disease: the status of the U shaped curve. BMJ, 303(6802), 565-568.

McKeon, P., \& Carrick, S. (1991). Public attitudes to depression: a national survey. Irish J Psychol Med, 8, 116-121.

Meeks, S., Murrell, S. A., \& Mehl, R. C. (2000). Longitudinal relationships between depressive symptoms and health in normal older and middle-aged adults. Psychol Aging, 15(1), 100-109.

Mojtabai, R., \& Olfson, M. (2004). Major depression in community-dwelling middle-aged and older adults: prevalence and 2- and 4-year follow-up symptoms. Psychol Med, 34(4), 623-634.

Mynors-Wallis, L. M., Gath, D. H., Day, A., \& Baker, F. (2000). Randomised controlled trial of problem solving treatment, antidepressant medication, and combined treatment for major depression in primary care. BMJ, 320(7226), 26-30.

NCEP. (2001). Executive Summary of The Third Report of The National Cholesterol Education Program (NCEP) Expert Panel on Detection, Evaluation, And Treatment of High Blood Cholesterol In Adults (Adult Treatment Panel III). Jama, 285(19), 2486-2497.

Penninx, B. W., Beekman, A. T., Smit, J. H., Zitman, F. G., Nolen, W. A., Spinhoven, P., et al. (2008). The Netherlands Study of Depression and Anxiety (NESDA): rationale, objectives and methods. Int $J$ Methods Psychiatr Res, 17(3), 121-140.

Prescott, E., Godtfredsen, N., Osler, M., Schnohr, P., \& Barefoot, J. (2007). Social gradient in the metabolic syndrome not explained by psychosocial and behavioural factors: evidence from the Copenhagen City Heart Study. Eur J Cardiov PrevR, 14, 405-412.

Qin, P., Agerbo, E., \& Mortensen, P. B. (2003). Suicide risk in relation to socioeconomic, demographic, psychiatric, and familial factors: a national register-based study of all suicides in Denmark, 19811997. Am J Psychiatry, 160(4), 765-772.

Raikkonen, K., Matthews, K. A., \& Kuller, L. H. (2002). The relationship between psychological risk attributes and the metabolic syndrome in healthy women: antecedent or consequence? Metabolism, 51(12), 1573-1577.

Segal, Z. V., Gemar, M., \& Williams, S. (1999). Differential cognitive response to a mood challenge following successful cognitive therapy or pharmacotherapy for unipolar depression. J Abnorm Psychol, 108(1), 3-10.

Segal, Z. V., Kennedy, S., Gemar, M., Sagrati, S., Hood, K., \& Pedersen, R. (2003). Using mood induction to activatedepression relapse vulnerability following cognitive or pharmacological treatment. Paper presented at the Society for Research in psychopathology.

Valtonen, M., Laaksonen, D. E., Tolmunen, T., Nyyssonen, K., Viinamaki, H., Kauhanen, J., et al. (2008). Hopelessness -- novel facet of the metabolic syndrome in men. Scand J Public Health, 36(8), 795802. 
Van der Does, A. J. W., \& Williams, J. M. G. (2003). Leiden Index of Depression Sensitivity-Revised (LEIDS$R)$. Leiden: Leiden University.

Van der Does, W. (2002). Cognitive reactivity to sad mood: structure and validity of a new measure. Behav Res Ther, 40(1), 105-120.

Van Gool, C. H., Kempen, G. I., Penninx, B. W., Deeg, D. J., Beekman, A. T., \& van Eijk, J. T. (2003). Relationship between changes in depressive symptoms and unhealthy lifestyles in late middle aged and older persons: results from the Longitudinal Aging Study Amsterdam. Age Ageing, 32(1), 81-87.

Van Schaik, D. J., Klijn, A. F., van Hout, H. P., van Marwijk, H. W., Beekman, A. T., de Haan, M., et al. (2004). Patients' preferences in the treatment of depressive disorder in primary care. Gen Hosp Psychiatry, 26(3), 184-189.

Vogelzangs, N., Suthers, K., Ferrucci, L., Simonsick, E. M., Ble, A., Schrager, M., et al. (2007). Hypercortisolemic depression is associated with the metabolic syndrome in late-life. Psychoneuroendocrinology, 32(2), 151-159.

Wannamethee, S. G., Shaper, A. G., \& Whincup, P. H. (2006). Modifiable lifestyle factors and the metabolic syndrome in older men: Effects of lifestyle changes. J Am Geriatr Soc, 54(12), 1909-1914.

WHO. (2004). Global status report on alcohol 2004. Geneva: World Health Organisation, Department of mental health and substance abuse.

Williams, J. M. G., Van der Does, A. J. W., Barnhofer, T., Crane, C., \& Segal, Z. S. (2008). Cognitive reactivity, suicidal ideation and future fluency: preliminary investigation of a differential activation theory of hopelessness/suicidality. Cogn Ther Res, 32, 83-104. 

CHAPTER 8

Discussion 


\section{DISCUSSION}

In this thesis, we set out to study the associations between socioeconomic status, psychosocial attributes and health in order to elucidate possible psychosocial pathways explaining health differences from socioeconomic status. Corresponding with the order of our research questions (see chapter 1, page 7), we found that:

1. rebelliousness, an innovative concept, was not more highly prevalent in lower SES groups (chapter 3); hostility and depressive symptoms were associated with SES disfavouring the low SES groups (chapter 2); and an adverse psychosocial profile was more often found in lower adulthood and childhood SES (chapter 6)

2. hostility and depressive symptoms were associated with hospital admission due to incident ischaemic heart disease (chapter 2); cognitive hostility, but not anger, aggressiveness and rebelliousness were associated with all-cause mortality in late middle and old age (chapter 4); the prediction of health risk can be optimised by studying the covariation and possible synergy between relevant psychosocial attributes (chapter 5), rather than by assessing health risk of yet another characteristic such as rebelliousness (chapters 3 and 4)

3. the socioeconomic gradient in health indeed was mediated by psychosocial attributes (depressive symptoms and hostility in chapter 2 and a psychosocial profile in chapter 6 ), but there might be gender differences for some of the attributes, in particular for hostility (chapter 2)

4. early life poverty affects psychosocial pathways leading up to poor health in late middle and old age indicating early life as a critical period for later life adversity (chapter 6).

As for the likelihood of health-related adversities in a specific sample of individuals with a major depressive disorder, we found that there is a social gradient in disease burden, disfavouring lower class (chapter 7). 


\section{Interpretation of the findings}

The above findings are discussed and interpreted below according to major themes in the current discourse on socioeconomic health inequalities, being the measurement of psychosocial health risk, the interplay between psychosocial risk factors and other (upstream and downstream) risk factors that contribute to health inequalities, and psychosocial health risk from a lifecourse perspective, including selection and causation mechanisms.

\section{Measuring psychosocial health risk}

The present findings underscore the importance of psychosocial factors in explaining social inequalities in health and provide insight into the optimisation of the measurement of psychosocial health risk. In previous studies, psychosocial health risk was predominantly determined by fairly straightforward linear models leading from one exposure $X$ to one health outcome $Y$; for example see the review of Kuper and colleagues (Kuper, Marmot, \& Hemingway, 2002). Defining the health risk of a person in terms of his score on for instance the aggression questionnaire (Buss \& Perry, 1992), though perhaps informative and statistically relevant (Meesters, Muris, Bosma, Schouten, \& Beuving, 1996), does not do justice to the total person and to the factors that may attenuate or enhance a certain level of aggressiveness. From a holistic perspective, the whole of a person cannot be understood by merely adding up the parts, but it is the interplay between the parts that defines the personality of a person. The results of the innovative approach measuring those psychosocial attributes we proposed in chapter 5 , combined with existing evidence on the interplay between those attributes (Boyle, Jackson, \& Suarez, 2007; Brown, Andrews, Harris, Adler, \& Bridge, 1986; Felsten, 1996; Koster, Bosma, Kempen et al., 2006; Martin, Watson, \& Wan, 2000; Miller, Smith, Turner, Guijarro, \& Hallet, 1996; Smith, Glazer, Ruiz, \& Gallo, 2004), suggest that this holistic approach may be a valid one. We acknowledge that the (psychosocial) toxicity for health might lie within the total psychosocial make-up rather than within one characteristic, either through psychosocial attributes operating additively or synergistically with each other on health. This synergy is based on interpersonal theory, a theory on the development of the personality in interaction with the social surroundings suggests that personality influences social relationships because more agreeable or hostile personalities can lead to more or less close social relationships, which can in turn enhance personality (Pincus \& Ansell, 2003). Further, personality determines whether situations will be evaluated more positively or negatively, whether a person feels more in control or out of control, thus affecting coping styles (Kiesler, 1996). That these interrelationships exist and add to the understanding of psychosocial health risk, and substantially contribute to health inequalities is shown in 
chapters 5 and 6 . Further, children growing up in adverse socioeconomic circumstances, through primary socialisation, have been found prone to take over parental low control beliefs (Bosma, Schrijvers, \& Mackenbach, 1999), unhealthy coping styles (Bosma, van de Mheen, Borsboom, \& Mackenbach, 2001; McEwen \& Seeman, 1999) and depressive mood (Stansfeld, Head, Fuhrer, Wardle, \& Cattell, 2003), which are highly prevalent among lower SES persons. Such an adverse psychosocial profile indeed originates in early life SES, explaining a large part of health inequalities (chapter 6). Opening the 'black box' to unravel the exact pathways between psychosocial risk factors, through additive or multiplicative mechanisms, is recommended in further (longitudinal) study.

\section{Interplay between psychosocial risk and other (downstream and upstream) risk factors}

Research has predominantly evolved around health risk factors within a person: the so-called downstream factors (Berkman, Glass, Brissette, \& Seeman, 2000; Gehlert et al., 2008). Beside the psychosocial risk factors that were subject in this study, several types of individual risk factors that might explain socioeconomic health inequalities have been determined: health behavioural risk (smoking, sedentary lifestyle, diet) (Hemingway, 2007; Lynch, Davey Smith, Harper, \& Bainbridge, 2006), work-related risk (Bosma et al., 1997; Siegrist \& Marmot, 2004), and, in a more recent focus of research, biological risk, such as immunity (Dowd \& Aiello, 2009; Evans et al., 2000) inflammation (Koster, Bosma, Penninx et al., 2006; Marmot, Shipley, Hemingway, Head, \& Brunner, 2008) and even genetic predisposition (Johnson \& Krueger, 2005; Shiels et al., 2011). However, the exact pathways including potential sequences or interactions between biological, psychosocial, and lifestyle risk factors leading to health are to yet unknown. Current evidence suggests that a person's psychosocial environment not only determines his biological status, it is also related to the socioeconomic distribution of behavioural risk (Brunner, 1997; Delpierre \& Kelly-Irving, 2011; Siegrist \& Marmot, 2004) and to a person's well-being, his self-esteem and control beliefs (Siegrist \& Marmot, 2004). Selfesteem and control beliefs were also among the most important building blocks of the psychosocial profiles we have constructed (Chapter 5). Low self-efficacy or low self-esteem might lead to a more negative appraisal of circumstances, resulting in increased stress. This has previously been shown to lead to inflammation (Steptoe, Owen, Kunz-Ebrecht, \& Mohamed-Ali, 2002) affecting health negatively. Low control beliefs might thus increase susceptibility to disease through compromised immune responses to stress. Low control beliefs have even been found to substantially explain lower life expectancy in low SES (Bosma, et al., 1999): inflammation and immunity might be the mediating link, even independent of the well-known associations between low control and unhealthy behaviours. Future studies should 
aim at unraveling these pathways, in order to more completely elucidate downstream risk and perhaps substantiate the key role for perceived control therein.

Notwithstanding the fact that downstream risk factors are important determinants of health inequalities, they are not the only risk factors. Upstream factors, features of the social environment that influence individual health status are more and more considered as important as the downstream factors (Berkman, et al., 2000; Frohlich \& Potvin, 2010; Marmot, 2005; Ogilvie, Craig, Griffin, Macintyre, \& Wareham, 2009). Upstream factors comprise mid-level contextual factors such as housing, income, neighbourhood characteristics, and work environment, which are all considered important determinants of health (Turrell, 2002; Turrell, Kavanagh, Draper, \& Subramanian, 2007), as well as macro level contextual factors. Macrocultural and macro-economic factors are likely to be related with the well-being of people. Emile Durkheim was one of the first to explicitly recognise the influence of society, claiming that the social world constitutes a reality of its own, above and beyond the lives and experiences of individual persons. This claim was later modified by Giddens, who, in his Structuration Theory argued that this social world is constituted or produced by the active doings of subjects (Giddens, 1984). In other words, there is a mutual influence between social environment and individuals. It has been found that powerful determinants of health are inherent characteristics of society at large, such as a pronounced inequality of a country's income distribution, a high degree of regional disparities or a lack of social coherence and poor social capital (Diez-Roux, 1998; Kawachi, Kennedy, Lochner, \& Prothrow-Stith, 1997; Wilkinson, 1996). Although the influence of macro level factors on health has been established, the direction of the influence, in case of income distribution, has not been unequivocally determined yet (Kawachi, et al., 1997; Mackenbach et al., 2008). Alongside distributive politics, the way our society is organised and the norms and values we hold (be it often subconsciously) might also affect the persistence of health inequalities. For instance, most Western societies, including the Netherlands, can be viewed as meritocracies. Dutch policies until the 1980s were based on the principle of solidarity aiming at social inclusion of all individuals including those at the lower social ranks. Regardless of social background, everybody should have equal opportunities in life, starting with equal access to (higher) education. However, what started out as a solidarity principle, social inclusion being highly valued, had and still has negative and unforeseen consequences in a society that thrives on individualism. Achievements (careerwise, educational, incomewise), in other words the 'merits', are attributed to personal effort, and therefore are personal gain. On the other hand, not being so successful is viewed as a personal mistake or a lack of effort, since opportunities are (theoretically) the same for everyone (De Botton, 2004). However, it has been found that the value of individualism and personal responsibility can actually form a barrier in job-seeking. Finding a job is strongly associated with the use of social networks. In a study among US men 
and women, Smith (Smith, 2007) found that a strong sense of individualism dictating that one should succeed based on his own efforts, prevented persons from using their social networks and therefore failed to find a job. Explanations as to why unemployed people are jobless are often thought of in terms of individual shortcomings (Gallie, 1994). This could easily lead to stigmatisation which can seriously affect self-esteem and social relations (Berkman, et al., 2000; Link \& Phelan, 2006), providing evidence for the influence of upstream health risk factors on downstream health risk factors. The influence of upstream factors on psychosocial characteristics of individuals should be addressed in future research, in order to diminish health inequalities (Gehlert, et al., 2008; Ogilvie, et al., 2009).

\section{Lifecourse perspective}

In the study of health inequalities, the concept of a lifecourse approach to understand these inequalities has become increasingly important in the last decade. The lifecourse perspective states that cumulative, differential exposure to health damaging or health promoting circumstances can explain health inequalities (Kuh, BenShlomo, Lynch, Hallqvist, \& Power, 2003; Lynch \& Smith, 2005; Wadsworth, 1997). Determining 'critical periods', the timeframes in which future disease risk develops, is pivotal to timing interventions. Such critical periods can go back as far as birth, or even prebirth (Collins, David, Rankin, \& Desireddi, 2009; Eriksson et al., 1999; Lawlor, Ben-Shlomo, \& Leon, 2004; Leon et al., 1998). We showed (chapter 6) that poverty in early life not only leads to a more unfavourable psychosocial profile, but also to poorer health compared with people who did not grow up in poverty. An important question here is whether it is SES that primarily determines health (social causation) or (childhood) health determining one's ultimate position on the social ladder (health selection). From a lifecourse perspective, both could be at play and in previous studies indeed evidence has been found for either of them (Lichtenstein, Harris, Pedersen, \& McClearn, 1993; Stansfeld, Clark, Rodgers, Caldwell, \& Power), although arguably the stronger evidence exists for social causation (Link \& Phelan, 1996; Phelan \& Link, 2005). In chapter 6, we found a strong effect of early life poverty on adult health regardless of adulthood education, suggesting a temporal order that leads from socioeconomic status to health, which underpins the social causation perspective. However, we do need to be cautious in our interpretation, since we did not take into account the health status in early life and therefore we cannot rule out health selection mechanisms. In chapter 7, we found that among people with depression less educated individuals carry the higher disease burden. These findings cannot be explained from the perspective of health selection, because with the depressive disorder diagnosed in the last 6 months; this excess disease burden could not have caused the lower educational level in this population of persons aged 24 years and older. However, we cannot discard the 
selection mechanism for the total population of depressed individuals, not only is the prevalence of depressive disorder higher among lower socioeconomic status groups (Everson, Maty, Lynch, \& Kaplan, 2002), but occurrence at a young age might hamper education, or have serious effects on income through loss of work, especially considering the excess disease burden we found in this low SES group. Based on the existing evidence, it seems that both mechanisms, social causation and health selection, simultaneously contribute to the persistence of health inequalities, and both should be taken into consideration when developing interventions at tackling these inequalities.

\section{Limitations}

Some methodological limitations need to be acknowledged. Firstly, associations found in 3 studies (chapters 3, 6 and 7) were based on cross-sectional analyses, which do not allow us to make causal inferences. No longitudinal data were available for these analyses. This is in particular important for chapter 6 in which we examined the associations between early life poverty, later life health and psychosocial profile. We do know, however, from the results of study in chapter 5, which was based on a longitudinal design, that the effect of the psychosocial profile on self-rated health at follow-up remained even after controlling for baseline selfrated health, suggesting a causal ordering between psychosocial profile and health. Further, chapter's 6 results were based on a case-control design, so we cannot rule out recall bias influencing both the self-report of health and psychosocial profile. This needs to be addressed in future longitudinal studies, by adjusting for baseline health. As for the consequences of the cross-sectional design for the results in chapter 7, we proved accumulation of adversity in less educated depressed individuals, but it would be worthwhile to study the mutual influences of these adversities by means of longitudinal data.

Secondly, four of the studies described are based on a late middle-aged and older population (chapters 3, 4, 5 and 6), which may have had consequences for the validity of the measurement instruments. The mean scoring levels on the psychosocial attributes, especially on the hostility-related attributes, were relatively low compared with the scale ranges. This could be a consequence of socially desirable answering that may be more common in older persons (Gibson, 1997), but it could also be a true age effect, i.e. that older persons are less hostile, less aggressive, less angry and less rebellious than younger persons (McDermott \& Apter, 1987; Meesters, et al., 1996; Siegler et al., 2003). Despite these low scoring levels we still found significant effects for cognitive hostility on all-cause mortality (chapter 4) and for the psychosocial profile on self-rated health (chapter 5 and 6). 
Thirdly, as in all cohort studies, we had to deal with non-response, attrition and missing data. The non-response was important in the studies based on the SMILE participants of 55 years and older. They were asked to give informed consent to linkage of their questionnaire data with medical data. Depending on the baseline, $60 \%$ (chapter 5) to $66 \%$ (chapter 4) consented to linkage. Sensitivity analyses showed that the people who consented did not differ by age, sex, or educational level from the persons who did not consent (chapters 4 and 5). The number of missing data varied per study, from as low as $10 \%$ for the psychometric evaluation of the Social Reactivity Scale (chapter 3 ) to as high as $37 \%$ in the examination of the psychosocial profile as predictor of health (chapter 5 ). We addressed these missing values by running sensitivity analyses and in one occasion by multiple imputation (chapter 4). The results of the sensitivity analyses differed according to the definition of the target population, the timing of the baseline measurement and the variables included, but they did not point to any serious bias in our results. Attrition, an important issue in the longitudinal analyses (chapters $2,4,5$ ) and the analyses using an extended baseline measurement (chapter 6 ) was in general agerelated, (those included in the analyses were younger), they were sex-related (those included were more likely to be male), and health-related (those included reported better health). We cannot be sure how this might have biased our results. It has been shown, however, that attrition, especially in older populations affects the estimation of prevalences rather than affecting estimations of associations (Deeg, 2002).

\section{Implications}

The present findings provide a good starting point to shape future research, and they also have implications for practice and policy. This will be discussed below.

\section{Studying the interplay between psychosocial health risk factors}

Clustering individuals based on their scoring levels on a number of psychosocial risk factors has proven a valid approach to determine psychosocial risk of poor (selfrated) health. Although this approach takes into account the covariation and interplay between psychosocial risk factors, the exact pathways between these factors remain unknown. One way to proceed in unraveling these pathways could be setting up a longitudinal population-based cohort study, preferably comprising individuals from all age groups, and measure these psychosocial factors and health at regular intervals with a substantial follow-up period, from a lifecourse perspective. Such a design would allow us to examine possible additive or multiplicative effects of the psychosocial factors on health, and also focus on the development and the 
dynamics of the psychosocial profile over time. Using such an approach, we could investigate the claim stated in interpersonal theory that the personality develops in concordance with the social environment in an iterative process (Pincus \& Ansell, 2003). Personality is prone to change over the life-course (Roberts, Walton, \& Viechtbauer, 2006). Given the health risk of adverse profiles and high adverse scoring levels (chapters 4, 5 and 6), we hypothesise that in younger people with higher adverse scoring levels the effects on health might even be stronger. Studying these effects in different age-groups would enable us to test these expectations. This would undoubtedly increase our understanding of psychosocial mechanisms leading to health status, and it might help shape and time interventions aimed at improving population health and diminish health inequalities. However, in the contemporary political climate, taking into account the financial crisis, the (financial) feasibility of such a design may be low. Another option to evaluate what growing up and living in socioeconomic hardship really means for those involved and how it affects their psychosocial functioning and health status is by interviewing the people involved. The evidence thus far collected is predominantly based on quantitative research, aimed at establishing associations and make causal inferences. But what actually goes on in people's lives at the lower end of the socioeconomic ladder, and the meaning those individuals attach to their lives and their health, might shed some new light on this matter. Narratives might provide a perfect tool to increase understanding about the interplay between psychosocial health risk factors. In addition, people living in unfavourable socioeconomic conditions can be involved in research agenda setting, in analogy with the trend (small scale so far) in medical ethical research where patients are considered important stakeholders in research and treatment of their conditions (Abma, Molewijk, \& Widdershoven, 2009). Until now, lower SES individuals have been mere recipients of interventions targeted at tackling health inequalities (Mackenbach, 2010; Mackenbach \& Bakker, 2003; Mackenbach \& Stronks, 2002). Research agenda setting will benefit from involvement of all the important stakeholders, but also more involvement in developing (health) interventions might improve compliance to these interventions. Preferably, a combination of both methodologies, quantitative and qualitative, will be applied.

\section{Studying the interplay between psychosocial and other (upstream and downstream) health risk factors}

Besides the interplay between psychosocial risk factors, the relationships between psychosocial risk, health behaviours, biological risk and societal risk are also important topics for future studies. A holistic approach, comprising these different types of risk factors and establishing pathways that lead from SES to health outcomes, does more justice to the multifactorial origin of the inequalities. To determine the 
contribution of downstream and mid-level and macro-level upstream factors to health inequalities, a multilevel design is preferably used (Diez-Roux, 1998). Apart from addressing the gap in knowledge concerning the influence of societal risk factors on psychosocial status, we need to focus on underlying biological pathways - such as stress-induced inflammation and stress-related compromise of immunity that might explain the contribution of psychosocial characteristics to health inequalities (Dowd \& Aiello, 2009; Evans, et al., 2000; Koster, Bosma, Penninx, et al., 2006; Marmot, et al., 2008). These pathways and sequencing might best be studied in a longitudinal design (see recommendation above).

\section{Implications for policy and practice}

This research does not directly lead to shaped and tailored interventions. However, the outcomes may help towards an increased understanding of the important role that psychosocial attributes play in explaining health inequities, and of unfavourable characteristics developing in concordance with each other and with socioeconomic circumstances. Therefore, in future interventions targeting health inequalities, a person's psychosocial profile needs to be taken into account. We most certainly do not advocate collective psychotherapy for those in lower SES groups. The danger in addressing merely downstream factors lies in 'blaming the victim', and we argued above that upstream risk factors might be as important as downstream factors. Both upstream and downstream psychosocial health risk factors need to be explicitly included in designing interventions directed at reducing health inequalities. We recommend more involvement of all stakeholders (including low SES people) in the design of interventions which might in turn lead to more empowerment and to feeling more in control. In designing interventions, the timing of deliverance is of great importance (see chapter 6 ). In general we state that reducing health inequalities is not as high on the (Dutch) political agenda as we would like. Policies and interventions are often fragmented and lack focus and thorough evaluation. As Mackenbach stated in his review on interventions aimed at tackling health inequalities: 'for the foreseeable future we need less ambitious aims, more focused approaches, and much more and better evaluation' (Mackenbach, 2010). The evaluation of adequately designed interventions and their effectiveness might also help in unraveling certain mechanisms between risk factors or in defining important contributors to health inequalities. In addition to aiming at improving interventions, we strongly advocate investing in observational longitudinal research to unravel the mechanisms leading from socioeconomic status to health through psychosocial risk. Only in truly understanding these health damaging pathways does the key lie to substantially reduce social health inequalities. 


\section{References}

Abma, T. A., Molewijk, B., \& Widdershoven, G. A. (2009). Good care in ongoing dialogue. Improving the quality of care through moral deliberation and responsive evaluation. Health Care Anal, 17(3), 217235.

Berkman, L. F., Glass, T., Brissette, I., \& Seeman, T. E. (2000). From social integration to health: Durkheim in the new millennium. Soc Sci Med, 51(6), 843-857.

Bosma, H., Marmot, M. G., Hemingway, H., Nicholson, A. C., Brunner, E., \& Stansfeld, S. A. (1997). Low job control and risk of coronary heart disease in Whitehall II (prospective cohort) study. BMJ, 314(7080), 558-565.

Bosma, H., Schrijvers, C., \& Mackenbach, J. P. (1999). Socioeconomic inequalities in mortality and importance of perceived control: cohort study. BMJ, 319(7223), 1469-1470.

Bosma, H., van de Mheen, H. D., Borsboom, G. J., \& Mackenbach, J. P. (2001). Neighborhood socioeconomic status and all-cause mortality. Am J Epidemiol, 153(4), 363-371.

Boyle, S. H., Jackson, W. G., \& Suarez, E. C. (2007). Hostility, anger, and depression predict increases in C3 over a 10-year period. Brain Behav Immun, 21(6), 816-823.

Brown, G. W., Andrews, B., Harris, T., Adler, Z., \& Bridge, L. (1986). Social support, self-esteem and depression. Psychol Med, 16(04), 813-831.

Brunner, E. (1997). Stress and the biology of inequality. BMJ, 314(7092), 1472-1476.

Buss, A. H., \& Perry, M. (1992). The aggression questionnaire. J Pers Soc Psychol, 63(3), 452-459.

Collins, J. W., Jr., David, R. J., Rankin, K. M., \& Desireddi, J. R. (2009). Transgenerational effect of neighborhood poverty on low birth weight among African Americans in Cook County, Illinois. Am J Epidemiol, 169(6), 712-717.

De Botton, A. (2004). Status anxiety. London: Hamish Hamilton.

Deeg, D. J. H. (2002). Attrition in longitudinal population studies: Does it affect the generalizability of the findings? An introduction to the series. J Clin Epidemiol, 55, 213-215.

Delpierre, C., \& Kelly-Irving, M. (2011). To what extent are biological pathways useful when aiming to reduce social inequalities in cancer? Eur J Public Health, 21(4), 398-399.

Diez-Roux, A. V. (1998). Bringing context back into epidemiology: variables and fallacies in multilevel analysis. Am J Public Health, 88(2), 216-222.

Dowd, J. B., \& Aiello, A. E. (2009). Socioeconomic differentials in immune response. Epidemiology, 20(6), 902-908.

Eriksson, J. G., ForsÃ@n, T., Tuomilehto, J., Winter, P. D., Osmond, C., \& Barker, D. J. P. (1999). Catch-up growth in childhood and death from coronary heart disease: longitudinal study. BMJ, 318(7181), 427-431.

Evans, P., Der, G., Ford, G., Hucklebridge, F., Hunt, K., \& Lambert, S. (2000). Social class, sex, and age differences in mucosal immunity in a large community sample. Brain Behav Immun, 14(1), 41-48.

Everson, S. A., Maty, S. C., Lynch, J. W., \& Kaplan, G. A. (2002). Epidemiologic evidence for the relation between socioeconomic status and depression, obesity, and diabetes. J Psychosom Res, 53(4), 891895.

Felsten, G. (1996). Hostility, Stress and symptoms of depression. Pers Indiv Differ, 21(4), 461-467.

Frohlich, K. L., \& Potvin, L. (2010). Commentary: Structure or agency? The importance of both for addressing social inequalities in health. Int J Epidemiol, 39(2), 372-377.

Gallie, D. (1994). Are the unemployed an underclass? Some evidence from the social change and economic life initiative. Sociology, 28(3), 737-757.

Gehlert, S., Sohmer, D., Sacks, T., Mininger, C., McClintock, M., \& Olopade, O. (2008). Targeting Health Disparities: A Model Linking Upstream Determinants To Downstream Interventions. Health Affair, 27(2), 339-349.

Gibson, S. J. (1997). The Measurement of Mood States in Older Adults. J Gerontol B: Psychol Sci Soc Sci, 52B(4), P167-P174.

Giddens, A. (1984). The constitution of society. Cambridge: Polity Press. 
Hemingway, A. (2007). Determinants of coronary heart disease risk for women on a low income: literature review. J Adv Nurs, 60(4), 359-367.

Johnson, W., \& Krueger, R. F. (2005). Genetic effects on physical health: lower at higher income levels. Behav Genet, 35(5), 579-590.

Kawachi, I., Kennedy, B. P., Lochner, K., \& Prothrow-Stith, D. (1997). Social capital, income inequality, and mortality. Am J Public Health, 87(9), 1491-1498.

Kiesler, D. J. (1996). Contemporary interpersonal theory and research: Personality, psychopathology, and psychotherapy. New York: John Wiley \& Sons.

Koster, A., Bosma, H., Kempen, G. I., Penninx, B. W., Beekman, A. T., Deeg, D. J., et al. (2006). Socioeconomic differences in incident depression in older adults: the role of psychosocial factors, physical health status, and behavioral factors. J Psychosom Res, 61(5), 619-627.

Koster, A., Bosma, H., Penninx, B. W., Newman, A. B., Harris, T. B., van Eijk, J. T., et al. (2006). Association of inflammatory markers with socioeconomic status. J Gerontol A Biol Sci Med Sci, 61(3), 284-290.

Kuh, D., Ben-Shlomo, Y., Lynch, J., Hallqvist, J., \& Power, C. (2003). Life course epidemiology. J Epidemiol Community Health, 57(10), 778-783.

Kuper, H., Marmot, M., \& Hemingway, H. (2002). Systematic review of prospective cohort studies of psychosocial factors in the etiology and prognosis of coronary heart disease. Semin Vasc Med, 2(3), 267-314.

Lawlor, D. A., Ben-Shlomo, Y., \& Leon, D. (2004). Pre-adult influences on cardiovascular disease (2nd ed.). New York: Oxford University Press.

Leon, D. A., Lithell, H. O., Vagero, D., Koupilova, I., Mohsen, R., Berglund, L., et al. (1998). Reduced fetal growth rate and increased risk of death from ischaemic heart disease: cohort study of 15000 Swedish men and women born 1915-29. BMJ, 317(7153), 241-245.

Lichtenstein, P., Harris, J. R., Pedersen, N. L., \& McClearn, G. E. (1993). Socioeconomic status and physical health, how are they related? An empirical study based on twins reared apart and twins reared together. Soc Sci Med, 36(4), 441-450.

Link, B. G., \& Phelan, J. C. (1996). Understanding sociodemographic differences in health--the role of fundamental social causes. Am J Public Health, 86(4), 471-473.

Link, B. G., \& Phelan, J. C. (2006). Stigma and its public health implications. Lancet, 367(9509), 528-529.

Lynch, J., Davey Smith, G., Harper, S., \& Bainbridge, K. (2006). Explaining the social gradient in coronary heart disease: comparing relative and absolute risk approaches. J Epidemiol Community Health, 60(5), 436-441.

Lynch, J., \& Smith, G. D. (2005). A life course approach to chronic disease epidemiology. Annu Rev Public Health, 26, 1-35.

Mackenbach, J. P. (2010). Has the English strategy to reduce health inequalities failed? Soc Sci Med, 71(7), 1249-1253; discussion 1254-1248.

Mackenbach, J. P., \& Bakker, M. J. (2003). Tackling socioeconomic inequalities in health: analysis of European experiences. Lancet, 362(9393), 1409-1414.

Mackenbach, J. P., Stirbu, I., Roskam, A. J., Schaap, M. M., Menvielle, G., Leinsalu, M., et al. (2008). Socioeconomic inequalities in health in 22 European countries. N Engl J Med, 358(23), 2468-2481.

Mackenbach, J. P., \& Stronks, K. (2002). A strategy for tackling health inequalities in the Netherlands. BMJ, 325(7371), 1029-1032.

Marmot, M. (2005). Social determinants of health inequalities. Lancet, 365(9464), 1099-1104.

Marmot, M. G., Shipley, M. J., Hemingway, H., Head, J., \& Brunner, E. J. (2008). Biological and behavioural explanations of social inequalities in coronary heart disease: the Whitehall II study. Diabetologia, 51(11), 1980-1988.

Martin, R., Watson, D., \& Wan, C. K. (2000). A three-factor model of trait anger: dimensions of affect, behavior, and cognition. J Pers, 68(5), 869-897.

McDermott, M. R., \& Apter, M. J. (1987). An Introduction \& Guide to the Negativism Dominance Scale. In M. R. McDermott (Ed.), Rebelliousness in adolescence and young adulthood. Cardiff: University of Wales. 
McEwen, B. S., \& Seeman, T. (1999). Protective and damaging effects of mediators of stress. Elaborating and testing the concepts of allostasis and allostatic load. Ann N Y Acad Sci, 896, 30-47.

Meesters, C., Muris, P., Bosma, H., Schouten, E., \& Beuving, S. (1996). Psychometric evaluation of the Dutch version of the Aggression Questionnaire. Behav Res Ther, 34(10), 839-843.

Miller, T. Q., Smith, T. W., Turner, C. W., Guijarro, M. L., \& Hallet, A. J. (1996). A meta-analytic review of research on hostility and physical health. Psychol Bull, 119(2), 322-348.

Ogilvie, D., Craig, P., Griffin, S., Macintyre, S., \& Wareham, N. J. (2009). A translational framework for public health research. BMC Public Health, 9, 116.

Phelan, J. C., \& Link, B. G. (2005). Controlling disease and creating disparities: a fundamental cause perspective. J Gerontol B Psychol Sci Soc Sci, 60 Spec No 2, 27-33.

Pincus, A. L., \& Ansell, E. B. (2003). Interpersonal theory of personality. In T. Millon, M. J. Lerner \& I. B. Weiner (Eds.), Handbook of psychology. Personality and social psychology. (Vol. 5, pp. 209-229). New York: John Wiley \& Sons, Inc.

Roberts, B. W., Walton, K. E., \& Viechtbauer, W. (2006). Patterns of mean-level change in personality traits across the life course: a meta-analysis of longitudinal studies. Psychol Bull, 132(1), 1-25.

Shiels, P. G., McGlynn, L. M., Maclntyre, A., Johnson, P. C. D., Batty, G. D., Burns, H., et al. (2011). Accelerated telomere attrition is associated with relative household income, diet and inflammation in the pSoBid Cohort. PLoS One, 6(7), e22521.

Siegler, I. C., Costa, P. T., Brummett, B. H., Helms, M. J., Barefoot, J. C., Williams, R. B., et al. (2003). Patterns of change in hostility from college to midlife in the UNC Alumni Heart Study predict highrisk status. Psychosom Med, 65(5), 738-745.

Siegrist, J., \& Marmot, M. (2004). Health inequalities and the psychosocial environment-two scientific challenges. Soc Sci Med, 58(8), 1463-1473.

Smith, S. (2007). Lone pursuit. New York: Russel Sage Foundation.

Smith, T. W., Glazer, K., Ruiz, J. M., \& Gallo, L. C. (2004). Hostility, anger, aggressiveness, and coronary heart disease: an interpersonal perspective on personality, emotion, and health. $J$ Pers, 72(6), 1217-1270.

Stansfeld, S. A., Clark, C., Rodgers, B., Caldwell, T., \& Power, C. Repeated exposure to socioeconomic disadvantage and health selection as life course pathways to mid-life depressive and anxiety disorders. Soc Psychiatry Psychiatr Epidemiol.

Stansfeld, S. A., Head, J., Fuhrer, R., Wardle, J., \& Cattell, V. (2003). Social inequalities in depressive symptoms and physical functioning in the Whitehall II study: exploring a common cause explanation. J Epidemiol Community Health, 57(5), 361-367.

Steptoe, A., Owen, N., Kunz-Ebrecht, S., \& Mohamed-Ali, V. (2002). Inflammatory cytokines, socioeconomic status, and acute stress responsivity. Brain Behav Immun, 16(6), 774-784.

Turrell, G. (2002). Reducing socioeconomic health inequalities: issues of relevance for policy. N $\mathrm{W}$ Public Health Bull, 13(3), 47-49.

Turrell, G., Kavanagh, A., Draper, G., \& Subramanian, S. V. (2007). Do places affect the probability of death in Australia? A multilevel study of area-level disadvantage, individual-level socioeconomic position and all-cause mortality, 1998-2000. J Epidemiol Community Health, 61(1), 13-19.

Wadsworth, M. E. (1997). Health inequalities in the life course perspective. Soc Sci Med, 44(6), 859-869. Wilkinson, R. (1996). Unhealthy societies:The afflictions of inequality. London: Routledge. 

CHAPTER 9

\section{Summary}

Samenvatting

Dankwoord

About the author

Publications 
CHAPTER 9 


\section{SUMMARY}

This thesis examines the associations between socioeconomic status, psychosocial health risk factors, and health.

Chapter 1 outlines the background and presents the objectives of this thesis. Socioeconomic inequalities in health generate a major public health problem worldwide. With each step down the socioeconomic ladder health gets poorer and life expectancy shorter. Most interventions aimed at reducing health inequalities have been based on eliminating or diminishing risk, with risk factors determined by prior research. Evidence so far indicates that psychosocial factors could be of major importance in the explanation of socioeconomic health inequalities, either through their direct long-term adverse effects on the immune and cardiovascular systems or indirectly through lifestyle effects. Adverse (levels of) psychosocial characteristics are more highly prevalent at lower socioeconomic status (SES), such as depressive symptoms, hostility, neuroticism, low control beliefs, ineffective coping mechanisms, lack of social support, and social isolation, perhaps due to a long-term exposure to adverse circumstances, which might originate in childhood, when one is socialised within unfavourable surroundings. There is also a substantial body of evidence which demonstrates that individual psychosocial factors affect (somatic) health and longevity. Given these findings, it is highly likely that unfavourable socioeconomic conditions, and growing up in them, affect health through psychosocial make-up. As yet, the contributions of those psychosocial factors to social health inequalities are relatively understudied. Further, psychosocial risk factors are often included separately and individually in various studies. However, they might have synergistic effects on health and longevity; many psychological attributes are interrelated. Taking account of this covariation and the potentially synergistic effects on health outcomes might add to their predictive power for health inequalities. In this thesis we set out to study the associations between socioeconomic status (SES), psychosocial risk factors and health, in order to increase understanding of health inequalities and the extent to which psychosocial risk contributes to these inequalities, thereby taking account of a lifecourse perspective. We also specifically focused on the measurement and operationalisation of psychosocial risk. We shaped our research according to four main research questions:

1. What psychosocial attributes are important in their relationship with SES and how can they be measured?

2. What psychosocial attributes are important in their relationship with health and how can they be measured?

3. Do psychosocial factors contribute to explaining health from SES?

4. What is the influence of early life poverty on a person's psychosocial profile and health in later life? 
Besides these four questions we also studied the likelihood of health-related adversities across different educational levels in persons with a psychiatric disorder.

Chapter 2 addresses the question whether hostility and depressive symptoms, two well known risk factors for cardiac disease, contribute to the income inequalities in hospital admission because of incident ischaemic heart disease (IHD) (research question 3). This has been examined in a Dutch prospective population-based cohort study (GLOBE study), with participants aged 15 to 74 years ( $n=2,374)$. Selfreported data on income, hostility and depressive symptoms, lifestyle, and biomedical factors, were linked to hospital admissions due to incident IHD over a period of 12 years follow-up. By means of Cox proportional hazard models the contributions of hostility and depressive symptoms to the association between income and time to incident IHD were studied. The relative risk of incident IHD was highest in the lowest income group, with a hazard ratio of 2.71 (95\% Cl 1.60-4.61). Men in the lowest income groups reported more adverse lifestyles and biomedical factors, which contributed to their higher risk of incident IHD. Unhealthy levels of hostility in particular contributed to the income differences in incident IHD among women. The low number of IHD incidents in the women, however, warrants additional research in larger samples.

Apart from depressive symptoms and hostility, rebelliousness, an innovative concept, might be of importance to socioeconomic status and health (research questions 1 and 2). Rebelliousness might influence health via opposing health campaigns and refraining from healthy behaviours. Rebelliousness is measured by the Social Reactivity Scale, a 14-item questionnaire. In Chapter 3, we examined the psychometric properties of this scale, encompassing the factor structure, the internal consistency and the construct validity in two Dutch samples of the SMILE and MAAS study (mean age 69 and 60 respectively.) We could confirm the two-factor structure of the scale; proactive and reactive rebelliousness. We found moderate support for the reliability and construct validity of the scale. Findings were suggestive of rebelliousness, firstly, being associated with low control beliefs, secondly, being related to hostility, and, thirdly, also heightening the risk of engaging in unhealthy behaviours and that of poor health (perhaps through deliberately rejecting health education messages). Contrary to our expectations, higher levels of rebelliousness were found in higher SES groups, not in lower SES groups.

Chapter 4 describes the association between hostility, anger, aggression, rebelliousness, and all-cause mortality in a late middle-aged and older population (research question 2). Most but not all evidence supports hostility-related attributes to increase mortality risk. However, studies usually include single attributes, their effects have been studied predominantly in younger populations and behavioural 
pathways explaining the mortality effect seem to differ by age. Data were derived from the longitudinal Dutch SMILE study among 2,679 late middle-aged and older Dutch people. Psychological characteristics were self-reported in 2004/2005 and mortality was monitored from 2005 to 2010. Cox regression analyses were used to calculate the mortality risk by each unique psychological variable with additional adjustments for the other psychological variables, and for health behaviours. Baseline adjustments included age, sex, educational level and prevalent morbidity. Cognitive hostility was associated with all-cause mortality, independent of health behaviours (on a scale ranging from 6 to 30, the hazard ratio was 1.05; 95\% Cl: $1.01-$ 1.09). Anger, aggression and rebelliousness were not associated with mortality risk.

In Chapter 5 we used a new approach in establishing psychosocial health risk; thereby taking into account potentially synergistic effects between different psychosocial characteristics (research question 2). Prospective, longitudinal data from 1912 Dutch participants from the SMILE study aged 55-91 years were used to determine distinct psychosocial profiles using two-step cluster analysis. By means of a two-step cluster analysis, these individuals were grouped, characterised by a distinct profile, based on their scoring levels on a range of psychosocial variables, including psychological attributes and functioning, coping styles and social support. The predictive power of these profiles over a five-year follow-up was determined by the Schwarz Bayesian Information Criterion (BIC) for Cox regression models for GP-diagnosed somatic morbidity and all-cause mortality, and logistic regression models for self-rated health. Three distinct psychosocial risk profiles emerged: an adverse, an average and a beneficial profile. These profiles strongly predicted selfrated health but not morbidity or mortality. Based on the BICs, the cluster (profile) model proved to be a stronger predictor than the model comprising individual psychosocial characteristics in predicting self-rated health, substantiating the relevance of looking at accumulation of and possibly synergism between psychosocial factors.

In Chapter 6 we examined the associations between early life SES, adulthood SES, psychosocial profiles and self-rated health (research questions 3 and 4). Early life socioeconomic status has been associated with health status in later life, either through, or independent of, adulthood socioeconomic status. Apart from health behavioural risk, psychosocial functioning might be an important explanatory factor, being related not only to early life circumstances but also to health status. We set out to determine whether early life poverty was associated with self-rated health independently of adulthood socioeconomic status, and the extent to which the psychosocial profile contributed to this association. We used cross-sectional data on socio-demographics, early life poverty, psychosocial profile (adverse, average or beneficial), health behaviours and self-rated health collected among 1688 
late middle and older aged participants of the Dutch SMILE study. By means of logistic regression analyses we calculated the association between early life poverty and self-rated health; we compared this with models separately and simultaneously including adulthood education, psychosocial profile, and health behaviours, adjusted for age and sex. Individuals who had experienced poverty in early life reported more often less than good health (OR $=1.52,95 \% \mathrm{Cl} 1.06-2.18)$ than their better off counterparts, partially independent of adulthood educational level. The psychosocial profile explained a substantial part of the excess risk of early life poverty for less than good health, while health behaviours hardly contributed at all. These results suggest that health status in later life results from pathways starting in early life, with adverse socioeconomic conditions in that critical period sensitising people towards more adverse psychosocial functioning, leading in turn to poorer self-rated health compared with people who had a better start in life.

Chapter 7 describes the educational patterning of health-related adversities in individuals diagnosed with a major depressive disorder. Major depressive disorder and depression severity are socially patterned, disfavouring individuals from lower socioeconomic groups. Depressive disorders are associated with several (adverse) health-related outcomes, such as cardiac risk (measured by the metabolic syndrome), lifestyles, psychological function and treatment modalities (medication or psychotherapy). We used cross-sectional medical and psychiatric data from 992 participants of the Netherlands Study of Depression and Anxiety (NESDA) with a diagnosed current major depressive disorder. Associations of education with the metabolic syndrome, health behaviours, psychological outcomes, and with treatment modalities, adjusted for depression severity, were examined by means of (multinomial and binary) logistic and linear regression analyses. We found that in addition to and independent of major depression being more severe in the less educated patients, metabolic syndrome, current smoking, low alcohol consumption, hopelessness and low control were more prevalent in a group of less educated individuals, compared with their more highly educated peers. The less educated persons were more likely to be treated with antidepressant medication and less likely to receive psychotherapy treatment. None of these observations were explained by a higher depression severity in the less educated group.

In Chapter 8 the main conclusions are presented and the findings are interpreted in light of the current discourse on socioeconomic health inequalities. Our results showed that psychosocial risk is an important contributor to socioeconomic health inequalities, in particular when the possible synergy between different psychosocial attributes is taken into account. The effects of psychosocial risk on health are substantial, even in late middle and old age. The psychosocial profile seems to originate partially in early life; those who grew up in poverty more often have an ad- 
verse psychosocial profile explaining their poor health to a large extent. In addition, we found that the disease burden in individuals suffering from a major depression is educationally patterned, disfavouring the less educated.

The present findings can shape future research in this field. The holistic approach, encompassing total psychosocial functioning has proven to be more valid for the prediction of health and for socioeconomic health inequalities than merely measuring a single psychosocial characteristic. However, the exact interplay between these attributes need to be unravelled in future research, either by means of a prospective population-based cohort study including different age groups with a long-term follow-up period, or by collecting the narratives of persons that live in sustained economic hardship within a mixed-methods approach. Further, the interrelationships with health behavioural, biological, and societal health risk factors need to be addressed as well, in order to determine chains of risk (by additive or multiplicative effects), the 'toxic' components, the temporal ordering, and the onset of risk, in order to reduce health inequalities. In addition to an ongoing investment in observational longitudinal research to unravel the mechanisms leading from socioeconomic status to health, we recommend that interventions address upstream and downstream risk factors and that they be thoroughly evaluated. 
CHAPTER 9 


\section{SAMENVATTING}

In dit proefschrift worden de associaties tussen sociaaleconomische status, psychosociale risicofactoren, en gezondheid onderzocht.

In Hoofdstuk 1 worden de achtergrond en doelen van het proefschrift beschreven. Sociaaleconomische gezondheidsverschillen vormen wereldwijd een groot probleem voor de publieke gezondheid. ledere trede lager op de sociaaleconomische ladder gaat gepaard met een slechtere gezondheid en een lagere levensverwachting. De meeste interventies gericht op het verkleinen van deze gezondheidsverschillen zijn gebaseerd op het elimineren of verkleinen van gezondheidsrisico's, waarbij de risicofactoren zijn vastgesteld in eerder onderzoek. Wetenschappelijk bewijs tot dusverre duidt op het grote belang van psychosociale factoren in het verklaren van sociaaleconomische gezondheidsverschillen. Enerzijds door directe ongunstige lange-termijn effecten op het immuunsysteem en cardiovasculaire systeem, of anderzijds indirect door leefstijleffecten. Ongunstige psychosociale kenmerken, zoals depressieve symptomen, hostiliteit, neuroticisme, laag niveau van ervaren controle, ineffectieve coping stijlen, gebrek aan sociale steun, en sociale uitsluiting komen relatief vaak voor bij personen met een lage sociaaleconomische status (SES). Waarschijnlijk wordt dit veroorzaakt door een langdurige blootstelling aan ongunstige omstandigheden. Geboren worden en opgroeien in dergelijke omstandigheden beïnvloedt de ontwikkeling van de persoonlijkheid, van copingstijlen en van sociale relaties mogelijkerwijs op een negatieve manier. Er is ook substantieel bewijs voor de invloed van individuele psychosociale kenmerken op gezondheid en levensverwachting. Gegeven deze bevindingen is het aannemelijk dat opgroeien in ongunstige sociaaleconomische omstandigheden de gezondheid beïnvloedt via psychosociale factoren. Tot nu toe is de bijdrage van psychosociale factoren aan de sociaaleconomische gezondheidsverschillen relatief weinig onderzocht. Verder zijn psychosociale effecten op gezondheid meestal los van elkaar bestudeerd in de verschillende studies. Echter, mogelijk hebben deze factoren een synergistisch effect op gezondheid en levensverwachting; veel van deze factoren zijn immers geassocieerd met elkaar. Rekening houden met deze covariatie en de mogelijke synergistische effecten op gezondheidsuitkomsten kan bijdragen aan een beter begrip van het ontstaan van gezondheidsverschillen.

Het doel van dit proefschrift is om de associaties tussen SES, psychosociale risicofactoren en gezondheid in een levensloop perspectief vast te stellen, om het inzicht in gezondheidsverschillen, en de mate waarin psychosociaal risico daaraan bijdraagt, te vergroten. Daarbij hebben we ons ook specifiek gericht op het meten en operationaliseren van psychosociaal risico. Deze studie is vormgegeven aan de hand van vier hoofdvraagstellingen: 
1. Welke psychosociale kenmerken zijn in belangrijke mate geassocieerd met SES en hoe kunnen deze kenmerken worden gemeten?

2. Welke psychosociale kenmerken zijn belangrijk voor gezondheid en hoe kunnen ze worden gemeten?

3. Dragen psychosociale factoren bij aan de verklaring van sociaaleconomische gezondheidsverschillen?

4. Wat is de invloed van ervaren armoede in de kindertijd op het psychosociaal profiel en de gezondheid van een persoon op latere leeftijd?

Naast deze vier vraagstellingen, hebben we ook de associatie bestudeerd tussen opleidingsniveau en gezondheidsgerelateerde kenmerken in een subgroep van personen met een ernstige depressie.

In Hoofdstuk 2 wordt de vraagstelling beantwoord of hostiliteit en depressieve symptomen, twee bekende risicofactoren voor hartziekte, bijdragen aan inkomensverschillen in ziekenhuisopname ten gevolge van incidente ischemische hartziekte (IHD) (onderzoeksvraagstelling 3). Dit is onderzocht door middel van een prospectieve cohortstudie (GLOBE), bestaande uit Nederlandse respondenten uit de algemene populatie van 15-74 jaar $(n=2374)$. Zelfgerapporteerde gegevens over inkomen, hostiliteit en depressieve symptomen, leefstijl, en biomedische factoren zijn gekoppeld aan ziekenhuisopnamen ten gevolge van incidente IHD over een periode van 12 jaar. Door middel van Cox regressie is de bijdrage van hostiliteit en depressieve symptomen aan de associatie tussen inkomen en tijd tot ziekenhuisopname onderzocht. Het relatieve risico van incidente IHD was het hoogst in de laagste inkomensgroep, met een hazard ratio van 2.71 (95\% BI 1.60-4.61). Mannen uit de laagste inkomensgroep rapporteerden vaker een ongezonde leefstijl en ongunstige biomedische factoren, welke bijdroegen aan het hogere risico op incidente IHD in die groep. Met name een hoge mate van hostiliteit droeg bij aan inkomensverschillen in incidente IHD bij vrouwen. Het geringe aantal incidente IHD gevallen bij vrouwen maakt verder onderzoek in grotere steekproeven echter noodzakelijk.

Naast depressieve symptomen en hostiliteit is rebellie, een innovatief concept, mogelijk van belang voor SES en voor gezondheid (onderzoeksvraagstelling 1 en 2). Rebellie zou, door weerstand tegen gezondheidsvoorlichting en het nalaten van gezond gedrag, gezondheid kunnen beïnvloeden. Rebellie is in onderhavig proefschrift gemeten met behulp van de Social Reactivity Scale (SRS), een vragenlijst bestaande uit 14 items. In Hoofdstuk 3 hebben we de psychometrische eigenschappen van de SRS, waaronder de factor structuur, interne consistentie en constructvaliditeit, onderzocht in twee steekproeven van de SMILE en MAAS studie (met een gemiddelde leeftijd van resp. 69 en 60 jaar). De twee-factor structuur, proactieve en reactieve rebellie, werd bevestigd. Er was matig bewijs voor de betrouwbaarheid en constructvaliditeit van de schaal. De bevindingen lieten zien dat 
rebellie negatief geassocieerd is met ervaren controle en positief geassocieerd met hostiliteit, en dat een hogere mate van rebellie leidt tot schadelijker gezondheidsgedrag en een slechtere gezondheid (mogelijk door verzet tegen gezondheidsvoorlichting). In tegenstelling tot onze verwachtingen kwam een hoge mate van rebellie vaker voor onder personen met een hoge SES in vergelijking met personen met een lage SES.

In Hoofdstuk 4 worden de associaties tussen hostiliteit, woede, agressie, rebellie en sterfte beschreven in een populatie van personen van middelbare en oudere leeftijd (onderzoeksvraagstelling 2). Eerdere bevindingen tonen nagenoeg alle aan dat er een verhoogd sterfterisico is onder degenen die een hoge mate van hostiliteit of gerelateerde persoonlijkheidskenmerken, zoals woede of aggressie,vertonen. Gewoonlijk wordt echter telkens slechts één kenmerk onderzocht en zijn de effecten voornamelijk bestudeerd in jongere populaties. Bovendien is gevonden dat gezondsheidsgedrag, dat de effecten van persoonlijkheidskenmerken op sterfte zou kunnen verklaren varieert met de leeftijd. Gegevens zijn afkomstig van het longitudinale Nederlandse SMILE onderzoek, betreffende 2679 Nederlanders van middelbare en oudere leeftijd. De psychologische kenmerken zijn zelfgerapporteerd in 2004/2005 en sterfte is continu geregistreerd tussen 2005 en 2010. Door middel van Cox regressie analyses is de sterftekans voor elk van de psychologische kenmerken berekend, gecontroleerd voor de andere psychologische kenmerken en voor gezondheidsgedrag. In alle modellen werd eveneens gecontroleerd voor leeftijd, geslacht, opleidingsniveau en aanwezige ziekte bij aanvang van de metingen. Cognitieve hostiliteit was geassocieerd met sterfte, onafhankelijk van gezondheidsgedrag (op een schaal van 6-30, de hazard ratio was 1.05 ; 95\% BI $1.01-1.09$ ). Woede, agressie en rebellie waren niet geassocieerd met het sterfterisico.

In Hoofdstuk $\mathbf{5}$ hebben we een nieuwe benadering in het bepalen van psychosociaal gezondheidsrisico onderzocht, door rekening te houden met mogelijke synergistische effecten tussen verschillende psychosociale kenmerken (onderzoeksvraagstelling 2). Prospectieve longitudinale data van 1912 Nederlandse deelnemers, in de leeftijd van 55-91 jaar, aan het SMILE onderzoek zijn gebruikt om (afzonderlijke) psychosociale profielen vast te stellen door middel van een 'two-step' clusteranalyse. Op basis van de scores op verschillende psychosociale kenmerken, waaronder psychologische kenmerken, psychisch functioneren, copingstijlen en sociale steun, werden deelnemers in groepen, gekenmerkt door een afzonderlijke profiel, ingedeeld. De voorspellende waarde van deze profielen voor gediagnosticeerde somatische ziekte en sterfte over een periode van 5 jaar werd vastgesteld door middel van de Schwarz Bayesian Information Criterion (BIC) voor Cox regressie, en de voorspellende waarde voor ervaren gezondheid over dezelfde periode door de BIC voor logistische regressie. Drie afzonderlijke psychosociale profielen konden 
worden onderscheiden: een ongunstig, een gemiddeld, en een gunstig profiel. Deze profielen voorspelden ervaren gezondheid in sterke mate, maar niet gediagnosticeerde ziekte of sterfte. De profielen (clusters) bleken een betere voorspeller van gezondheid dan de cumulatieve individuele psychosociale kenmerken volgens de BIC's, wat de relevantie voor onderzoek naar opeenstapeling en mogelijke synergistische effecten van psychosociale factoren bevestigt.

In Hoofdstuk 6 zijn de associaties tussen SES in de vroege jeugd en tijdens volwassenheid, psychosociale profielen en ervaren gezondheid onderzocht (onderzoeksvraagstelling 3 en 4). SES in de vroege jeugd is in eerdere studies geassocieerd met gezondheid tijdens het latere leven, zowel onafhankelijk of juist afhankelijk van SES tijdens volwassenheid. Mogelijk is psychosociaal functioneren, naast gezondheidsgedrag, een belangrijke verklarende factor voor een hoger gezondheidsrisico van vroege lage SES; eerdere bevindingen tonen aan dat psychosociaal functioneren niet alleen gerelateerd is omstandigheden in de vroege jeugd maar ook aan gezondheid. Het doel van deze studie was om te bepalen of armoede tijdens de vroege jeugd geassocieerd was met ervaren gezondheid onafhankelijk van SES tijdens volwassenheid, en de mate waarin het psychosociaal profiel bijdroeg aan deze associatie. Hiervoor werden cross-sectionele gegevens van 1688 deelnemers aan het SMILE onderzoek gebruikt, over sociodemografische kenmerken, armoede tijdens de vroege jeugd, het psychosociaal profiel (ongunstig,gemiddeld, gunstig), gezondheidsgedrag en ervaren gezondheid. Door middel van logistische regressie analyses hebben we de associatie tussen armoede tijdens de vroege jeugd en ervaren gezondheid op latere leeftijd berekend; deze hebben we vergeleken met modellen waarin ook SES tijdens volwassenheid, psychosociaal profiel en gezondheidsgedrag opgenomen waren, zowel afzonderlijk als simultaan. In alle analyses werd gecontroleerd voor leeftijd en geslacht. Personen die armoede ervoeren tijdens de vroege jeugd rapporteerden vaker ongezondheid (OR = 1.52, 95\% BI 1.062.18), dan personen die geen armoede hadden gekend. Dit risico bleek gedeeltelijk onafhankelijk te zijn van hun sociaaleconomische status tijdens volwassenheid. Het psychosociaal profiel verklaarde een substantieel gedeelte van het extra risico op ongezondheid door ervaren armoede, terwijl gezondheidsgedrag nauwelijks bijdroeg aan dit extra risico. Deze bevindingen suggereren dat de gezondheidstoestand op latere leeftijd terug te voeren is op de vroege jeugd, dat ongunstige sociaaleconomische omstandigheden in deze periode personen gevoelig maakt voor een ongunstige psychosociale ontwikkeling, wat weer leidt tot grotere ongezondheid in vergelijking met personen die een betere start in het leven hebben.

In Hoofdstuk 7 worden de opleidingsverschillen in gezondheidsgerelateerde ongunstige factoren (zoals roken of bijkomende psychologische problemen) onder 
personen met een gediagnosticeerde depressieve stoornis beschreven. De prevalentie van depressieve stoornissen alsmede de ernst hiervan (er zijn 3 gradaties) is sociaal bepaald: personen met een lage SES hebben vaker een depressieve stoornis en vaker een ernstige depressieve stoornis dan personen met een hoge SES. Depressieve stoornissen zijn geassocieerd met een aantal (ongunstige) gezondheidsgerelateerde uitkomsten, zoals het risico op hartziekten (gemeten door het metabool syndroom), leefstijl, psychologisch functioneren en soorten behandeling (psychotherapie of medicatie). Cross-sectionele medische en psychiatrische gegevens zijn gebruikt van 992 deelnemers van de Nederlandse Studie naar Depressie en Angst (NESDA), allen recent gediagnosticeerd met een depressieve stoornis. Associaties tussen enerzijds opleiding en anderzijds metabool syndroom, gezondheidsgedrag, psychologische uitkomsten en soort behandeling, gecontroleerd voor ernst van de depressie zijn onderzocht door middel van (multinomiale en binaire) logistische en lineaire regressie analyses. Niet alleen was de de depressie onder laagopgeleide deelnemers ernstiger, ook bleek dat onafhankelijk van de ernst, het metabool syndroom, roken, lage alcohol consumptie, gevoelens van hopeloosheid en lage ervaren controle vaker voorkwamen bij lager opgeleide personen dan bij hoger opgeleide personen. Laagopgeleiden kregen vaker een behandeling met antidepressiva en minder vaak psychotherapie dan hoger opgeleiden. Geen van deze opleidingsverschillen werden verklaard door de hogere mate van ernst van de depressie onder de laagopgeleiden.

In Hoofdstuk 8 worden de belangrijkste conclusies gepresenteerd en worden de bevindingen geïnterpreteerd in het licht van de huidige discussie binnen de literatuur over sociaaleconomische gezondheidsverschillen. Onze resultaten laten zien dat psychosociaal risico in belangrijke mate bijdraagt aan sociaaleconomische gezondheidsverschillen, in het bijzonder als ook de mogelijke synergie tussen de verschillende kenmerken in ogenschouw wordt genomen. De effecten van psychosociaal risico op gezondheid zijn substantieel, zelfs op middelbare en latere leeftijd. Het psychosociaal profiel lijkt gedeeltelijk zijn oorsprong te hebben in de vroege jeugd; zij die opgroeiden in armoede hebben vaker een ongunstig psychosociaal profiel, en dit verklaart voor een groot deel hun grotere ongezondheid. Naast deze bevindingen is er tevens gebleken dat er opleidingsverschillen zijn in de ziektelast ten gevolge van een depressieve stoornis, deze ziektelast is groter in laagopgeleiden.

Deze bevindingen kunnen als leidraad dienen voor toekomstig onderzoek op dit terrein. Het in ogenschouw nemen van het gehele psychosociaal functioneren is een meer valide benadering voor de voorspelling van gezondheid en van sociaaleconomische gezondheidsverschillen, dan het slechts meten van een enkel psychosociaal kenmerk. De precieze interactie tussen deze kenmerken zal echter verder bestudeerd moeten worden in toekomstig onderzoek, bij voorkeur in een mixedmethods benadering; enerzijds door middel van prospectieve cohortstudies met 
een langdurige follow-up waarin verschillende leeftijdsgroepen gerepresenteerd zijn, anderzijds door middel van narratief onderzoek bij personen die langdurig in ongunstige sociaaleconomische omstandigheden verkeren. Verder zullen de relaties tussen psychosociale risicoprofielen en andere risicofactoren zoals gezondheidsgedrag, biologische factoren en maatschappelijke factoren meer gedetailleerd in observationeel, longitudinaal onderzoek in kaart moeten worden gebracht, om risico 'ketens' (additief of multiplicatief) vast te kunnen stellen, de toxische componenten te kunnen identificeren, en de volgorde en het ontstaan van risico te kunnen bepalen. Naast een noodzakelijke continue investering in longitudinaal onderzoek om de mechanismen te ontrafelen die leiden van lage SES naar ongezondheid pleiten wij voor het includeren van zowel persoonlijke als maatschappelijke risicofactoren in interventies, en voor systematische evaluatie van de effectiviteit hiervan. 


\section{DANKWOORD}

Toen ik begon aan mijn promotietraject had ik bepaald een rooskleurige voorstelling van zaken. Achteraf bleek de werkelijkheid weerbarstiger. De uitdrukking $10 \%$ inspiratie, 90\% transpiratie die vaak wordt gebruikt om een promotietraject te beschrijven bleek ook (!) voor mij te gelden. Maar het was een uitdaging, een taak die ik mezelf had gesteld en die ik moest en zou volbrengen. Hoe groot ook de intrinsieke motivatie, ik had mijn doel nooit bereikt zonder jullie, die ik hier bij naam ga noemen.

Allereerst mijn promotieteam, mijn promotoren Jacques van Eijk en Ruud Kempen en copromotor Hans Bosma.

Jacques, in het begin van mijn traject was onze samenwerking nogal zakelijk en afstandelijk. Naarmate het project vorderde leerde ik je meer en meer kennen als een uitermate betrokken mens, niet alleen toonde je je betrokkenheid bij mijn werk, maar ook bij mij als persoon. Als geen ander had en heb je oog voor persoonlijke omstandigheden die (positief danwel negatief) van invloed zijn geweest op mijn werk. Jouw begrip en jouw steun toen mijn motivatie wat minder was, hebben zeker bijgedragen aan het succesvol afronden van mijn traject. Wat me verder altijd zal bijblijven zijn de avondjes uit, en de gezelligheid die jij (en Toos natuurlijk) uitstraalden. Dank daarvoor!

Ruud, ik heb je leren kennen als een nuchtere en zakelijke begeleider, en juist die neutraliteit was af en toe van onschatbare waarde, vooral tijdens menig verhitte discussie waarin de gemoederen hoog opliepen. Evenzo van onschatbare waarde was jouw commentaar op mijn werk, gedetailleerd, kritisch, gedegen, maar altijd constructief. Ik hoop dat ik iets van jouw scherpe blik heb overgenomen. Dank je wel, ik heb onze samenwerking als zeer prettig ervaren.

Hans, onze samenwerking verliep soms verre van vlekkeloos en we hebben veel verhitte discussies en behoorlijk wat ergernissen achter de rug. Mijn hang (drang?) naar vrijheid botste meer dan eens met jouw kwaliteitsbewaking (tot in het kleinste detail). Het gekke is dat onze botsingen beperkt bleven tot de inhoud van het werk, want op persoonlijk vlak was er wel een klik, ondanks onze verschillende opvattingen over het werk. Die klik bleek met name tijdens onze 'pauzes' buiten. Ik heb veel van jou geleerd. Vooral 'doorgaan', een probleem vanuit meerdere (alle!) kanten benaderen en ook op verschillende manieren proberen op te lossen zijn kenmerkend voor de grondigheid en gedegenheid waarmee jij te werk gaat. Wat dat betreft ben ik nog niet uitgeleerd. Het feit dat jij ook weer betrokken bent bij mijn huidige onderzoek geeft al aan dat het met onze samenwerking uiteindelijk toch goed is gekomen! Dank voor al je inspanningen om van mij een goede onderzoeker te maken! 
Jacques, Ruud en Hans, alle drie waren jullie in de becommentariëring van mijn stukken altijd grondig en ontzettend snel. In de laatste fase, waarin ik zo gedreven was om mijn proefschrift af te ronden en ik jullie het een na het andere stuk toestuurde, heeft mij dat enorm vooruit geholpen. Ik kan jullie daarvoor niet genoeg bedanken!

De leden van de beoordelingscommissie, voorzitter prof. dr. Klasien Horstman, prof. dr. N. de Vries, prof. dr J. van Os, prof. dr. D. van de Mheen, en dr. P Lemmens, wil ik bedanken voor hun bereidheid zitting te nemen in de commissie en het concept proefschrift van commentaar te voorzien.

Dank ook aan allen die aan mijn artikelen hebben bijgedragen. Marjan, jij bent nauw betrokken bij de SMILE studie en daardoor ook co-auteur geweest bij vier van mijn artikelen. Als ik vragen had of als ik omhoog zat kon ik altijd bij je terecht om een oplossing te vinden, en je commentaar op mijn stukken was pragmatisch en positief. Ben, als datamanager van SMILE reageerde je altijd meteen op mijn dringende verzoeken om aanvullende data, die ik dan ook per ommegaande kreeg opgestuurd. Johan Mackenbach en Frank van Lenthe van de GLOBE studie, Brenda Penninx, Nicole Vogelzangs en Willem van der Does van de NESDA studie, en Martin van Boxtel van de MAAS studie, dankzij jullie gestructureerde en immer scherpe commentaar zijn er mooie publicaties gekomen, en er is ook gebleken dat samenwerking 'op afstand' geen belemmering hoeft te vormen voor de voortgang. Dank voor de fijne samenwerking en natuurlijk voor jullie bijdragen! Mark McDermott, you designed the Social Reactivity Scale upon which two of my articles were based, thank you for commenting on the drafts and for the pleasant long distance communication. Perhaps our cooperation will be continued in the future, as you expressed your desire to study rebelliousness in our student population. Michaela Benzeval, you co-authored one of my most difficult papers, that on psychosocial profiling, and I want to express my gratitude for your patience, and your always positive and constructive comments on yet another draft. It is such a pleasure working with you and I am really glad that we are continuing our cooperation in my current project based on the Twenty-07 data. I am looking forward to meet you in Maastricht! Verder was advies over ingewikkelde statistische bewerkingen ook altijd welkom en wat dat betreft dank ik Math Candell en Frans Tan voor het delen van hun kennis over CFA en multiple imputations met mij. Zonder de juiste statistische programma's geen analyses natuurlijk, en ik wil Arnold bedanken voor je hulp hierbij, ik weet dat je een aantal keer je nek hebt uitgestoken om de juiste programma's op mijn computer geinstalleerd te krijgen die (nog) niet standaard in het pakket zaten en daarmee heb je me enorm vooruit geholpen. Ook als ik weer eens op het punt stond om 'dat ding' uit het raam te kieperen omdat er weer iets mis was, stond jij altijd direct voor me klaar, super! 
Mijn collega's, eerst bij Medische Sociologie, en later bij Sociale Geneeskunde waar we, althans een aantal van ons, in opgingen, dank voor de gezellige sfeer op de afdeling! We hebben in de begintijd van Sociale Geneeskunde roerige tijden meegemaakt, en ik denk dat we er als hechter team uit zijn gekomen. Door de reorganisaties, en vertrek van een aantal collega's heb ik verschillende kamergenoten 'versleten'. Maar allemaal hebben ze ervoor gezorgd dat ik een leuke tijd heb gehad als promovenda. Allereerst Marja, ik vond het zo gezellig met jou, en je hebt me echt door de eerste onwennige weken bij MedSoc heen geholpen. Je bent al lang weg bij de UM, maar ik vond het fijn om je nog vaak tegen te komen bij de creche, waar onze kids in dezelfde groep zaten. Jammer dat daaraan nu een einde is gekomen! Toen kwam Tanja, met jou kon ik altijd zo lekker klagen over promoveren, en hoe zwaar het was om alles tig keer over te moeten doen, en wat hebben we ongegeneerd gemopperd over onze begeleiders....heel fijn om bij elkaar stoom te kunnen afblazen! Daarna Vivian, de verhouding werktijd/kletstijd pakte niet altijd gunstig uit voor het werk... . Toen Michel, wij waren er een kei in om de ander verbaal af te troeven, uiteraard met veel humor. Ik heb dikke pret met jou gehad! Twan, schat, je was onnavolgbaar maar daarover straks meer als ik het over mijn paranimfen ga hebben... . Last but not least, Katarina. We've been roommates for two and a half (three?) years now, and I am sooooooo glad we will remain roommates. We shared laughter, but we certainly shared tears when things did not go well for us, and I am eternally grateful for your support and for your friendship. You know that I wanted you to be my paranimf, but the (very pleasant) circumstances did not allow it.

Mijn Work\& Health collega's, Angelique, Inge, Nicole, Rineke en Elisabeth, wat was ik blij toen ik hoorde dat jullie ook bij Sociale Geneeskunde zouden komen. Ik heb een erg plezierige tijd gehad bij BEOZ toen ik voor Work \& Health (toen nog: Arbeid \& Gezondheid) als toegevoegd docent kwam werken. Angelique, jij hebt me toen aangenomen, net klaar met de studie, en je hebt me vanaf het begin je vertrouwen gegeven om me te ontwikkelen als docent. Dat vertrouwen heb ik aldoor gevoeld, ook toen ik aan het promoveren sloeg en niet altijd alles van een leien dakje ging. Je bent me blijven betrekken bij jouw projecten en nu ik klaar ben met het proefschrift zijn er zelfs plannen om samen een subsidieaanvraag te schrijven. We zien elkaar ook vaak omdat onze mannetjes zo gezellig met elkaar kunnen spelen en ik hoop dat ze dat in de toekomst nog vaak blijven doen. Dank voor je vertrouwen en voor je vriendschap! Inge, jij hebt me sterk geinspireerd om onderzoek te willen doen, door je bezielende begeleiding bij mijn afstudeerscriptie. Je bent een superfijne collega, bij wie ik graag binnenloop om wat te kletsen, over werk, kinderen en allerlei andere dingen. Je weet dat ik heel graag met je had willen samenwerken, maar mijn hart lag bij een ander project. Jij begrijpt dat als geen ander, en ik hoop dat we in de toekomst wellicht samen iets moois kunnen gaan doen! Nicole, toen het even wat minder ging, heb jij me geholpen om uit te vinden wat ik nodig had, dank daarvoor! 
Isel, bij jou kon en kan ik altijd binnenlopen voor een praatje, dat is zo fijn. Je staat altijd voor iedereen klaar, en je maakt het gezellig op de vakgroep door je attenties met feestdagen en verjaardagen, super! Terwijl je het druk had, na een voor jou ook hectische en onzekere tijd, bood je zelfs aan de layout te doen van mijn proefschrift voor de leescommissie en dat heb je, zoals alles wat je doet, grondig gedaan, het zag er goed uit. Dank je wel!

Alle collega's die ik niet bij naam genoemd heb, ik heb een prettige tijd bij Sociale Geneeskunde en dat komt mede door jullie!

Ook de collega's van de IPC en van de educational board een vermelding. Ik heb in de afgelopen jaren plezierig met jullie samengewerkt. Met name wil ik Hannerieke, Marla en Katarina danken voor de samenwerking aan 'ons' supervisie-project. Onze meningen komen weliswaar niet altijd overeen, maar toch zorgen we samen voor een prettig verloop van dit project. Ik ben ervan overtuigd dat dit gaat resulteren in een fantastische publicatie!

Alle vrienden die in de afgelopen jaren zo veel belangstelling hebben getoond voor waar ik mee bezig was en hoe het vorderde (neehee het is nog niet klaar!), thanks voor jullie meeleven! En natuurlijk ook voor de gezellige koffieklets, etentjes, borrels en feestjes, kortom, voor alle fijne momenten buiten het werk die voor de broodnodige gezelligheid en afleiding hebben gezorgd, ik hoop nog veel meer leuke dingen met jullie mee te mogen maken. Het voert te ver om iedereen hier bij naam te noemen maar jullie weten wel dat ik het over jullie heb!

Twan, wat hebben wij veel pret gehad als kamergenoten! Met name de ' wine dates', samen met Katarina tijdens de organisatie van het dagje uit (15 minuten organisatie, daarna oeverloos ouwehoeren en drinken), en daarna samen met Harry (!) zijn om nooit meer te vergeten. Super dat jij mijn paranimf wilt zijn (= excuus voor weer enkele wine dates!)

Lieve Karin, al 29 jaar ben jij mijn beste vriendin en delen we lief en leed samen. De afstand en ons beider hectische bestaan zorgen ervoor dat we niet zo vaak kunnen afspreken als ik zou willen. Ik hoop dat nu deze horde genomen is er iets meer rust komt en we weer eens ouderwets samen leuke dingen kunnen gaan doen (dagje Spa?). Geweldig dat je de kaft voor mijn boekje hebt ontworpen (= heel mooi!), en ik vind het super dat je mijn paranimf bent!

Lieve tante Leentje, helaas kun je dit voor mij zo belangrijke moment niet meer meemaken, ik had je graag bij me gehad. Ik heb dit proefschrift opgedragen aan jou, jij weet wel waarom! 
Maarten, liefste, jij staat me al 17 jaar bij, in goede en slechte tijden, als een rots in de branding. $\mathrm{Nu}$ is de ergste drukte in ons leven eindelijk voorbij en keert de rust weer terug (maar we moeten het nog wel hebben over de verbouwing thuis ...). Dank je wel voor je luisterend oor, voor je steun en voor je liefde. Ik hou van jou!

Lauren en Maxim, mijn allerliefste schatjes, behalve voor een hele hoop plezier (en drukte!) zorgen jullie er ook voor dat ik met beide benen op de grond blijf staan. Hoe belangrijk dit boekje ook voor mij is, er kan niks aan jullie tippen! Ik hou van jullie! 


\section{ABOUT THE AUTHOR}

Gonnie Klabbers was born on April 9, 1970 in Venlo, the Netherlands. She completed the VWO at the Blariacumcollege in Venlo, after which she spend a year travelling and working abroad, for the main part in an outpatient clinic in Cameroon. She studied physiotherapy at the Hogeschool Zuyd, University of Applied Sciences (former: Hogeschool Heerlen), and she spend 7 years working as a physiotherapist, the last 3 years in her own private practice in Langerwehe, Germany. After giving it careful consideration, she decided to switch careers, and started working as a research assistant/physiotherapist at the department of Epidemiology, Maastricht University. She obtained a master's degree in Health Sciences, Work \& Health, Vocational rehabilitation, and was hired as a lecturer for that same master's education shortly after, a position which she held for 2 years. She then got a PhD position at the CAPHRI School for Public Health and Primary Care, which revolved around psychosocial explanations for socioeconomic health inequalities, using advanced methodological techniques and innovative approaches to determine psychosocial risk. During her fourth year, she also held a part-time lecturing position for the Work \& Health master's education. During the entire PhD track, she was involved in PhD policy and affairs, being a representative for CAPHRI in the Interfaculty PhD Committee (IPC), an advisory committee on PhD policy and affairs for different research schools of Maastricht University. Because of her IPC membership she also took part in the educational board meetings of CAPHRI, which also dealt with PhD policy and affairs. In that position, she initiated a qualitative research project on the evaluation of supervision of PhD students, of which the data collection has been completed, and the analysis phase has started. She is currently working as a fellow researcher at the department of Social Medicine, in close collaboration with the Medical Research Council, Social and Public Health Sciences Unit in Glasgow, studying psychobiological pathways that lead from socioeconomic status to health. Gonnie lives in Maastricht together with her husband Maarten Klabbers and her two children Lauren and Maxim. 


\section{PUBLICATIONS}

G. Klabbers, H. Bosma, A.J.W. van der Does, N. Vogelzangs, G.I.J.M Kempen, J. Th. M. van Eijk, B.W.J.H. Penninx (2010). The educational patterning of health-related adversities in individuals with major depression. Journal of Affective Disorders, 126, 96-102

G. Klabbers, H. Bosma, F.J. Van Lenthe, G.I. Kempen, J. T. Van Eijk, J.P. Mackenbach (2009).The relative contributions of hostility and depressive symptoms to the income gradient in hospital-based incidence of ischaemic heart disease: 12-Year follow-up findings from the GLOBE study. Social Science \& Medicine, 69, 1272-1280.

G. Klabbers, H. Bosma, M. van den Akker, M.P.J. van Boxtel, G.I.J.M. Kempen, J. Th. M. van Eijk (2009). Measuring rebelliousness and predicting health behaviour and outcomes: an investigation of the construct validity of the Social Reactivity Scale. Journal of Health Psychology, 14(6), 771-779.

C.H.G. Bastiaenen, R.A. de Bie, P.M.J.C. Wolters, J.W.S. Vlaeyen, J.M. Bastiaanssen, A.B.A. Klabbers, A. Heuts, P.A. van den Brandt, G.G.M. Essed (2004). Treatment of pregnancy-related pelvic girdle and/or low back pain after delivery design of a randomized clinical trial within a comprehensive prognostic cohort study. BMC Public Health, 4(67).

G. Klabbers, H. Bosma, M. van den Akker, G.I.J.M. Kempen, and J.Th.M. van Eijk . Cognitive hostility predicts all-cause mortality irrespective of behavioural risk at late middle and older age. (accepted for publication in the European Journal of Public Health)

G.Klabbers, H. Bosma, G.I.J.M. Kempen, M. Benzeval, M. van den Akker, and J.Th.M. van Eijk. Predicting health in late middle-aged and older persons: the comparison of a new psychosocial health risk approach with individual psychosocial characteristics. (under review)

G. Klabbers, H. Bosma, G.I.J.M. Kempen, M. van den Akker, J.Th.M. van Eijk. Early life poverty associated with poor self-rated health in late middle and old age: a pathway through psychosocial profiles.(submitted)

H. Bosma, A. Gerritsma, G. Klabbers, M. van den Akker. Unfairness and socioeconomic inequalities in health-related functional decline: the Dutch SMILE prospective cohort study. (submitted) 
H. Bosma, A. Simons, D. Groffen, G. Klabbers. Stigmatisation and socioeconomic differences in health in modern welfare states. (submitted)

\section{International presentations}

G. Klabbers, H. Bosma, F.J. Van Lenthe, A.J.W. van der Does, N. Vogelzangs, G.I.J.M Kempen, J. Th. M. van Eijk, B.W.J.H. Penninx, J.P. Mackenbach. Psychological responses in the explanation of socioeconomic inequalities in heart disease. Seminar for MRC Social and Public Health Sciences Unit, University of Glasgow, 2010, Glasgow, UK. (invited)

G. Klabbers, H. Bosma, F.J. Van Lenthe, G.I. Kempen, J. T. Van Eijk, J.P. Mackenbach. Socioeconomic differences in hospital-based incidence of ischemic heart disease; the relative contribution of hostility and depressive symptoms. Findings from the 12-year GLOBE follow-up. $10^{\text {Th }}$ International Congress of Behavioral Medicine 2008, Tokyo, Japan. (oral presentation)

G.Klabbers, A.E. de Rijk, I. Houkes. Exposure to work-related risk factors during pregnancy: a longitudinal survey on women, work and health. Premus 2004, Fifth International Scientific Conference of Work-related Musculoskeletal disorders. Zürich, Switserland. (oral presentation)

G. Klabbers, H. Bosma, M. van den Akker, M.P.J. van Boxtel, G.I.J.M. Kempen, J. Th. M. van Eijk. Measuring rebelliousness: Psychometric evaluation of the Social Reactivity Scale. The Gerontological Society of America, 60th annual scientific meeting, 2007, San Francisco, USA. (poster presentation) 